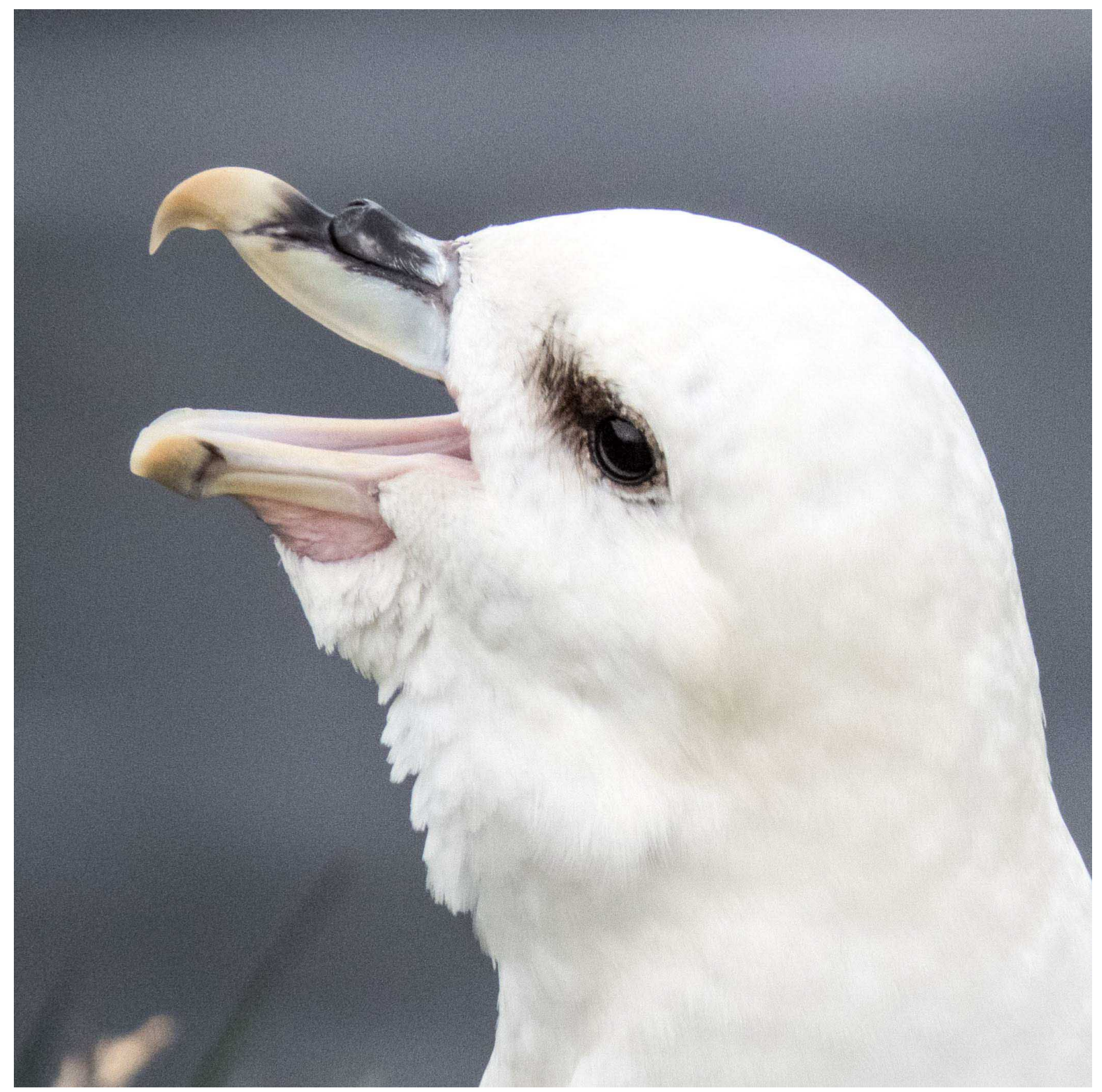

\title{
Fulmar Litter EcoQO monitoring in the Netherlands - Update 2018
}




\section{Citation:}

Van Franeker, J.A. \& Kühn, S. (2019)

Fulmar Litter ECoQO monitoring in the Netherlands - Update 2018.

Wageningen Marine Research Report C077/19 \& RWS Centrale Informatievoorziening BM 19.16

\section{Keywords:}

OSPAR-ECoQO; MSFD-GES; KRM-GMT; Fulmarus glacialis; monitoring; marine litter; plastic ingestion

$\begin{array}{lll}\text { Wageningen } & \text { Offerte nr: } & 15.43 .128 \\ \text { Marine } & \text { project nr: } & 4312100031 \\ \text { Research } & \text { project name: } & \text { Fulmar-EcoQO-NL2015-19 } \\ \text { references: } & \text { contact: } & \text { Dr. Jan Andries van Franeker, Wageningen Marine Research } \\ & & \text { Ankerpark 27, 1781 AG Den Helder, The Netherlands } \\ & & \text { E: jan.vanfraneker@wur.nl T: +31 317 } 487085\end{array}$

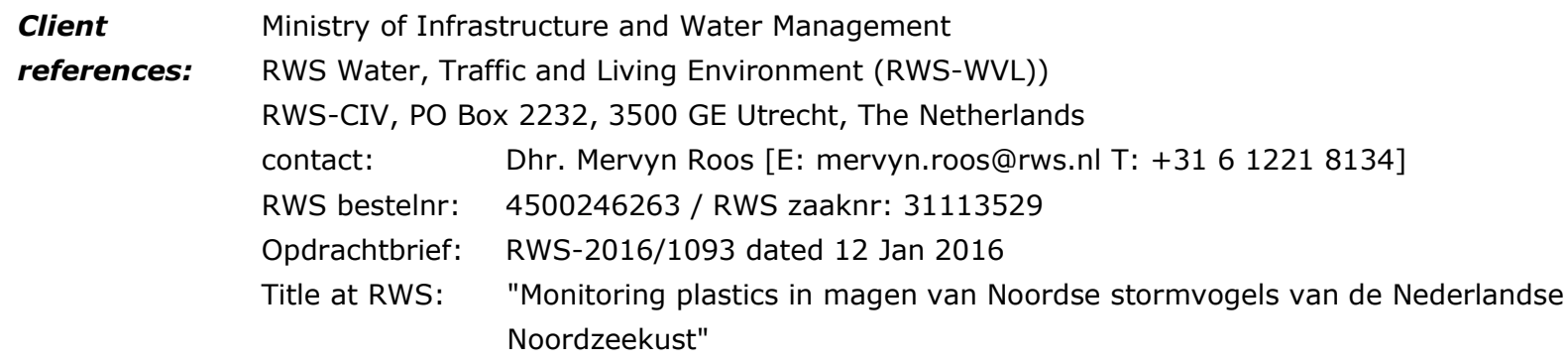

This report can be downloaded for free from https://doi.org/10.18174/486799

Wageningen Marine Research provides no printed copies of reports

Wageningen Marine Research is ISO 9001:2015 certified.

Photo cover: Northern Fulmar displaying on cliff in Iceland.

All photos in this document were made by the authors.

(C) Wageningen Marine Research
Wageningen Marine Research, an institute Wageningen Marine Research accepts no liability for consequential damage, nor within the legal entity Stichting for damage resulting from applications of the results of work or other data Wageningen Research (a foundation under obtained from Wageningen Marine Research. Client indemnifies Wageningen Dutch private law) represented by Dr. Marine Research from claims of third parties in connection with this application. M.C.Th. Scholten, Managing Director All rights reserved. No part of this publication may be reproduced and / or
KvK nr. 09098104, published, photocopied or used in any other way without the written permission WMR BTW nr. NL 8113.83.696.B16.

Code BIC/SWIFT address: RABONL2U IBAN code: NL 73 RABO 0373599285 


\section{Contents}

SUMMARY

1 Introduction

$2 \quad$ Marine litter and policy measures

3 The Fulmar as an ecological monitor of marine litter

$4 \quad$ Materials and Methods

$5 \quad$ Results \& Discussion

5.1 The year 2018

5.2 Current levels for the Netherlands (2014-2018)

5.3 Trends

5.3.1 Long-term trends

5.3.2 Recent trends

5.4 Dutch data in terms of the OSPAR EcoQO metric 39

5.5 Modelling future EcoQO performance. $\quad 41$

5.6 Data-based MSFD Threshold Definition 45

$6 \quad$ Concluding remarks $\quad 46$

$\begin{array}{llr}7 & \text { Acknowledgements } & 47\end{array}$

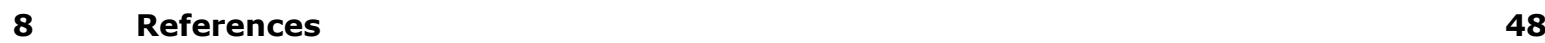

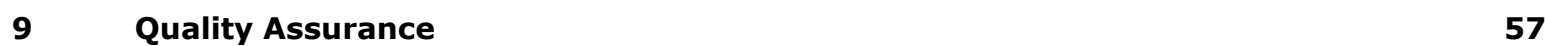

10 Justification $r$ 


\section{SUMMARY}

\section{Fulmar Litter EcoQO monitoring in the Netherlands - Update 2018}

Marine debris has serious economic and ecological consequences. Economic impacts are most severe for coastal communities, tourism, shipping and fisheries. Marine wildlife suffers from entanglement and ingestion of debris, with micro-particles potentially affecting marine food chains up to the level of human consumers. In the North Sea, marine litter problems were firmly recognized in 2002 when surrounding states assigned to OSPAR the task to include marine plastic litter in its system of Ecological Quality Objectives (EcoQOs) (North Sea Ministerial Conference 2002). At that time, in the Netherlands, marine litter was already monitored by the abundance of plastic debris in stomachs of a seabird species, the Northern Fulmar (Fulmarus glacialis).

Fulmars are purely offshore foragers that ingest all sorts of litter from the sea surface and normally do not regurgitate poorly degradable diet components like plastics. Initial size of ingested debris is usually in the range of millimetres to centimetres, but may be considerably larger for flexible items as for instance threadlike or sheetlike materials. Items must gradually wear down in the muscular stomach to a size small enough to pass into the intestines. During this process, plastics accumulate in the stomach to a level that integrates litter levels encountered in their foraging area for a period of probably up to a few weeks. The Dutch monitoring approach using beached fulmars was developed for international implementation by OSPAR as one of its EcoQOs for the North Sea (OSPAR 2008, 2009, 2010a,b; Van Franeker et al. 2011). This approach is now also implemented as an indicator for 'Good Environmental Status (GES)' in the Marine Strategy Framework Directive (MSFD) (EC 2008, 2010; Galgani et al. 2010; MSFD-TSML 2011, 2013). International guidelines on the monitoring methods and data presentation have been published (OSPAR 2015a,b) and were implemented in 'Intermediate Assessment' (OSPAR 2017, 2019).

OSPAR has identified a long-term (undated) target for ecological quality as follows:

"There should be less than 10\% of Northern Fulmars (Fulmarus glacialis) having 0.1 gram or more plastic in the stomach in samples of 50-100 beached fulmars from each of 5 different areas of the North Sea over a period of at least 5 years".

The European MSFD aims for Good Environmental Status (GES) by the year 2020 and defines GES for marine litter as the situation in which "properties and quantities of marine litter do not cause harm to the coastal and marine environment". The concept of 'no harm' is difficult to quantify (Rochman et al. 2016; Werner et al. 2016) but a threshold value for plastics in fulmars is currently developed which is closely related to the OSPAR ECOQO but has an improved data and statistical basis (Van Franeker \& Kühn 2019). For European marine areas where fulmars do not occur, other species are needed as ingestion indicators, for which methodology and targets are being developed (e.g. Matiddi et al. 2017; Pham et al. 2017; Bray et al. 2019).

The monitoring system uses fulmars found dead on beaches, often slowly starved but also accidentally killed e.g. as in fisheries bycatch. In a pilot study, it has been shown that the amount of plastic in stomachs of slowly starved beached birds was not statistically different from that of healthy birds killed in instantaneous accidents in the same area. Standard procedures for dissection and stomach analyses have been documented in a manual, reports, scientific literature and formal OSPAR guidelines.

Although the standard EcoQO guidelines have been designed to provide detailed data analyses and statistics, the focus of this summary report is on the most policy relevant aspect: that is the proportion of fulmars exceeding a threshold level of 0.1 gram of plastic in the stomachs (EcoQO performance, or EcoQ\%). The OSPAR long-term policy target in the above definition is thus that the EcoQO \% will be reduced to under $10 \%$. Full details on e.g. different categories of industrial plastics (the raw granular feedstock for producers) as opposed to user plastics (from all sorts of consumer waste) are dealt with in the detailed results \& discussion chapter of this report. 


\section{Info box}

Suitability of beached fulmar corpses for monitoring plastics

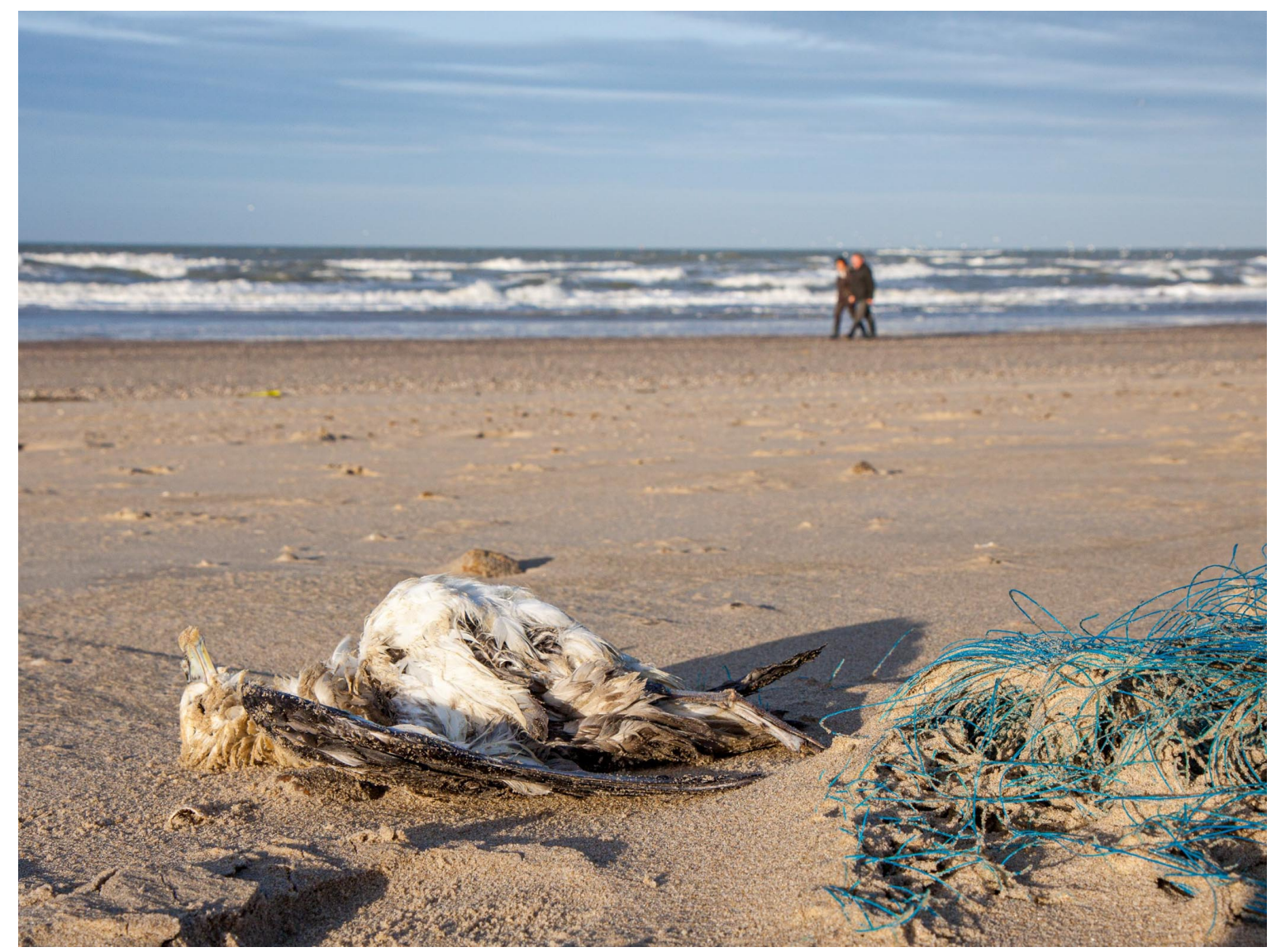

Photo 1 Beached fulmar, Texel Christmas day 2011

The OSPAR plastic monitoring study uses fulmars corpses found on our beaches. In addition to natural mortality from age or disease, such birds may have died for a complicated mix of other reasons. For example, birds may be affected by environmental pollutants such as oil, paraffin like substances, palm fat, chemicals and ingested plastics. All of such factors may interact or have cumulative effects. When not directly lethal they will reduce body condition and health, which in turn will interact with natural events such as e.g. prolonged periods of storms or natural changes in food availability. Birds dying from such reasons will usually slowly starve and will completely emaciate before dying en being beached. Such emaciated birds are the most common type on our beaches. However, another type of dead beached fulmars is also found. These have their origin in sudden accidents, such as e.g. collisions with lights or cables or drowning in fishing nets or on longlines. Such individuals died instantly and 'healthy' in good body condition. It may appear likely that a weak starving bird would eat anything available, and thus might ingest more plastic debris than a healthy bird. However, the pilot study for the fulmar monitoring project could not detect a significant difference in plastic mass in stomachs of slowly starved fulmars as compared to that in the stomach of instantly killed healthy birds. Therefore, data collected from beached fulmars in the monitoring program are representative for the whole fulmar population. 


\section{The 2018 update of monitoring data for the Netherlands}

This report adds new data for year 2018 to Van Franeker \& Kühn (2018). In spite of major efforts, only fifteen birds were collected. Annual numbers of beached birds may vary considerably for unknown reasons. One of the corpses had no stomach, one of them had a damaged stomach, and one had been treated in a rehabilitation centre for about a week. For our monitoring purposes, we do not use birds that have spent more than 3 days under human care, because particles break and wear down in the muscular stomach and disappear through the intestines (Van Franeker \& Law 2015) and are not replaced by new plastics from the marine environment. This means only 12 stomachs were available for the 2018 data calculations. We additionally processed two 'late-delivered' fulmars found in 2017, increasing the 2017 sample from 36 to 38 birds. The desired annual sample size is \pm 40 birds or more (Van Franeker \& Meijboom 2002). Smaller annual samples are not a problem for the monitoring system but may delay the detection of significant trends. Sample size will be better in 2019, as close to 40 fulmars were already collected during the first half of the year.

The OSPAR long-term target requires an EcoQ\% under 10\% for at least 5 consecutive years. Therefor data are also pooled in 5-year periods, as 'current period' in Table $i$. Over the most recent 5 years (2014-2018), in a sample of 115 birds, $43 \%$ of stomachs contained more than $0.1 \mathrm{~g}$ plastic (EcoQ\%). Although this is the best EcoQO performance in the Dutch monitoring program, it clearly is still far off the OSPAR long-term target. In this sample, $93 \%$ of fulmars contained some plastic, with an average over all birds of 24 plastic particles per stomach, weighing 0.26 gram.

The small 2018 sample showed exceptionally low abundance of plastic. Only two of 12 birds exceeded the $0.1 \mathrm{~g}$ level $(17 \%)$. However, the excluded partially damaged and rehabilitation samples both had more than $0.1 \mathrm{~g}$ of plastic. With those included, 4 out of 14 stomachs $(28 \%)$ would exceed the $0.1 \mathrm{~g}$ threshold. This once again illustrates the need to only consider larger samples, over 5-year periods.

Table $i$ Data summary for study year added to the existing monitoring series. The table presents year or period of sampling with sample size in brackets, and then the percentage of birds that exceeds $0.1 \mathrm{~g}$ of plastic mass in the stomach (EcoQO\%), followed by details for the proportion of birds with any plastic (\%FO) the average number of particles ( $n$ ) and the associated average mass of plastic per bird in gram $(g)$.

\begin{tabular}{ccc} 
year & (sample size) & EcoQ\% \\
\hline 2018 & $(12)$ & $17 \%$ \\
period & & \\
\hline $\mathbf{2 0 1 4 - 1 8}$ & $(115)$ & $\mathbf{4 3 \%}$
\end{tabular}

\begin{tabular}{ccc}
$\% \mathrm{FO}$ & average $\mathrm{n}$ & average $\mathrm{g}$ \\
\hline $100 \%$ & 15.8 & 0.12 \\
& & \\
\hline $93 \%$ & 23.6 & 0.26
\end{tabular}
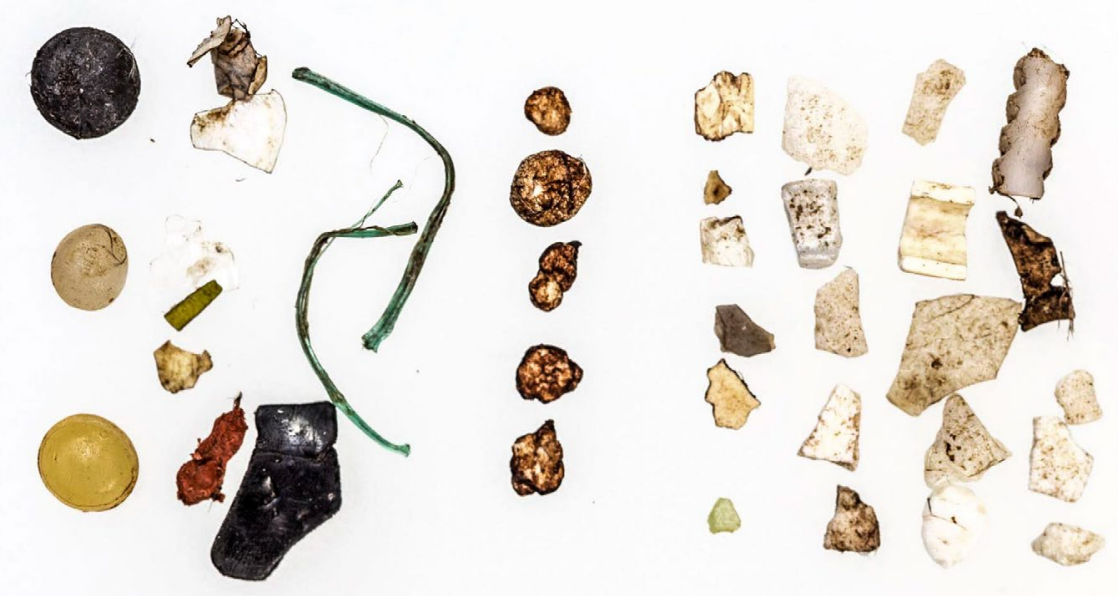

Photo 2 A representative fulmar stomach content. On average, fulmars from the Dutch coast contain about 24 plastic particles weighing $0.26 \mathrm{~g}$ (Table $i$ ). The stomach content on the photo (NET-2018-010) is then a fairly representative example. With 38 plastic particles the number of particles may be above average, but overall mass of plastic, which is our main monitoring metric, is $0.2367 \mathrm{~g}$ so somewhat below the recent Dutch 2014-18 average. 


\section{Trend and prediction}

In order to provide policy makers with simple straightforward information, this summary report focuses on a new predictive EcoQO model to estimate when in future the EcoQO target may be reached if the current trend persists. This model simply uses the existing annual figures for sample size plus the number of birds within that sample exceeding the $0.1 \mathrm{~g}$ threshold. These data are analysed in a General Linearized Model (GLM) which uses a logistic approach to binomial data (bird yes or no above threshold) resulting in a trend within the observed data that can be extrapolated to the future. OSPAR guidelines request trend analyses to be conducted over a recent 10-year period, but that applies to a large number of individual data over those years. The new GLM calculation has only one data-point per year, and longer time series are recommended. For the time being we focus on the period starting 2002, the year when international fulmar monitoring was started in the EU Interreg IIB project 'Save the North Sea'.

GLM analysis over the 17-year period 2002-2018 for the Netherlands indicated a highly significant improvement in EcoQ performance (EcoQ\% decreased significantly a $p<0.001 ;$ Fig. $i$ ). When the calculated trend is projected into the future, results suggest that the OSPAR Long-term target may be reached in year 2049.

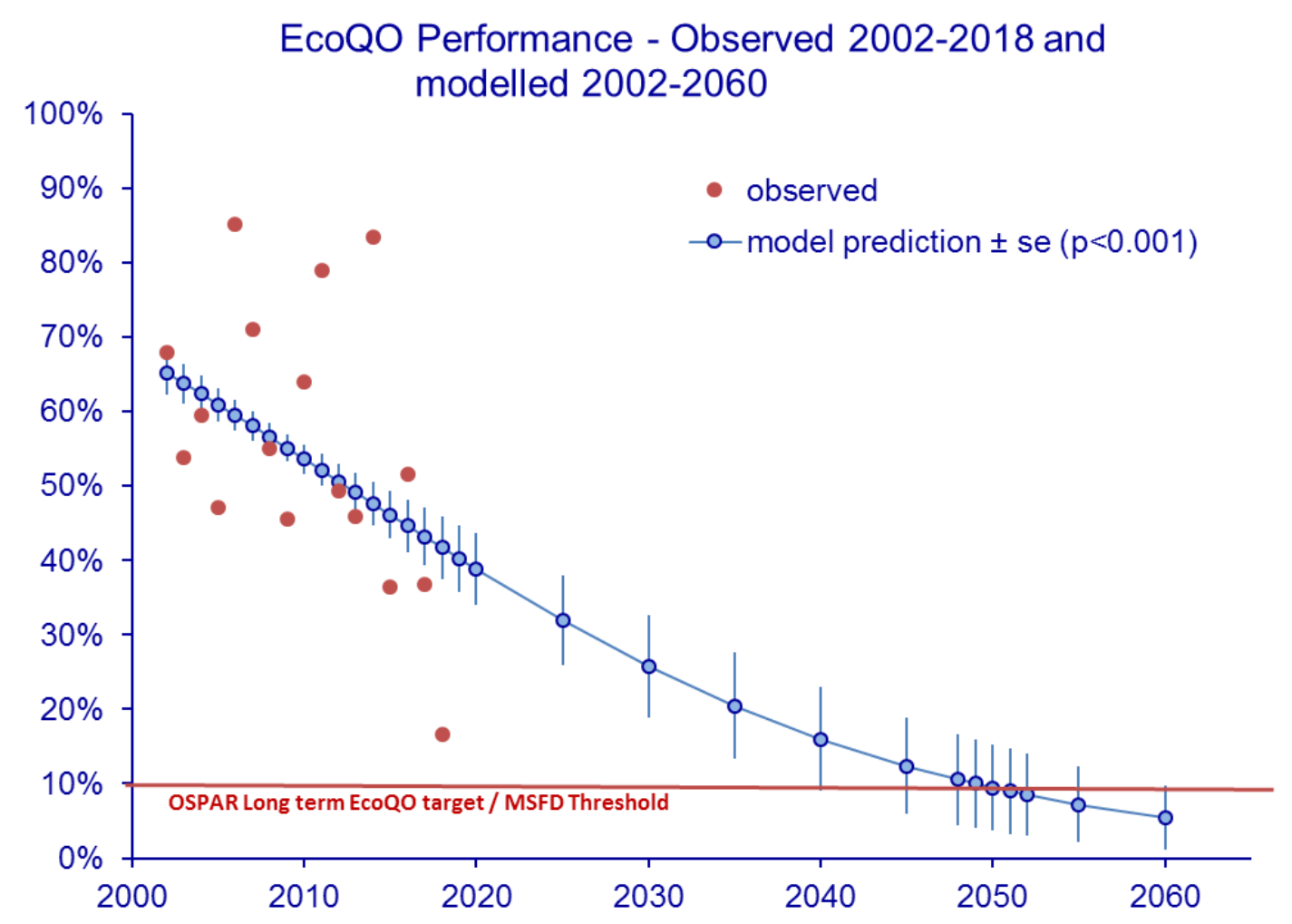

Figure $i \quad G L M$ model analyses of annual EcoQO performance using 17 years of EcoQO data (2002-2018). Observed data are the red circles in the graphs. When the model is significant, the predicted annual values and standard errors (vertical lines) are shown by blue closed circles and solid lines, connected by a trendline. When the model from observed data is not significant, predicted values and standard error lines are dashed, and no trendline is shown.

It has to be emphasized that the predictive trendline does not imply that we can now relax and take no further action. The model predicts the future development if we continue, at the same rate as we have done so far, to take new policy measures and if we continue to create further changes in awareness and behaviour. No extra effort means that the trendline will level off and that the EcoQO target will not be reached. Intensifying further measures and efforts could mean that the target might be reached earlier than predicted by the current model.

Existing OSPAR guidelines prescribe the tests for trends over time as analyses over the most recent 10 years, using linear regression analyses of log transformed values of individual plastic mass against year of collection. Those tests (see Chpt 4.3) do show negative correlations between plastics and the year of observation, but not significant (343 birds: $p=0.072$ ). Over the $2002-2018$ period as used in 
the GLM procedure, the test is significant ( 729 birds: $p=0.043$ ). So both approaches indicate a gradual decrease in plastics ingested by fulmars, but statistics differ per method and the time period considered.

A non-statistical way to illustrate and double-check the trends in plastic ingestion over time is by comparison of separate age classes. Monitoring results are mostly presented for birds of all ages together, but since the pilot study for the fulmar monitoring project (Van Franeker \& Meijboom 2002) it is known that younger birds on average carry a higher load of ingested plastic than adult birds. As long as age composition shows no substantial persistent change, age groups may be combined. The difference between age groups should also be reflected in the respective EcoQO data. Fig. ii illustrates EcoQO performance for separate adult and non-adult age groups. This is done by means of running 5 year data-points because annual figures are often too variable (see the red data-points for observed data in Fig. i), and certainly so when sample size is reduced by splitting into subgroups. Data for the 1980s have been grouped into a single data-point. The graph clearly illustrates similarity in trends for the separate age groups both in a longer-term and in several shorter-term variations. This supports the validity of GLM modelling using annual data. Data from running 5-year averages cannot be used for statistics as those figures entail repeated use of the same individuals.

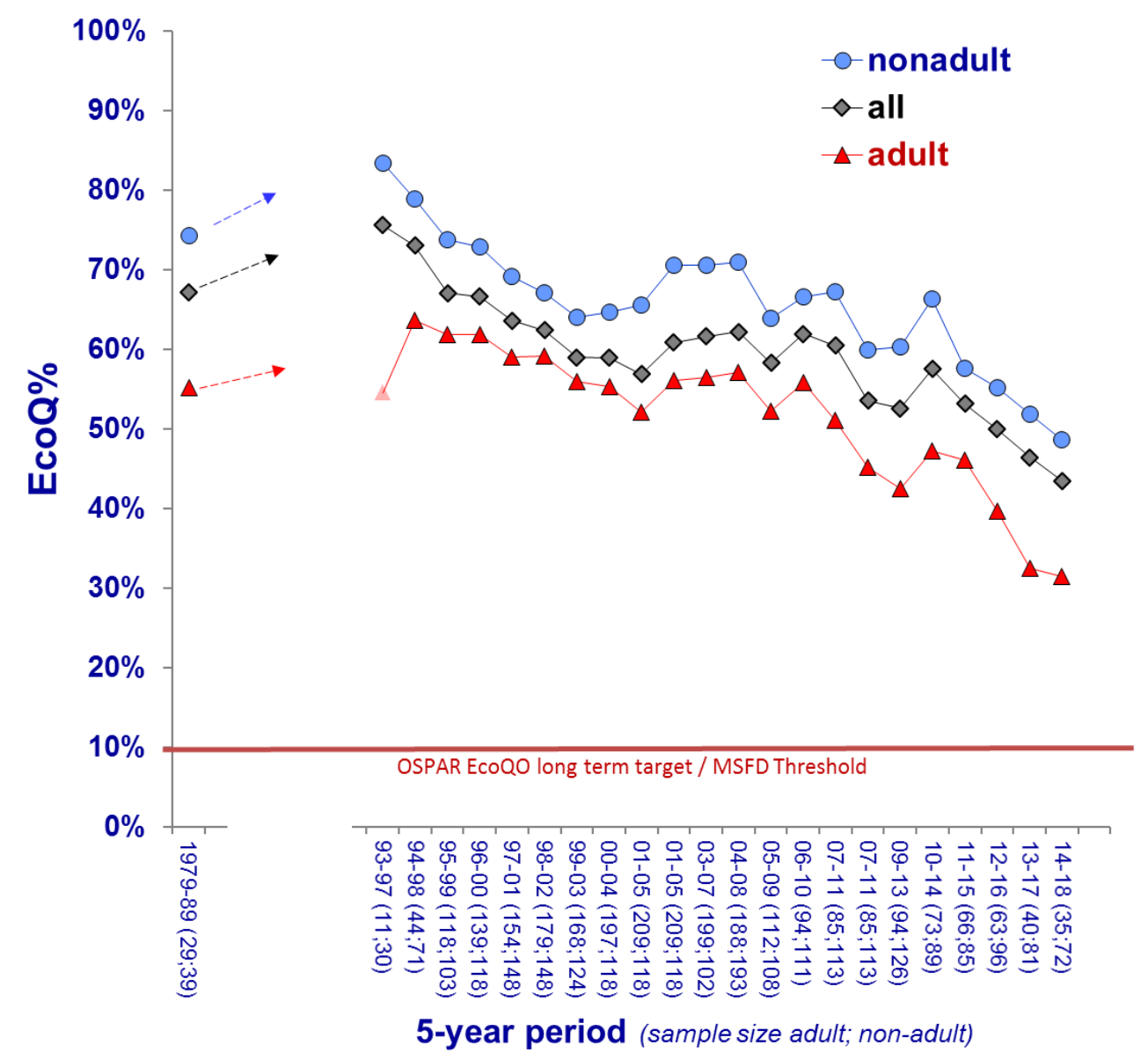

Figure ii Trend in EcoQO performance of different age classes of beached fulmars from the Netherlands 1979-2018. Trendlines for all birds combined (grey diamonds, including birds of unknown age), for adult birds (red triangles) and for non-adults (blue circles). This graphic visualization is based on a single data-point for the 1980s and overlapping running 5-year averages in later periods. Periods with less than 10 birds in the sample during the late 1980s and early 1990s are not shown in the graph. This visualization in itself does not represent a statistical trend analysis.

It is difficult to pinpoint specific events that may have triggered increases in ingested plastics from the 1980 s into the 1990s, and subsequent decreases. Different trends for industrial plastics and consumer waste complicate the issue. Since the start of the Save the North Sea project in 2002 and up to 2014, no significant trends were detected in the ingested mass of plastics over 10-year time series.

However, over 10-year periods 2006-2015 and 2007-2016, an in absolute terms moderate, but 
statistically significant decrease in ingested plastic mass was observed. Although this slow change has continued over the 2008-2017 and 2009-2018 periods, there was no statistically significant 10-year trend. Ongoing significant reduction may be considered an intermediate aim in terms of the European MSFD and GES by the year 2020, but will be hard to show at a significant level within 10 -year periods.

\section{MAIN POINTS}

1. North Sea governments aim at a long-term OSPAR Ecological Quality Objective (EcoQO) in which for at least 5 consecutive years, the proportion of fulmars with more than 0.1 gram of plastic in the stomach remains under $10 \%$. The EU Marine Strategy Framework Directive (MSFD) is likely to set the same figure as its final threshold, with intermediate targets to be defined. The proportion of birds having more than $0.1 \mathrm{~g}$ plastic in the stomach is referred to as EcoQO-performance or EcoQ\%.

2. Over the 5-year period 2014-2018, EcoQO performance among 115 fulmars beached in the Netherlands was $43 \%$. In this period, $93 \%$ of fulmars had ingested some plastic, with an average over all birds of 24 particles per stomach, weighing 0.26 gram.

3. Although still far from the OSPAR long-term target, the current 5-year dataset is the best on record since the start of the monitoring program.

4. Trend analyses over the years 2002-2018 indicate a strong and significant decrease in annual EcoQ\% suggesting that the EcoQO may be reached in the year 2049, which is earlier than predicted in the previous analyses.

5. It is not possible to pinpoint single clear causes for the observed changes. Gradual improvement since the early 2000 s may be linked to media attention for oceanic garbage patches and plastic soup. Increased awareness among all stakeholders may slowly lead to gradually improved policy measures and implementation by marine industries and general public.

6. The model prediction is not based on a status-quo, but on the current rate of change, which is assumed to reflect intensified policy measures and improved awareness and behaviour. This implies that the predicted future change will require further policy measures and further changes in stakeholder awareness and behaviour. Without extra effort, it is unlikely that the EcoQO target could be reached in the predicted time period.

\section{CONCLUSION}

Stomach contents of fulmars beached in the Netherlands indicate that the marine litter situation off the Dutch coast is gradually improving, but still far off international long-term targets for ecological quality. Within 10-year evaluation periods the trend is not consistently significant, but considered over longer periods it is, and indicates that at its current rate the long-term EcoQO target may be reached around the year 2049.

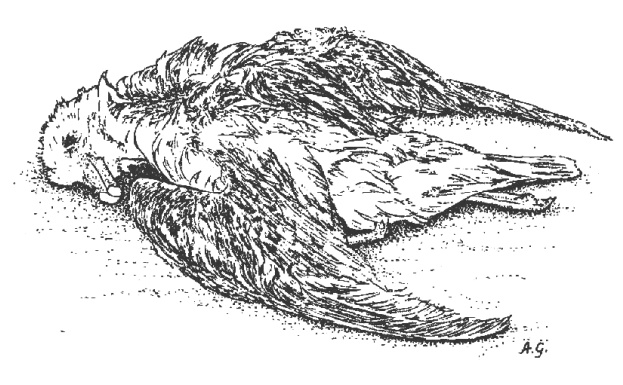

Beached fulmar (line-drawing by Arnold Gronert) 


\section{Introduction}

Marine litter, in particular plastic waste, represents an environmental problem in the North Sea and elsewhere, with considerable economic and ecological consequences. In 2005, a large study along the full $30 \mathrm{~km}$ coast length of the island of Texel revealed that each day, on each $\mathrm{km}$ of beach, 7 to $8 \mathrm{~kg}$ of debris washed ashore (Van Franeker 2005). Roughly half of the debris was wood, the other half was synthetic materials, with minor contributions from other materials such as glass and metals. On Texel, the main source of the debris, estimated at up to $90 \%$ of mass, was related to activities at sea, i.e. shipping, fisheries, aquaculture and offshore industries.

The economic consequences of marine litter affect many stakeholders. Coastal municipalities are confronted with excessive costs for beach clean-ups. Tourism suffers damage because visitors avoid polluted beaches especially when health-risks are involved. Fisheries are confronted with a substantial bycatch of marine litter, which causes loss of time, damage to gear, and tainted catch. Shipping suffers financial damage and -more importantly- safety-risks from fouled propellers or blocked waterintakes. Marine litter blowing inland can even seriously affect farming practices. The overall economic damage from marine litter is difficult to estimate, but a detailed study in the Shetlands with additional surveys elsewhere indicate that even local costs may run into millions of Euros (Hall 2000; Lozano \& Mouat 2009; Mouat et al. 2010; Newman et al. 2015).

The ecological consequences of marine litter are most obvious in the suffering and death of marine birds or mammals entangled in debris. Entangled whales are front-page news and attract a lot of public attention. However, only a small proportion of entanglement mortality becomes visible among beached animals. Even less apparent are the consequences from the ingestion of plastics and other types of litter. Ingestion is extremely common among a wide range of marine species including many seabirds, marine mammals and sea-turtles (Laist 1987, 1997; Derraik 2002; Kühn et al. 2015). It can cause direct mortality but the major impact most likely occurs through reduced fitness of many individuals.

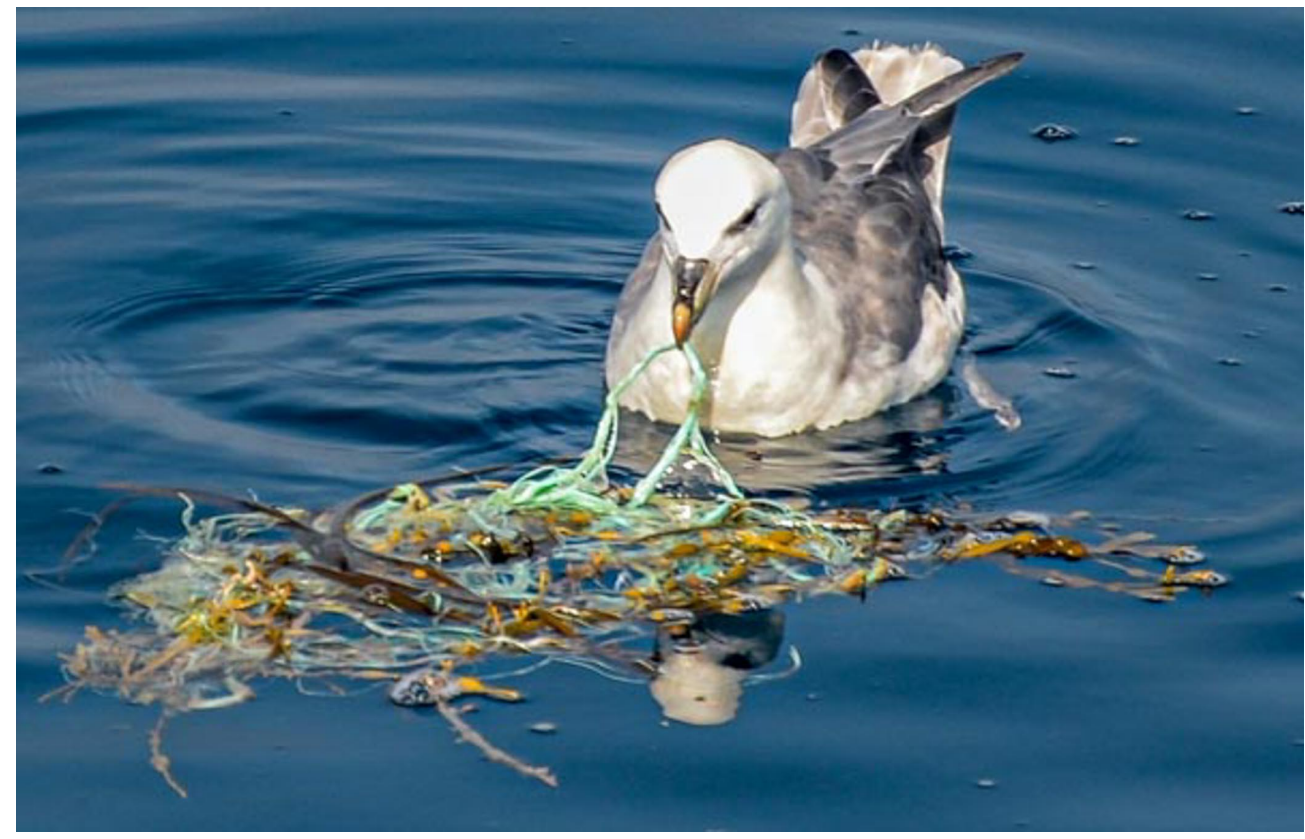

Photo 3 Northern Fulmar nibbling on synthetic thread. In most situations, the impact from ingested plastics will not be directly lethal to individual fulmars. However, sub-lethal effects such as from reduced fat reserves, or chemicals stored in fat, may play a role in breeding success and survival in periods of high energy requirements, such as during prolonged periods of storm or reduced food availability, during multi-day incubation shifts, the feeding chicks and moult. Since nearly every fulmar ingests plastics, such sub-lethal impacts affect the whole population. 


\title{
The $0.1 \mathrm{~g}$ plastic threshold and the $90 \%$ proportion rule in the Fulmar EcoQO target definition: history and application.
}
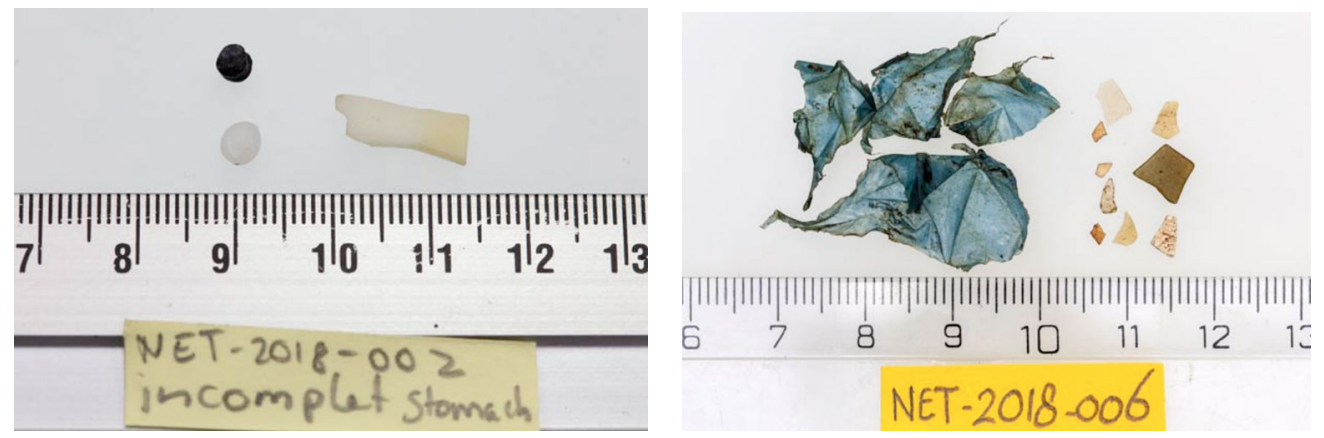

\begin{abstract}
Photo $4 \quad$ Near threshold examples of plastics in fulmar stomachs in 2018.
Fulmar NET-2018-002 had a partly scavenged stomach (and is thus not included in calculations), but still had 3 plastic particles ( 2 industrial granules and a fragment) weighing $0.1313 \mathrm{gram}$, so slightly above the threshold. The stomach of fulmar NET-2018-006 contained 13 user plastic particles, notably parts of a plastic bag, weighing $0.0781 \mathrm{gram}$, so under the $0.1 \mathrm{~g}$ threshold. The long-term EcoQO target implies that no more than $10 \%$ or less of the birds may contain the amount of plastic or more as on the left photo. However, up to $90 \%$ of birds is still allowed to have a quantity of plastics as on the right photograph.
\end{abstract}

In the Fulmar EcoQO target definition, the threshold level ( $0.1 \mathrm{~g}$ of plastic) and the proportion of individuals that should be under this threshold (90\%) have a historical background. In early phases of discussions to install an ECOQO on marine litter in the North Sea, working groups in ICES (Int. Council for the Exploration of the Sea) and in OSPAR followed the concept already used in the EcoQO on oiled seabirds. This EcoQO for marine oil pollution used the common guillemot (Uria aalge) as its monitored species, and the accepted target for ecological quality was that the proportion of oiled specimens among beached individuals should be reduced to under $10 \%$.

In a similar approach, it was proposed that the amount of plastics in seabirds should remain under 10 particles in at least $90 \%$ of stomachs of beached specimens. As in the guillemot EcoQO there was no ecological or health background to the target. The general concept was that such pollutants do not belong in the natural environment at all, and will always cause some level of harm. The only reason to not set the target at zero oil or zero plastics (or zero harm) was that even under maximum precautionary behaviour, some accidental losses should be accounted for in policy targets.

When fulmars were accepted as the monitoring species for the plastic EcoQO, the concept of 10 particles was changed to a threshold in terms of mass because that made more sense in ecological terms and offered more continuity as particle properties proved to change rapidly. The target of $90 \%$ of fulmars having less than $0.1 \mathrm{~g}$ was an arbitrary ambitious level in a period when over $60 \%$ of birds exceeded that level.

It was only later that this arbitrary target could be shown to be realistic and achievable as fulmars in the relative unpolluted areas of the high Canadian arctic were found to have plastic levels in the stomach close to the long-term OSPAR target. Canadian data are currently evaluated in more detail in order to define a more strict data derived 'threshold' to be developed within the MSFD monitoring.

Although the principle of monitoring plastic mass in stomachs can be widely applied to basically any species of marine wildlife, the target definition for ecological quality as used for fulmars should not be simply copied to other species. Each species has its own specific characteristics in body size and morphology, foraging ecology and dietary choices, all of which will strongly affect amounts of plastics in the stomachs. Under the same environmental conditions, species will have very different levels of ingested plastic. Target levels for acceptable ecological quality are species specific, and are best defined on the basis of earlier stomach content research in a range of different environments. 
Sub-lethal effects on animal populations remain largely invisible. In spite of spectacular examples of mortality caused by marine litter, the real impact on marine wildlife therefore remains difficult to estimate (Browne et al. 2015; Rochman et al. 2016; Werner et al. 2016). Plastics gradually break down to microscopically small particles, but these may pose an even more serious problem (Thompson et al. 2004; Bergmann et al. 2015). Although experimental results and model predictions are not all in agreement, concerns about microplastics are increasing as plastics can adsorb and concentrate organic pollutants from the surrounding water and, once ingested, might release chemicals into marine organisms with associated negative effects (Arthur et al. 2009; Browne et al. 2008, 2013; Endo et al. 2005, 2013; Gouin et al. 2011; Koelmans et al. 2013a,b, 2014, 2016; Moore 2008; Teuten et al. 2007, 2009; Chua et al. 2014; Rochman et al. 2013, 2014a,b; Tanaka et al. 2013; Thompson et al. 2009; Van Cauwenberghe \& Janssen 2014; Cole et al. 2015; Watts et al. 2015; CBD 2016; Beaman \& Bergeron 2016; Peda et al. 2016; Besseling et al. 2017; Heindler et al. 2017; Hermabessiere et al. 2017; Ribeiro et al. 2017). Thus, in addition to the toxic substances incorporated into plastics in the manufacturing process, plastics may concentrate pollutants from the environment and act as a pathway adding to their accumulation in marine organisms. Evidently, this same mechanism operates at all levels of organisms and sizes of ingested plastic material, from small zooplankton filter-feeders to large marine birds and mammals. However, it is especially the ingestion of microplastics by small filter-feeders that has emphasized the potential scale and urgency of the problem of marine plastic litter, as it may ultimately affect human food quality and safety as well (Hauser et al. 2015; Hunt et al. 2016). Concerns have also been expressed for the even smaller particles, those in the nano-size range, which might penetrate into tissues and cells with potential chemical and mechanical damage to e.g. DNA but are extremely difficult to quantify in nonexperimental situations (Koelmans et al. 2015; Booth et al. 2016; Gigault et al. 2016; Liu et al. 2016; Jahnke et al. 2017; Mintenig et al. 2018). Accumulation of marine plastic litter, including a 'soup' of microplastics, in all major gyres of the oceans (Moore et al. 2001; Moore 2008; Law et al. 2010; Maximenko et al. 2012; Van Sebille et al. 2012, 2015) and in deep-sea sediments and polar sea-ice (e.g. Obbard et al. 2014; Fischer et al. 2015; Cózar et al. 2017; Munari et al. 2017; Tekman et al. 2017) have emphasized the global scale of this marine litter problem. Less investigated, but potentially equally important is the terrestrial accumulation of micro- and nano-plastics (e.g. Huerta Lwanga et al. 2016; $\mathrm{Ng}$ et al. 2018).

Recognizing the negative impacts from marine debris, a variety of international policy measures has attempted to reduce the input of litter. Examples of these are the London Dumping Convention 1972; Bathing Water Directive 1976; MARPOL 73/78 Annex V 1988; Special Area status North Sea MARPOL Annex V 1991; and the OSPAR Convention 1992. In the absence of significant improvements, political measures have been intensified by for example the EU-Directive 2000/59/EC on Port Reception Facilities (EC 2000; EU 2019), the Declaration from the North Sea Ministerial Conference (2002) in Bergen, and recently in a revision of MARPOL Annex V (MEPC 2011) and the European Marine Strategy Framework Directive 2008/56/EC (EC 2008; EC 2010; EC 2017).

Policy initiatives have recognized the need to use quantifiable and measurable aims. Therefore, the North Sea Ministers in the 2002 Bergen Declaration decided to introduce a system of Ecological Quality Objectives for the North Sea (EcoQOs) (North Sea Ministerial Conference 2002). For example, the oil pollution situation in the North Sea is measured by the rate of oil-fouling among beached Guillemots (Uria aalge) with an EcoQO target of less than $10 \%$ of beached Guillemots having oil on the plumage (OSPAR 2005). Similarly, as proposed by ICES Working Group on Seabird Ecology (ICES-WGSE 2003), OSPAR decided to use the abundance of plastic in stomachs of seabirds, in casu the Northern Fulmar (Fulmarus glacialis) to measure quality objectives for marine litter (OSPAR 2008, 2009, 2010a, 2010b, $2015 a, b)$. The fulmar EcoQO monitoring has been included as an indicator for marine litter in the approach for Good Environmental Status in the European Marine Strategy Framework Directive (Galgani et al. 2010; EC 2010; MSFD GES Technical Subgroup on Marine Litter 2011).

Within the Netherlands, the Ministry of Infrastructure and Watermanagement (I\&W) has a coordinating role in governmental issues related to the North Sea environment. As such, I\&W is involved in the development of environmental monitoring systems ("graadmeters") for the Dutch continental shelf area. As a part of this activity, I\&W has commissioned several earlier projects by Wageningen Marine Research working towards a Fulmar-Litter-EcoQO. The first pilot project for the North Sea Directorate of I\&W considered stomach contents data of Dutch fulmars up to the year 2000 and made a detailed evaluation of their suitability for monitoring purposes (Van Franeker \& Meijboom 2002). A series of later reports commissioned by the Directorate-General for Civil Aviation and Maritime Affairs (DGLM) (see 'References') have provided annual updates on the Dutch time-series, paying special attention to shipping issues and EU Directive 2000/59/EC. As of 2010, updates of the 
fulmar monitoring reports have been commissioned by Rijkswaterstaat (RWS Water, Traffic and Living Environment RWS-WVL).

Internationally, as of 2002, the Dutch fulmar research was expanded to all countries around the North Sea as a project under the Save the North Sea (SNS) program. SNS was co-funded by EU Interreg IIIB over period 2002-2004 and aimed to reduce littering in the North Sea area by increasing stakeholder awareness. The fulmar acted as the symbol of the SNS campaign. The SNS fulmar study was published by Van Franeker et al. (2005). Findings strongly supported the important role of shipping (incl. fisheries) in the marine litter issue. For further publications of the SNS fulmar study see e.g. Save the North Sea (2004), Van Franeker (2004b,c), Edwards (2005), Guse et al. (2005), Olsen (2005). After completion of the European SNS project, the international work was continued through CSR awards from the NYK Group Europe Ltd and support from Chevron Upstream Europe. These funds contributed to further North Sea EcoQO wide updates in reports (Van Franeker \& the SNS Fulmar Study Group 2013), including peer reviewed scientific publications on the EcoQO methods with data up to 2007 (Van Franeker et al. 2011) and 2012 (Van Franeker \& Law 2015). These awards were used also to promote fulmar work in other areas of the world such as Ireland (Acampora et al. 2016), the Faroe Islands (Van Franeker 2012), Iceland (Kühn \& Van Franeker 2012), Svalbard (Trevail et al. 2015), Atlantic Canada (Bond et al. 2014), the Canadian Arctic (Mallory et al. 2006; Mallory 2008; Provencher et al. 2009; Poon et al. 2017; Avery-Gomm et al. 2018) and the Pacific (Nevins et al. 2011; Avery-Gomm et al. 2012; Donnelly et al. 2014; Terepocki et al. 2017) and to explore the potential use of other marine species for ingestion monitoring as intended in the European Marine Strategy Framework Directive (Bravo Rebolledo et al. 2013; Foekema et al. 2013; Matiddi et al. 2017; van Franeker et al. 2018). The most recent international overview of the monitoring of plastics in stomach contents of fulmars in the North Sea area includes data up to 2014 (Intermediate Assessment OSPAR 2017). A second intermediate assessment using data up to 2016 has been prepared and will likely be published by OSPAR in 2019. Currently there is no funding dedicated to international coordination and integrated data analysis and reporting.

The current assignment from I\&W, through its section Rijkswaterstaat Water, Traffic and Living Environment RWS-WVL included:

$>\quad$ Update of the Dutch time series on litter in stomachs of fulmars with the data of year 2018.

$>\quad$ Continued co-ordination of the beached fulmar sampling in the Netherlands.

$>\quad$ Addition to the basic raw data to be added to databases of RWS CIV (Centrale Informatievoorziening, Lelystad) or via CIV to third parties like OSPAR.
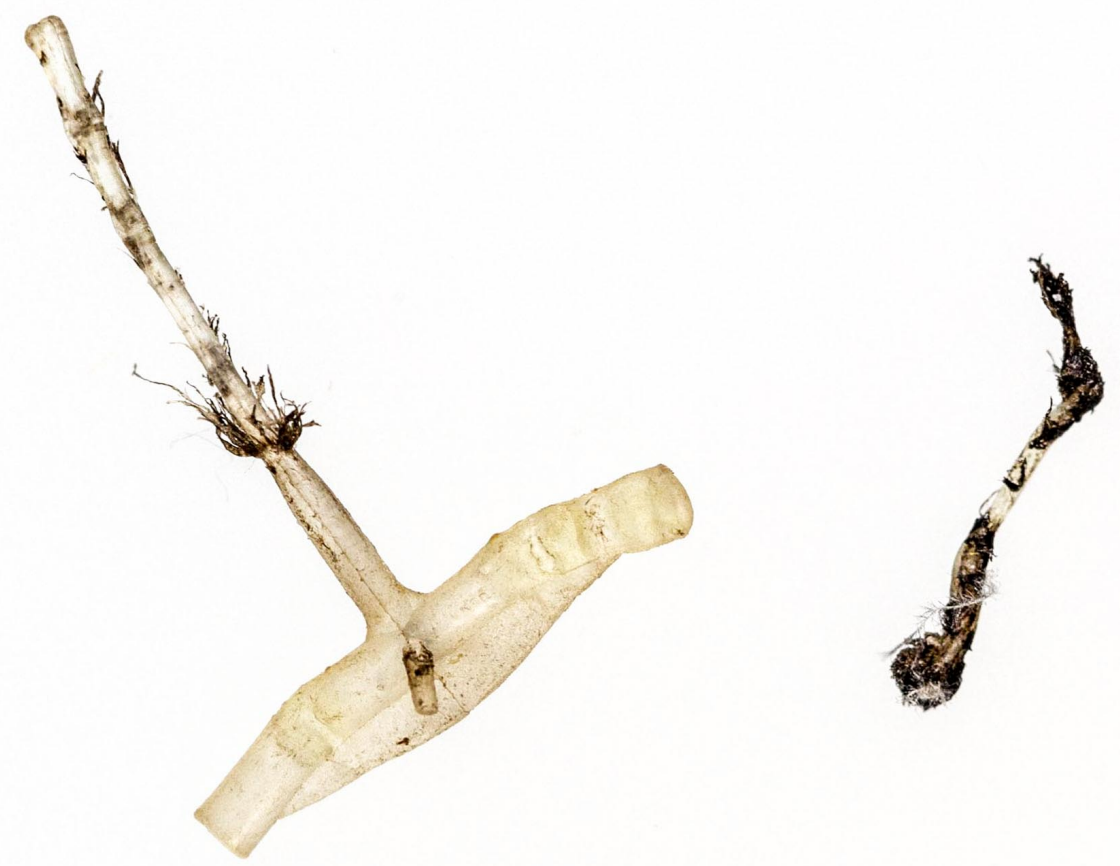

Photo 5 Plastic tag holders are regularly found in fulmar stomachs: here in fulmar NET2018-007. The bit to the right is probably a broken off part of the same item. 


\section{$2 \quad$ Marine litter and policy measures}

Compared to the problems from dumping of oil or toxic wastes, the issue of disposal of 'garbage' into the marine environment has long been considered of minor importance. It might still be considered that way if not for plastics. Plastics, although known since the early 1900s, started their real development only after 1960 (Andrady \& Neal 2009). Since then, they have found their way into almost every application, replacing old materials in existing products, and creating a new and endless array of 'disposable' packaging products.

Unfortunately, the same factors that made plastics such a popular product have resulted in them becoming a serious environmental problem. Low production costs have promoted careless use and low degradability leads to accumulation in the environment. In 2016, the world production of raw plastic resins reached a new height of 348 million tons (PlasticsEurope 2018), and when fibre production is included at least 380 million tons (Geyer et al. 2017). Around $40 \%$ of the plastics is used for single use packaging. It is estimated that from 1950 to 2015 over 8 billion tons of plastics have been produced, of which over 6 billion tons has turned to waste, $79 \%$ of which has ended up in landfills or the environment (Geyer et al. 2017). Calculations on mismanaged waste have indicated that annually 4.8 to 12.7 million tonnes of plastics are lost from global land-based sources to the marine environment (Jambeck et al. 2015). Plastic consumption continues to grow; annual growth rates of between 5 to $10 \%$ were interrupted by the economic crisis in 2008 , but this was a temporary interruption.

Litter in the marine environment originates from a variety of sources, including merchant shipping, fisheries, offshore industry, recreational boating, coastal tourism, influx from rivers, sewage outflows, or direct dumping of wastes at sea or along seashores (Veiga et al. 2016). Coastal dumping of debris was common practise in many areas of northwestern Europe during the previous century. For example, in the 1950s the city of Den Helder in the Netherlands operated dedicated ships to dispose of municipal waste at sea. However, in western Europe most of such dumping has stopped tens of years ago. In addition, sewage treatment systems and risk for overflow during periods of excessive rain have strongly improved in the western European region. The relative importance of various sources differs strongly in different parts of the world, and is almost impossible to quantify in detail. As for the Netherlands, Dutch Coastwatch studies (e.g. Stichting de Noordzee 2003) score litter into categories 'from sea' (shipping, fisheries, offshore); 'beach-tourism'; 'dumped from land'; and 'unknown'. In the Netherlands, the 'from sea' category consistently represents in the order of $40 \%$ of litter items recorded. The 'unknown' category scores a similar percentage. Considerable uncertainties are linked to this categorization. More specific information may come from the OSPAR initiative for monitoring litter on beaches in a somewhat more systematic approach. In a first German report (Fleet 2003), ten years of Coastwatch-like surveys, plus two years of the more detailed OSPAR pilot project, were evaluated. From both studies, it is concluded that shipping, fisheries and offshore installations are the main sources of litter found on German North Sea beaches. The larger proportion of litter certainly originates from shipping, with a considerable proportion of this originating from the fisheries industry. In the Netherlands, data to this effect were collected in a large beach litter study on Texel (van Franeker 2005) suggesting that up to $90 \%$ of plastic litter originates from shipping and fisheries in the Dutch area. More recent analyses of OSPAR beach survey data have not yet ventured in new estimates of proportional roles of sources (Schulz et al. 2013, 2017; Dagevos et al. 2013). A lot of attention is given to touristic sources of debris on beaches and consumer behaviour in general.

In spite of the uncertainties in details, there is little doubt that waste disposal by ships is one of the important remaining sources of marine litter around the North Sea and worldwide, a fact also recognized by the International Maritime Organization (IMO) in its stepwise strengthening of the specific 'garbage-annex' to the MARPOL Convention. The International Convention for the Prevention of Marine Pollution from Ships (MARPOL 73/78) entered into force on 2nd October 1983 for Annexes I (oily wastes) and II (bulk liquid chemicals), but its Annex V, covering garbage, only achieved sufficient ratifications to enter into force on 31st December 1988. MARPOL Annex $V$ contained the following main prohibitions for discharge of solid wastes:

$>\quad$ No discharge of plastics.

$>\quad$ No discharge of buoyant dunning, lining or packaging material within 25 nautical miles $(\mathrm{nm})$. 
No discharge of garbage within $12 \mathrm{~nm}$. Food waste may be discharged if ground to pieces smaller than one inch.

$>\quad$ No discharge of any solid waste, including food waste, within $3 \mathrm{~nm}$.

Unfortunately, control of compliance with Annex $V$ regulations on ships is difficult (OECD-MTC 2003; Trouwborst 2011; Rakestraw 2012).

In the European region, and especially the North Sea area, the sheer intensity of merchant shipping and fisheries makes them an undisputed source of marine litter. From that background, North Sea states promoted that the North Sea received the status of MARPOL Special Area for its annexes I (oil) and V (garbage). Amendments to that effect were made in 1989, and the Special Area status for the North Sea entered into force in February 1991. "Special Areas" under MARPOL Annex V have a more restrictive set of regulations for the discharge of garbage, with the main additions being:

$>\quad$ No discharge, not only of plastics, but also of any sort of metal, rags, packing material, paper or glass.

$>\quad$ Discharge of food wastes must occur as far as practicable from land, and never closer than 12 nm.

Finally, MARPOL Annex $V$ was in 2001 revised by the Marine Environment Protection Committee (MEPC 2011). The important change is that the former approach of 'waste disposal at sea is allowed except ......' has been replaced by an approach of 'waste disposal is forbidden except ...'. Under the new regulations, entering into force on $1^{\text {st }}$ January 2013, nearly all waste disposal is thus completely prohibited irrespective of distance to land. This now includes glass, metal and all packaging materials, so it is similar to the Special Area Status that was already longer in force (1991) in the North Sea. Only food-wastes and 'non-harmful' cargo residues plus cleaning agents used in hold or on decks may be discharged under certain conditions such as distance to land.

Within the European Union, progress under worldwide MARPOL regulations was considered insufficient. High costs of proper disposal in combination with low risk of being fined for violations are a clear cause. Poor functioning of available reception facilities definitely plays a role as well. Compliance with MARPOL regulations is hard to enforce at sea, especially when many ships fall under jurisdiction of cheap flag-states with little concern for environmental issues. Compliance can only be promoted by measures that can be enforced when ships visit the harbour. From this perspective, the European Commission and parliament have installed the EU-Directive on Port Reception Facilities for shipgenerated waste and cargo residues (Directive 2000/59/EC). Key elements of the Directive are:

$>\quad$ Obligatory disposal of all ship-generated waste to reception facilities before leaving port. Shipgenerated waste includes operational oily residues, sewage, household and cargo-associated waste, but not residues from holds or tanks.

$>\quad$ Indirect financing, to a 'significant' degree, of the delivery of ship-generated waste. Finances for such 'free' waste reception should be derived from a fee system on all ships visiting the port. Delivery of cargo residues remains to be paid fully by the ship.

> Ports need to develop and implement a 'harbour waste plan' that guarantees appropriate reception and handling of wastes.

The term 'Significant' was later identified as meaning 'in the order of at least $30 \%$ '. The implementation date for the Directive was December 2002, but unfortunately suffered some delay in several countries. In the Netherlands, the Directive became implemented in late 2004, operating at or above the minimum level of indirect financing depending on the harbour. In 2019 a revision of the Directive, promoting indirect fees and shore delivery of fished waste was accepted by the European Parliament and Commission (EU 2019). On an annual basis, results are evaluated by the Minister of $\mathrm{I} \& \mathrm{~W}$ in which also the results of the Fulmar-Litter-EcoQO monitoring are being used. This tool complements surveys of quantities of litter delivered in ports, or beach surveys for quantities of waste washing onto beaches. These approaches have their specific merits but do not measure residual levels of litter in the marine environment itself. The Fulmar-Litter-EcoQO does look at this marine environment and at the same time places such information in the context of ecological effects.

The EU Marine Strategy Framework Directive (MSFD) (EC 2008, 2010, 2017; Galgani et al. 2010; MSFD GES Technical Subgroup on Marine Litter 2011) is a strongly developing instrument for initiation of new policies. The MSFD aims for 'Good Environmental Status (GES)' in which regionally important sources of debris need to be specifically addressed. A start was made in the OSPAR Regional Action Plan (OSPAR 2014) which does not yet specify a target for fulmar plastic ingestion by the year 2020 in relation to GES. There appears to be a tendency to agree with the long-term OSPAR target, with a GES 2020 target of a significant reduction in plastic ingestion by fulmars. Currently within MSFD a system of 'Thresholds' ( long-term targets) is being considered for various indicators. The threshold for plastic ingestion by the fulmar will likely follow the lines of the long-term OSPAR EcoQO. 
 of marine litter}

The interpretation of monitoring information presented in this report requires a summary of earlier findings as published in earlier reports and peer reviewed literature (Van Franeker et al. 2011; Van Franeker \& Law 2015).

Since the early days of plastic pollution of our oceans, the Northern Fulmar has been known as a species that readily ingests marine plastic debris (Bourne 1976; Baltz \& Morejohn 1976; Day et al. 1985; Furness 1985; Van Franeker 1985; Moser \& Lee 1992; Robards et al. 1995; Blight \& Burger 1997). Nevertheless, it took until the pilot study of Van Franeker \& Meijboom (2002) to properly investigate the feasibility of using stomach contents of Northern Fulmars to monitor changes in marine litter abundance in an ecological context. Samples of fulmars available for a feasibility study of monitoring in the Netherlands mainly originated from the periods 1982 to 1987 and 1996 to 2000 , with smaller numbers of birds from the years in between.

Reasons for selection of the fulmar out of a list of potential seabird species for monitoring are of a practical nature:

$>\quad$ Fulmars are abundant in the North Sea area (and elsewhere) and are regularly found in beached bird surveys, which guarantee supply of an adequate number of bird corpses for research.

$>\quad$ Fulmars are known to consume a wide variety of marine litter items.

$>\quad$ Fulmars avoid inshore areas and forage exclusively at sea (never on land).

> Fulmars do not normally regurgitate indigestible items, but accumulate these in the stomach (digestive processes and mechanical grinding gradually wear down particles to sizes that are passed on to the gut and are excreted).

> Thus, stomach contents of fulmars are representative for the wider offshore environment, averaging pollution levels over a foraging space and time span that avoids bias from local pollution incidents.

$>\quad$ Historical data are available in the form of a Dutch data series since 1982 (one earlier 1979 specimen); and literature is available on other locations and related species worldwide (Van Franeker 1985; Van Franeker \& Bell 1988).

$>\quad$ Other North Sea species that ingest litter either do not accumulate plastics (they regurgitate indigestible remains); are coastal only and/or find part of their food on land (e.g. Larus gulls); ingest litter only incidentally (e.g. North Sea alcids) or are too infrequent in beached bird surveys for the required sample size or spatial coverage (e.g. other tubenoses or Kittiwake Rissa tridactyla).

Beached birds may have died for a variety of reasons. For some birds, plastic accumulation in the stomach is evidently the direct cause of death, e.g. by plastic sheets blocking food passage. More often the effects of litter ingestion act at sub-lethal levels, except maybe in cases of ingestion of chemical substances. For other birds, fouling of the plumage with oil or other pollutants (Camphuysen 2018), collisions with ships or other structures, drowning in nets, extremely poor weather or foodshortage may have been direct or indirect causes of mortality.

At dissection of birds, their sex, age, origin, condition, likely cause of death and a range of other potentially relevant parameters are determined. Standardized dissection procedures for EcoQO monitoring have been described in detail in a manual (Van Franeker 2004b), subsequent peer reviewed publications (Van Franeker et al. 2011; Van Franeker \& Law 2015) and OSPAR Guidelines (OSPAR 2015a,b).

Stomach contents are sorted into main categories of plastics (industrial and user plastics), non-plastic rubbish, pollutants, natural food remains and natural non-food remains. Each of these categories has a number of subcategories of specific items. For each individual bird and litter category, data are recorded on presence or absence ("incidence"), the number of items, and the mass of subcategory (see methods). For efficiency/economy reasons, some of the details described in the manual and earlier reports were discontinued in the current research projects. 
The pilot study undertook extensive analyses to check whether time-related changes in litter abundance were susceptible to errors caused by bias from variables such as sex, age, origin, condition, cause of death, or season of death. If any of these would substantially affect quantities of ingested litter, changes in sample composition over the years could hamper or bias the detection of time-related trends.

A very important finding of the pilot study was that no statistical difference was found in litter in the stomach between birds that had slowly starved to death and 'healthy' birds that had died instantly (e.g. because of collision or drowning). This means that our results, which are largely based on beached starved birds, are representative for the 'average' healthy fulmar living in the southern North Sea.

Only age was found to have an effect on average quantities of ingested litter, adults having less plastic in their stomach than younger birds. Possibly, adults loose some of the plastics accumulated in their stomach when they feed chicks or spit stomach-oil during defence of nest-sites. Another factor could be that foraging experience may increase with age. Our understanding of the observed age difference in plastic accumulation is poor. In search of better understanding of such issues, Chevron Upstream Europe has funded a cooperative project with the Faroese Fisheries Laboratory. Using fulmars from the Faroe Islands, we investigate seasonal and age related variations in stomach contents. On the Faroe Islands, fulmars are hunted for consumption and large numbers of samples are easily obtained. Additional samples have been obtained from fisheries by-catch in the area. Stomach contents are analysed for both normal diet (Faroese component in the study; Danielsen et al. 2010) and for accumulated litter (Dutch contribution to the study). General results were published in Van Franeker (2012), but detailed analyses of samples obtained from all months of the year during several years continue to be analysed.

Although age has been shown to affect absolute quantities of litter in stomach contents, changes over time follow the same pattern in adults or non-adults. As long as no directional change in age composition of samples is observed, trends may be analysed for the combined age groups. However, background information for the presentation of results and their interpretations always requires insight in age composition of samples.

Significant long-term trends from 1982 to 2000 were detected in incidence (Frequency of Occurrence $\%$ FO), number of items and mass of industrial plastics, user plastics and suspected chemical pollutants (often paraffin-like substances). Over the 1982-2000 period, only industrial plastics decreased while user plastics significantly increased. When comparing averages in the 1980 s to those in the 1990s, industrial plastics approximately halved from 6.8 granules per bird (77\% incidence; $0.15 \mathrm{~g}$ per bird) to 3.6 granules $(64 \% ; 0.08 \mathrm{~g})$. User plastics almost tripled from 7.8 items per bird $(84 \% ; 0.19 \mathrm{~g})$ to 27.6 items $(97 \% ; 0.52 \mathrm{~g})$.

Analysis of variability in data and Power Analysis revealed that reliable figures for litter in stomachs in a particular region and specific time period are obtained at a sample size of about 40 birds and that reliable conclusions on change or stability in ingested litter quantities can be made after periods of 4 to 8 years, depending on the category of litter. Lower annual sample sizes are no problem, but will lengthen the periods needed to draw conclusions on regional levels and trends.

Mass of litter, rather than incidence or number of items, should be considered the most useful unit of measurement in the long-term. Mass is also the most representative unit in terms of ecological impact on organisms. Frequency of occurrence loses its sensitivity as an indicator when virtually all birds are positive (as is the case in fulmars). In regional or time-related analyses, mass of plastics is a more consistent measure than number of items, because the latter appears to vary with changes in plastic characteristics.

The pilot study concluded that stomach content analysis of beached fulmars offers a reliable monitoring tool for (changes in) the abundance of marine litter off the Dutch coast. By its focus on small-sized litter in the offshore environment, such monitoring has little overlap with, and high additional value to beach litter surveys of larger waste items. Furthermore, stomach contents of fulmars reflect the potential ecological consequences of litter ingestion on a wide range of marine organisms and create public awareness of the fact that environmental problems from marine litter persist even when larger items are broken down to sizes below the range of normal human perception. As indicated, there is an increasing concern on the dangers from microplastics, but monitoring quantities and effects in these species is more difficult than that of intermediate sized plastics in seabirds. 
The pilot study recommended that Dutch fulmar litter monitoring should focus on mass of plastics (industrial plastic and user) and suspected chemical substance. Each of these represents different sources of pollution, and thus specific policy measures aimed at reduced inputs. Because no funding was obtained to work on suspected chemicals, this element has been dropped and plastics have become the main focus. However, data-recording procedures are such that at the raw data-level, various sub-categories of plastics, other rubbish and suspected chemicals continue to be recorded by number and mass, and can be extracted from databases, should the need and funding arise.

After publication of the pilot study, the Dutch monitoring has continued annually and has resulted in a series of annual reports (Van Franeker et al. 2003 to 2018) that initially confirmed further decrease of industrial and but especially showed a drop in user plastics after the late 1990s. However, this was soon followed by a halt or at least serious slow-down of such trends. Since about 2015 (Van Franeker et al. 2016, 2017, 2018), the analyses indicate a continuing trend of slow but significant decrease.

Internationally, the fulmar litter monitoring was boosted by the Save the North Sea campaign 20022004, which was co-funded by EU Interreg IIIB and aimed at increasing awareness among stakeholders to reduce littering behaviour. Expanding the Dutch fulmar study to locations all around the North Sea was one of the project components. Co-operation was established with interested groups in all countries around the North Sea. The final project report (Van Franeker et al. 2005) showed that fulmars from the southern North Sea had almost two times more plastic in the stomach than fulmars from the Scottish Islands, and almost four times as much as that in a small sample from the Faroe Islands. Van Franeker et al. (2011) confirmed these patterns with data up to 2007. Location differences and relative abundances of different types of litter suggested a major role of shipping, and showed that the bulk of the litter problem in the North Sea region is of local origin.

Also in 2002, North Sea Ministers in the Bergen Declaration, decided to start a system of 'Ecological Quality Objectives (EcoQOs) for the North Sea'. One of the EcoQOs to be developed was for the issue of marine litter pollution, using stomach contents of a seabird, the fulmar, to monitor developments, and to set a target for 'ecological quality'. OSPAR was requested to look after implementation of the ecological quality objectives. Since then, a number of steps has been taken, based on reports from the Dutch studies and the Save the North Sea project. The current wording of the EcoQO target level (OSPAR 2010b) is:

"There should be less than $10 \%$ of Northern Fulmars (Fulmarus glacialis) having more than 0.1 gram plastic particles in the stomach in samples of 50 to 100 beach-washed fulmars from each of 4 to 5 different areas of the North Sea over a period of at least 5 years".

As recommended from the Dutch studies, the mass of plastics forms the basis of the EcoQO monitoring system. Rather than using average plastic mass for the target definition, a combination is used of frequency of occurrence of plastic masses above a certain critical mass level $(10 \% ; 0.1 \mathrm{~g})$. The background of such approach is that a few exceptional outliers can have a strong influence on the calculated average. The wording of the target level basically excludes influence of exceptional outlying values. A similar effect can be obtained by calculating mean values from logarithmically transformed data (Geometric means). The OSPAR Fulmar EcoQO has been published in a background document (OSPAR 2008) and its implementation was included in the OSPAR Quality Status Report (OSPAR $2010 a, b)$. Formal guidelines and assessment methods have been published (OSPAR 2015a,b). Recently OSPAR (2017) published an analysis of data up to 2014 for all five North Sea areas, indicating continued although less pronounced latitudinal differences as compared to Van Franeker et al. 2005 and 2011, and the absence of significant trends. A second version of such 'Intermediate Assessment' is about to be published by OSPAR (2019).

As indicated in Chapter 1, the international work was continued and expanded after the SNS project. The EcoQO approach to marine litter is now an element for assessment of 'Good Environmental Status' in the European Marine Strategy Framework Directive (Galgani et al. 2010; EC 2010, 2017; MSFD GES Technical Subgroup on Marine Litter 2011). Quality of the methodology has been established by publications in peer reviewed scientific articles (Ryan et al. 2009; Van Franeker et al. 2011; Kühn \& Van Franeker 2012; Trevail et al. 2015; Van Franeker \& Law 2015). This monitoring is used by researchers in the Canadian Atlantic and arctic and in the Pacific (Mallory 2008; Provencher et al. 2009; Nevins et al. 2011; Avery-Gomm et al. 2012, 2018; Donnelly-Greenan et al. 2014; Bond et al. 2014; Poon et al. 2017; Terepocki et al. 2017). In principle this monitoring can be implemented throughout the fulmars Atlantic and Pacific breeding ranges (Hatch \& Nettleship 1998). 
The results of fulmar studies were also used in the UNEP yearbook 2011 (UNEP 2011), which devoted a chapter to the global problem of marine litter (Kershaw et al. 2011), ranking plastic pollution as one of the main global threats to the marine environment. The example of fulmar monitoring methods and its long-term character were extensively used in the most recent UNEP report on the marine plastic issue (UNEP 2016) and GESAMP (2019).

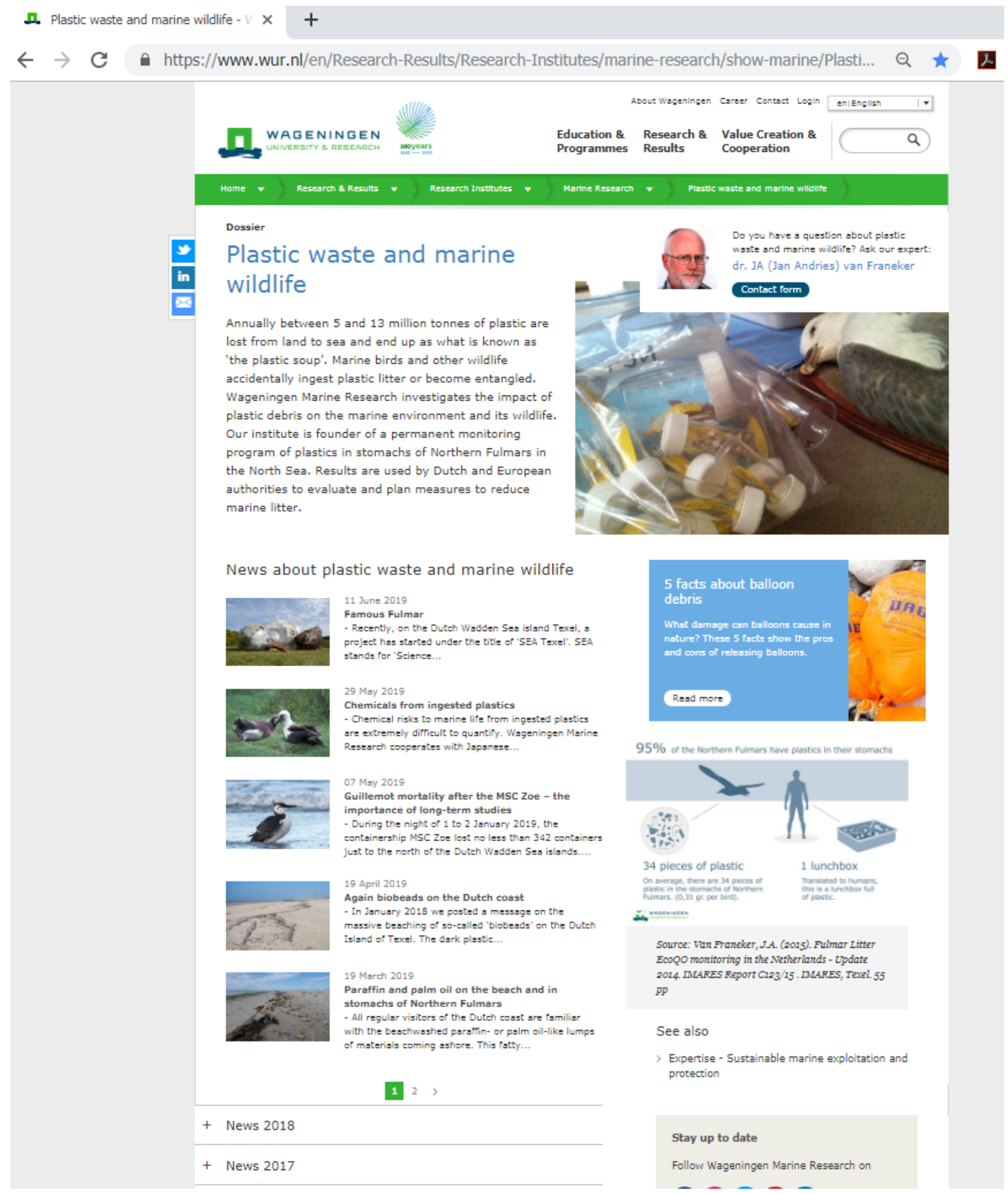

Etc

Photo 6 Outreach. In the fulmar monitoring project, we aim to disseminate knowledge widely and promote participation. Through a webdossier www.wur.eu/plastics-fulmars we inform general public, policy makers, scientific colleagues and volunteers involved in the program on our achievements and important developments.

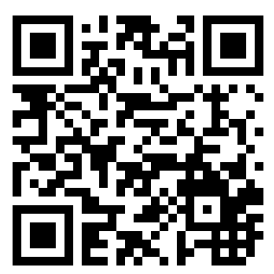




\section{Materials and Methods}

Wageningen Marine Research continues the collection of beached fulmars from Dutch beaches with the assistance of the Dutch Seabird Group (Nederlandse Zeevogelgroep - NZG) through its Working Group on Beached Bird Surveys (Nederlands Stookolieslachtoffer Onderzoek - NSO). In addition, several coastal bird rehabilitation centres support the collection program. Sampling effort for the Dutch fulmar study is spread over the full Dutch coastline, but hard to define in detail. In general, most fulmars in our study originate from the more northern part of the Netherlands, with next in line fulmars from the Zeeland area. The lower number of beached fulmars from the more central parts of the Dutch coast may be due to lower observer effort, but also to more rapid disappearance of corpses due to higher numbers of scavenging foxes or cleaning activities on the touristic beaches.

With the Save the North Sea project in 2002, IMARES, now Wageningen Marine Research, started co-ordinated similar sampling projects at a range of locations in all countries around the North Sea. Organizations involved in different countries differ widely, and range from volunteer bird groups to governmental beach cleaning projects. Fig. 1 shows all locations that were involved in the Save the North Sea monitoring program, and their regional grouping. Lack of funding has led to a stop of the international coordination, although separate countries, except Sweden, have committed to continued monitoring and submission of basic data to OSPAR, also as a part of their involvement in the European Marine Strategy Framework Directive. These data are analysed in intermediate assessments (OSPAR 2017, 2019)

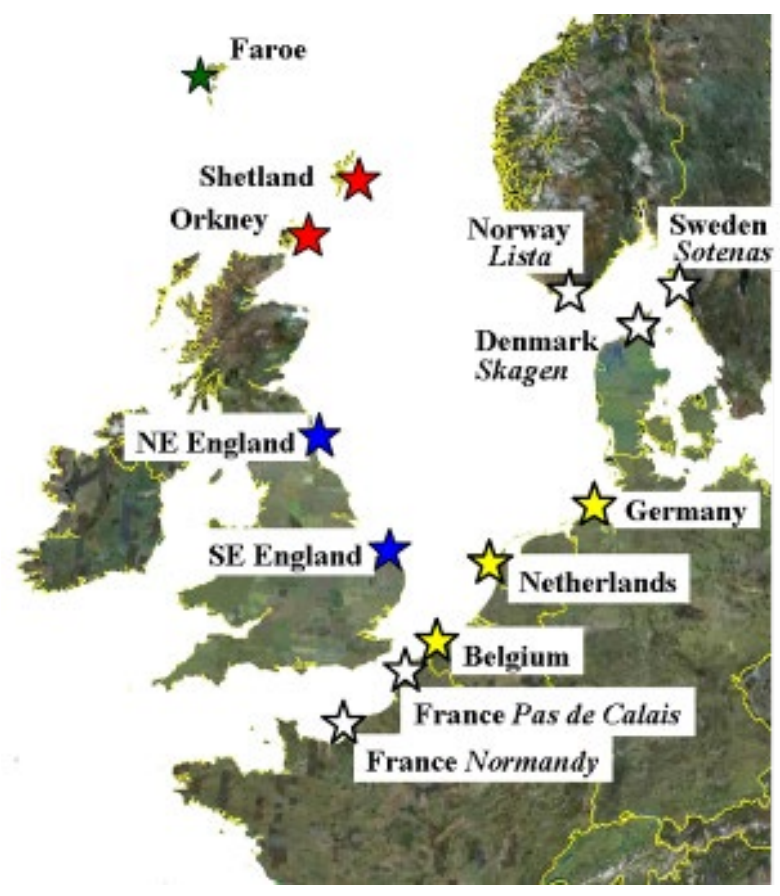

Figure 1. Fulmar-Litter study sites in the Save the North Sea Project (SNS). Colour of symbols indicates regional grouping into Scottish Islands (red), East England (blue), Channel area (white), Southeastern North Sea (yellow), and Skagerrak area (white). Not all locations are equally active. The Faroe Islands study area is considered as an external reference monitoring site for the North Sea. For further details, see the online supplement of Van Franeker et al. (2011).

Bird corpses are stored frozen until analysis. Standardized dissection methods for fulmar corpses have been published in a dedicated manual (Van Franeker 2004b) and are internationally calibrated during annual workshops. Stomach content analyses and methods for data processing and presentation of results were described in full detail in Van Franeker \& Meijboom (2002), further developed in consultation with ICES and OSPAR by updates in later reports and OSPAR documents (OSPAR 2008, 2010b). Scientific reliability of the methodology was established by its publication in the peer reviewed scientific literature (van Franeker et al. 2011; Van Franeker \& Law 2015) with condensed guidelines for future assessments recently published by OSPAR (OSPAR 2015a,b)

For convenience, some of the methodological information is repeated here in a condensed form. 


\section{Dissection}

At dissections, a full series of data is recorded that is of use to determine sex, age, breeding status, likely cause of death, origin, condition index and other issues. Age, the only variable found to influence litter quantities in stomach contents (Van Franeker \& Meijboom 2002), is largely determined on the basis of development of sexual organs (size and shape) and presence of Bursa of Fabricius (a gland-like organ positioned near the end of the gut which is involved in immunity systems of young birds. Bursa of Fabricius is well developed in chicks, but disappears within the first year of life or shortly after). Further details are provided in Van Franeker (2004b). In the future, an updated version of the manual should be published to improve details and maximize efficiency of methods.

\section{Stomach procedure}

After dissection, stomachs of birds are opened for analysis. Stomachs of fulmars have two 'units': initially food is stored and starts to digest in a large glandular stomach (the proventriculus) after which it passes into a small muscular stomach (the gizzard) where harder prey remains can be processed through mechanical grinding. In early phases of the project, data for the two individual stomachs were recorded separately, but for the purpose of reduction in monitoring costs, the contents of proventriculus and gizzard are now combined.

Stomach, contents are carefully rinsed in a sieve with a $1 \mathrm{~mm}$ mesh and then transferred to a petri dish for sorting under a binocular microscope. The $1 \mathrm{~mm}$ mesh is used because smaller meshes become clogged with mucus from the stomach wall and with food-remains. Analyses using smaller meshes were found to be extremely time consuming and particles smaller than $1 \mathrm{~mm}$ seemed rare in the stomachs, and when present contribute little to plastic mass.

If oil or chemical types of pollutants are present, these may be sub-sampled and weighed before rinsing the remainder of stomach content. Although this was a standard component at the start of our studies, requirements for the Dutch "graadmeter" and international EcoQO have a focus on plastic or at best MARPOL Annex $V$ litter types. Thus, for financial efficiency, potential chemical pollutants in the stomachs are no longer part of the project. If sticky substances hamper further processing of the litter objects, hot water and detergents are used to rinse the material clean as needed for further sorting and counting under a binocular microscope. In 2018, an internally funded project was conducted by Wageningen Marine Research looking at paraffin- or palmoil like substances collected from beaches and fulmar stomachs. In over $20 \%$ of fulmar stomachs, such substances are found without obvious trend over time. Chemical analyses identified both vegetable oils and paraffins in the stomachs. Paraffins dominated the beach samples (Van Franeker et al. 2019).

\section{Categorization of debris in stomach contents}

The following categorization is ideally used for plastics and other rubbish found in the stomachs, with acronyms between parentheses. However, please note that for financial efficiency in OSPAR EcoQO monitoring, the required dataset has been restricted to just categories 1.1 (Industrial Plastics) and 1.2 (User Plastics) without further subcategories (OSPAR 2015a,b).

\section{PLASTICS (PLA)}

1.1. Industrial plastic pellets (IND) are small, often cylindrically-shaped granules of \pm $4 \mathrm{~mm}$ diameter, but also disc and rectangular shapes occur. Various names are used, such as pellets, beads or granules. They can be considered as "raw" plastic or a half-product in the form of which, plastics are usually first produced (mostly from mineral oil). The raw industrial plastics are then usually transported to manufacturers that melt the granules and mix them with a variety of additives (fillers, stabilizers, colorants, anti-oxidants, softeners, biocides, etc.) that depend on the user product to be made. For the time being, included in this category are a relatively small number of very small, usually transparent spherical granules, also considered to be a raw industrial product.

1.2. User plastics (USE) (all non-industrial remains of plastic objects) may be differentiated in the following subcategories:

1.2.1. sheetlike user plastics (she), as in plastic bags, foils etc., usually broken up in smaller pieces;

1.2.2. threadlike user plastics (thr) as in (remains of) ropes, nets, nylon line, packaging straps etc. Sometimes 'balls' of threads and fibres form in the gizzard;

1.2.3. foamed user plastics (foam), as in foamed polystyrene cups or packaging or foamed polyurethane in matrasses or construction foams;

1.2.4. fragments (frag) of more or less hard plastic items as used in a huge number of applications (bottles, boxes, toys, tools, equipment housing, toothbrushes, lighters etc.); 
1.2.5. other (poth), for example cigarette filters, rubber, elastics etc., so items that are 'plastic-like' or do not fit into a clear category.

2. RUBBISH (RUB) other than plastic:

2.1. paper (pap) which besides normal paper includes silver paper, aluminium foil etc., so various types of non-plastic packaging material;

2.2. kitchenfood (kit) for human food wastes such as fried meat, chips, vegetables, onions etc., probably mostly originating from ships' galley refuse;

2.3. various rubbish (rubvar) is used for e.g. pieces of timber (manufactured wood); paint chips, pieces of metals etc.;

2.4. fish hook (hook) from either sport-fishing or long-lining.

Further optional categories of stomach contents (not included in this study)

3. POllUTANTS (POL)

3.1.1. For items indicating industrial or chemical waste remains such as slags (the remains of burning ovens, e.g. remains of coal or ore after melting out the metals); tar-lumps (remains of mineral oil); chemical (lumps or 'mud' of paraffin-like materials or sticky substances arbitrarily judged to be unnatural and of chemical origin) and featherlumps (indicating excessive preening by the bird of feathers sticky with oil or chemical pollutants).

\section{NATURAL FOOD REMAINS (FOO)}

4.1.1. Numbers of specific items may be recorded in separate subcategories (fish otoliths, eye-lenses, squid-jaws, crustacean remains, jelly-type prey remains, scavenged tissues incl. feathers, insects, other).

\section{NATURAL NON-FOOD REMAINS (NFO)}

5.1.1. Numbers of subcategories e.g. plant-remains, seaweed, pumice, stone and other may be recorded.

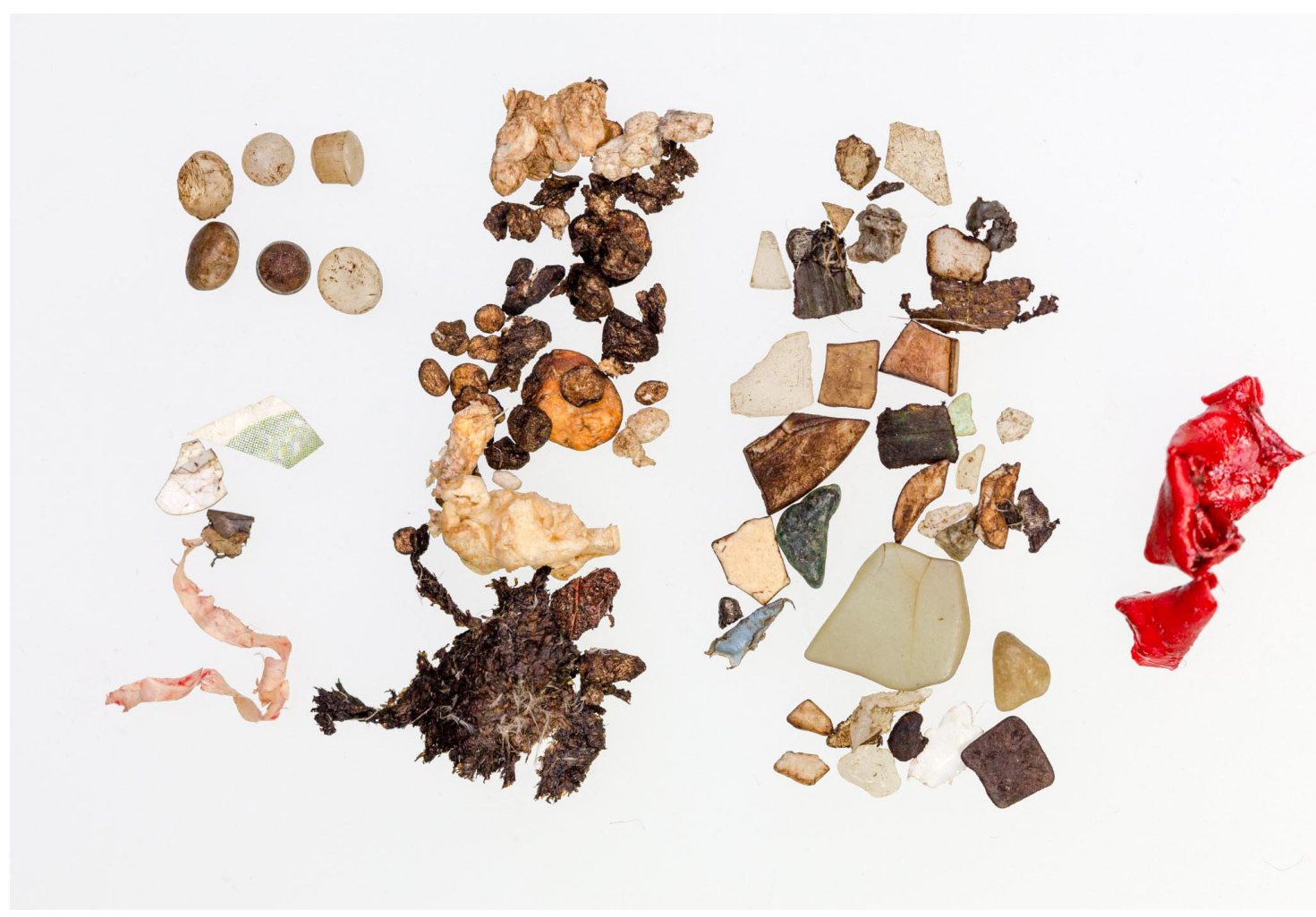

Photo 7 Different plastic categories in the stomach content of Fulmar NET-2018-015. This stomach shows a series of different industrial pellets (top left) a range of small sheetlike materials from different types (bottom left) a variety of foamed plastics, (middle left), a lot of hard plastic fragments (middle right) and a piece of red latex type balloon on the right. This bird was dissected during filming for Dutch television ('De Monitor) and was thus a good 'hit' to show the problems of marine plastic debris. 


\section{Non-plastic or debris categories}

To be able to sort out items of categories 1 and 2, all other materials in the stomachs described in categories 3 to 5, have to be cleaned out. However, in these latter categories, further identification, categorization, counting, weighing and data-processing is not essential for the EcoQO. Whether details are recorded depends of the interest of the participating research group and their reasons to collect beached fulmars.

\section{Acronyms}

In addition to the acronyms used for (sub)categories as above, further acronyms may be used to describe datasets. Logarithmic transformed data are initiated by 'In' (natural logarithm); mass data are characterized by capital G (gram) and numerical data by N (number). For example, InGIND refers to the dataset that uses In-transformed data for the mass of industrial plastics in the stomachs; acronym NUSE refers to a dataset based on the number of items of user plastics.

\section{Particle counts and category weights}

For the main categories 1 (plastic) and 2 (rubbish) we record for each bird and each (sub)category:

$>$ The number of particles ( $\mathrm{N}=$ count of number of items in each (sub)category)

$>$ mass ( $\mathrm{W}=$ weight in grams) using Sartorius electronic weighing scale after at least a two day period of air drying at laboratory temperatures. For marine litter (categories 1 to 3 above), this is done separately for all subcategories. In the early fulmar study, we also weighed the natural-food and natural-non-food categories as a whole, but this was discontinued in 2006 to reduce costs. Weights are recorded in grams accurate to the 4th decimal (= tenth of milligram).

\section{Data presentation}

On the basis of these records, data can be presented in different formats.

Frequency of Occurrence (\%FO)

The simplest form of data presentation is by proportional presence or absence. This metric is also referred to as Incidence or Prevalence. The \%FO gives the percentage of all investigated stomachs that contained the category of debris discussed. The quantity of debris in a stomach is irrelevant in this respect.

\section{Arithmetic Average}

Data for numbers or mass are frequently shown as averages with standard errors calculated for a specific type of debris by location and specified time period. Averages are calculated over all available stomachs in a sample, so including the ones that contained no plastic ('population averages'). Usage of standard error (se) is preferred over standard deviation (sd) because se reflects the reliability of the calculated average by taking into account the sample size where sd mainly considers the spread in the data. Especially when sample sizes are smaller, arithmetic averages may be influenced by short-term or local variations or extreme outliers. An option then is to pool data over a larger area or longer time period. An alternative to reduce influence of outliers is by logarithmic transformation of data.

\section{Geometric Mean}

Sample sizes may not be large enough to average out the impact of occasional extreme outliers. Therefore, data are often additionally presented as geometric means. Geometric mean is calculated as the average of logarithmically transformed data values, which is then back calculated to the normal arithmetic equivalent. Logarithmic transformation reduces the role of the higher values, but consequently the geometric mean is usually considerably lower than the arithmetic average for the same data. In mass data for plastics in the fulmar stomachs, geometric means are only about one third to half of the arithmetic averages. Geometric means are useful for comparative purposes between smaller sample sizes, for example when looking at annual data rather than at 5-year-periods. Logarithmic transformation cannot deal with the value zero, and thus the common approach chosen is to add a small value (e.g. $0.001 \mathrm{~g}$ in mass data) to all data-points, and then subtracting this again when the mean of log values is back-calculated to normal value. This however implies that geometric means become less reliable with an increasing number of zero values in a dataset. The natural logarithm (In) is used to run calculations for geometric means. Starting with the 2016 update, medians are included in some of the more detailed data sections of the report, as a different additional view on the strongly skewed data distributions that have to be handled.

\section{EcoQO performance (EcoQ\%)}

For early Dutch reports, the analyses focused on trends in average or mean mass data for different categories. However, OSPAR (2010b) words its Ecological Quality Objective (EcoQO) for levels of litter (plastic) in stomachs of fulmars (the 'Fulmar-Litter-ECoQO') as:

"There should be less than $10 \%$ of Northern Fulmars (Fulmarus glacialis) having more than 0.1 gram plastic particles in the stomach in samples of 50 to 100 beach-washed fulmars from each of 4 to 5 different areas of the North Sea over a period of at least 5 years". 
Thus, the information requested for OSPAR and the EcoQO focuses on the category of 'total plastic' and pooled data for 5-year periods over larger areas, and a simple decision rule for each stomach if the plastics in it weigh more than 0.1 gram or less, including zero.

EcoQO compliance or performance is defined as the percentage of birds in a sample that has $0.1 \mathrm{~g}$ or more plastic mass in the stomach (EcoQ\%). The OSPAR target is thus to reduce the EcoQ\% to under $10 \%$. The EcoQO format is a highly simplified form of data-presentation but through that simplicity escapes the problems faced by more sophisticated procedures as a consequence of excessive outliers or a large proportion of zero values in a dataset. In the background however, details of various subcategories of litter continue to play an important role for correct interpretation of the EcoQO metric.

\section{Data pooling}

To avoid that short-term variations cause erratic information on the level of ingested plastics, data are frequently pooled into 5-year periods. Such pooled data for 5-year periods are not derived from the annual averages, but are calculated from all individual birds over the full 5-year period. For data presentation, the Current Situation of plastic ingestion is defined as the figures for \%FO, number or mass abundance, and EcoQO\% for the most recent 5-year period, not the figures for the recent single year! Time related changes are illustrated in graphs by running 5-year averages, each time shifting one year and thus overlapping for four years. Such graphs are useful to visualize patterns, which in annual data would be obscured by annual variability and smaller sizes. However, they do not represent statistical evidence. The 5-year running averages cannot be used for statistical analyses as the same source data were repeatedly used.

For pooling study locations in the North Sea, the OSPAR EcoQO target definition has triggered a grouping into five sub-regions (Fig. 1): the Scottish Islands (Shetland and Orkney), East England (northeast and southeast England), the Channel (Normandy and Pas de Calais), South-Eastern North Sea (Belgium, Netherlands and Germany), and the Skagerrak (Skagen Denmark, Lista Norway and Swedish west coast).

\section{Statistical tests}

Data from dissections and stomach content analysis are recorded in Excel spreadsheets and next stored in an Oracle relational database. GENSTAT $18^{\text {th }}$ Edition was used for statistical tests. As concluded in the pilot study (Van Franeker \& Meijboom 2002) and later reports, statistical trend analysis is conducted using mass-data. Tests for trends over time are based on linear regressions fitting In-transformed plastic mass values for individual birds on the year of collection. Logarithmic transformation is needed because the original data are strongly skewed and need to be normalized for the statistical procedures. The natural logarithm ( $L n)$ is used. Tests for 'long-term' trends use the full dataset; 'recent' trends only use the past ten years of data. This 10-year period was derived from the pilot study (Van Franeker \& Meijboom 2002) which found that in the Dutch situation a series of about eight years was needed to have the potential to detect significant change. To be on the safe side in our approach, this period was arbitrarily increased to a standard period of 10 years for tests of current time related trends.

Statistical tests of regional differences (not included in this Dutch report) are conducted in GENSTAT $19^{\text {th }}$ edition, also using data from individual birds. Differences in plastic weight were evaluated by fitting a negative binominal generalized linear model with and without region included as a factor and differences between those two models were tested using a likelihood ratio test (Venables \& Ripley 2002; van Franeker et al. 2011).

Starting with the 2017 update report, a new additional approach was developed to directly evaluate the progress towards the OSPAR long-term target in which the EcoQ\% should be reduced to under $10 \%$. The new approach uses annual figures of EcoQO performance. Simplified data as percentages above or below a threshold do have the problem that the dataset is reduced to periodic (annual) average performance. In our approach of evaluating trends over a period of the most recent ten years, the statistical procedure then has only ten data-points available for statistical tests and modelling. Simple linear regression cannot be applied to this type of data. The data are considered in a GLM approach (Generalized Linear Modelling), more specifically in a logistic analysis dedicated for binomial distributions (number of birds in the sample and number of birds above threshold) and using logit transformed data. A similar type of analysis is already used in the analyses of oil-rates among seabirds for OSPAR (cf. Camphuysen 2018 and earlier publications on that topic). The statistical trend based on observed data, if significant, can be used to predict EcoQO performance in future years. 


\section{Summary of data presentation and analyses:}

$>$ Frequency of Occurrence (\%FO)

The percentage of birds having plastic in the stomach. Also referred to as Incidence or Prevalence

$>$ Average \pm se

Arithmetic population average with standard error (includes zeros).

\section{$>$ Geometric mean}

Population average calculated using data transformation (natural logarithm). In part of tables and graphs, also medians are shown as an alternative estimate for excluding outliers.

\section{$>$ EcoQO performance (EcoQ\%)}

The $\%$ of birds having more than 0.1 gram of plastic in the stomach.

\section{$>$ Pooled data}

Data pooled over 5-year periods.

\section{$>$ Current level of plastic ingestion}

Average plastic number or mass from pooled data for the most recent 5 years.

\section{$>$ Running average}

Sequential data pooled over 5 years, shifting one year by data-point, are used as a visual illustration of trends over time, but without statistical relevance.

\section{$>$ Statistics}

Statistical analyses are mainly based on the mass of plastic using In transformed data of individual birds. Tests for trends are based on linear regressions of In-transformed plastic mass against year of collection. The new additional approach of analysing trends based on annual figures of EcoQO performance may be based on the 10-year time period agreed in OSPAR recommendations, but other, longer periods should be considered as well. 


\section{Results \& Discussion}

This chapter follows the original format of our earlier reports, which uses the approach recommended in OSPAR Guidelines (OSPAR 2015). That approach has its focus on detailed analyses and statistics of

the data on mass of plastics found in individual birds, taking into account the details of different plastic categories (industrial versus user plastics) and the differences between adult and non-adult birds. In earlier reports, in a final section, these data were also viewed, but not statistically tested in terms of EcoQO performance, which is the proportion of birds having more than $0.1 \mathrm{~g}$ of plastic in the stomach. As the EcoQ\% is the most relevant for policy makers, starting with the 2017 update (Van Franeker \& Kühn 2018), a statistical analysis of annual EcoQ\%'s is included, which, if significant, can be used to predict future developments. The original detailed analyses remain essential to properly understand the EcoQO performance model as a basis for policy decisions. The abstract of the current report now strongly focuses on the most policy relevant EcoQO performance; underlying details and analyses are largely restricted to within this results and discussion chapter.

\subsection{The year 2018}

In 2018, in spite of considerable efforts and extensive contacts with the surveyor network, only fifteen beached fulmars could be collected. One of the corpses had no stomach, one of them had a damaged stomach, and one had been treated in a rehabilitation centre for about a week. For our monitoring purposes, we do not use birds that have been in rehabilitation for more than 3 days, because during treatment plastic particles break and wear down in the muscular stomach of the bird (Van Franeker \& Law 2015). This means only 12 stomachs were available for the 2018 data calculations. We additionally processed two 'late-delivered' fulmars found in 2017, increasing the 2017 sample from 36 to 38 birds. The desired annual sample size in our monitoring program is \pm 40 birds or more (Van Franeker \& Meijboom 2002). Smaller annual samples are not a problem for the monitoring system but may delay the detection of significant trends. Sample size will be better in 2019, as close to 40 fulmars were already collected during the first half of the year.

The small 2018 sample showed exceptionally low abundance of plastic (Table 2A). Plastics were found in all 12 birds (\%FO $100 \%$ ), but with a relatively very low average number of particles (15.8 \pm 7.8$)$ and mass $(0.12 \pm 0.06 \mathrm{~g})$. For comparison, in 2017,38 birds averaged at $26.8 \pm 14.1$ plastic particles per stomach, weighing $0.24 \pm 0.07 \mathrm{~g}$. Industrial plastics were rare compared to consumer debris plastics (Table 2B). In 2018, only two of the 12 birds exceeded the $0.1 \mathrm{~g}$ level of plastics (EcoQ\% 17\%). However, the two excluded samples (damaged and rehabilitation) both proved to still hold more than $0.1 \mathrm{~g}$ of plastic in their stomachs. With those included, 4 out of 14 stomachs (EcoQ\% $28 \%$ ) would have exceeded the $0.1 \mathrm{~g}$ mass value. Inter-annual differences and low reliability of small samples once again emphasize the need to only consider larger samples, over 5-year periods.

\subsection{Current levels for the Netherlands (2014-2018)}

Because of occasional years of low sample size and incidental variability the 'current pollution level' in the monitoring system is considered on the basis of average stomach contents over the most recent 5 years. That period is also used in the OSPAR EcoQO target definition.

Over the most recent 5 years (2014-2018), among 115 sampled stomachs from the Netherlands, 93\% of the birds had some plastic in the stomach, the average number of plastic particles was 23.6 \pm 5.9 and the average mass $0.26 \pm 0.05 \mathrm{~g}$. In this 5 year sample, $43 \% 50$ of the 115 stomachs had more than $0.1 \mathrm{~g}$ plastic (EcoQ\% 43\%). Although this is the best result on record throughout the history of fulmar monitoring in the Netherlands, the OSPAR long-term target requires an EcoQ\% under $10 \%$ for at least 5 consecutive years, so the situation is still far from the ecological objective. 


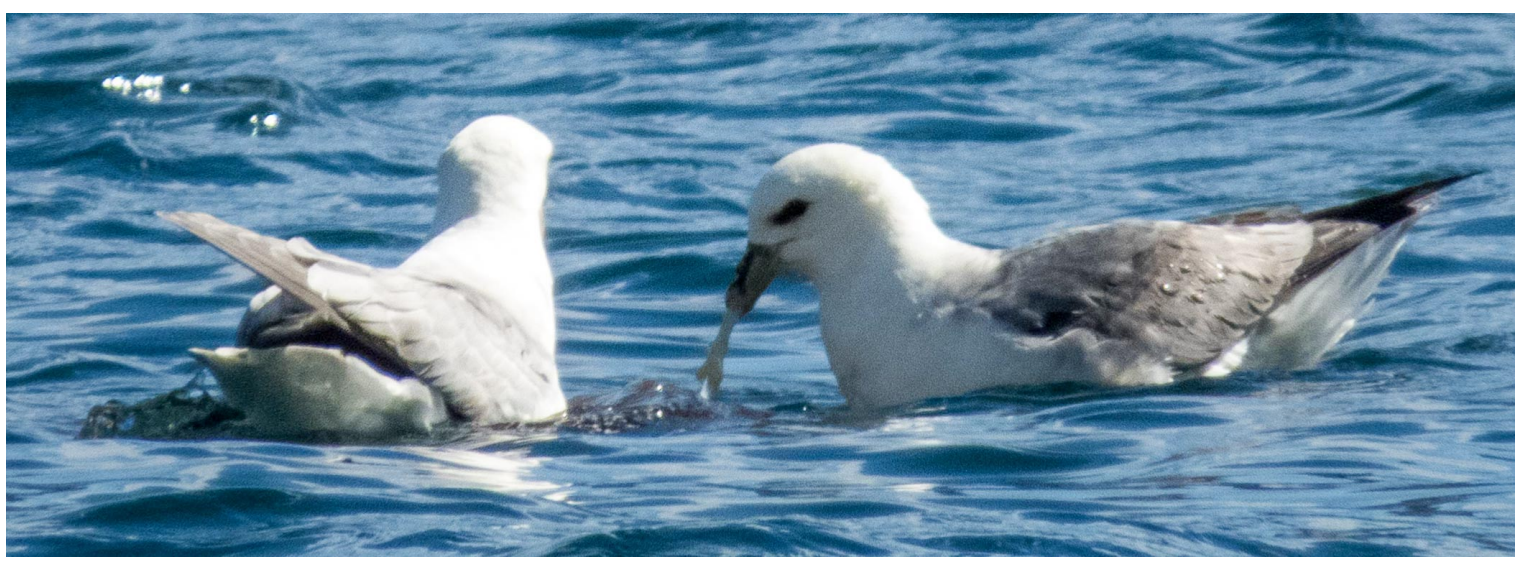

Photo $8 \quad$ Fulmars are highly flexible foragers. Here, two fulmars are foraging from a jellyfish. In spite of low energy content, apparently such food is still sufficiently nutritious to be eaten. In marine turtles, the habit of eating jellyfish is often linked to high abundance of transparent plastic sheets in stomachs of turtles.

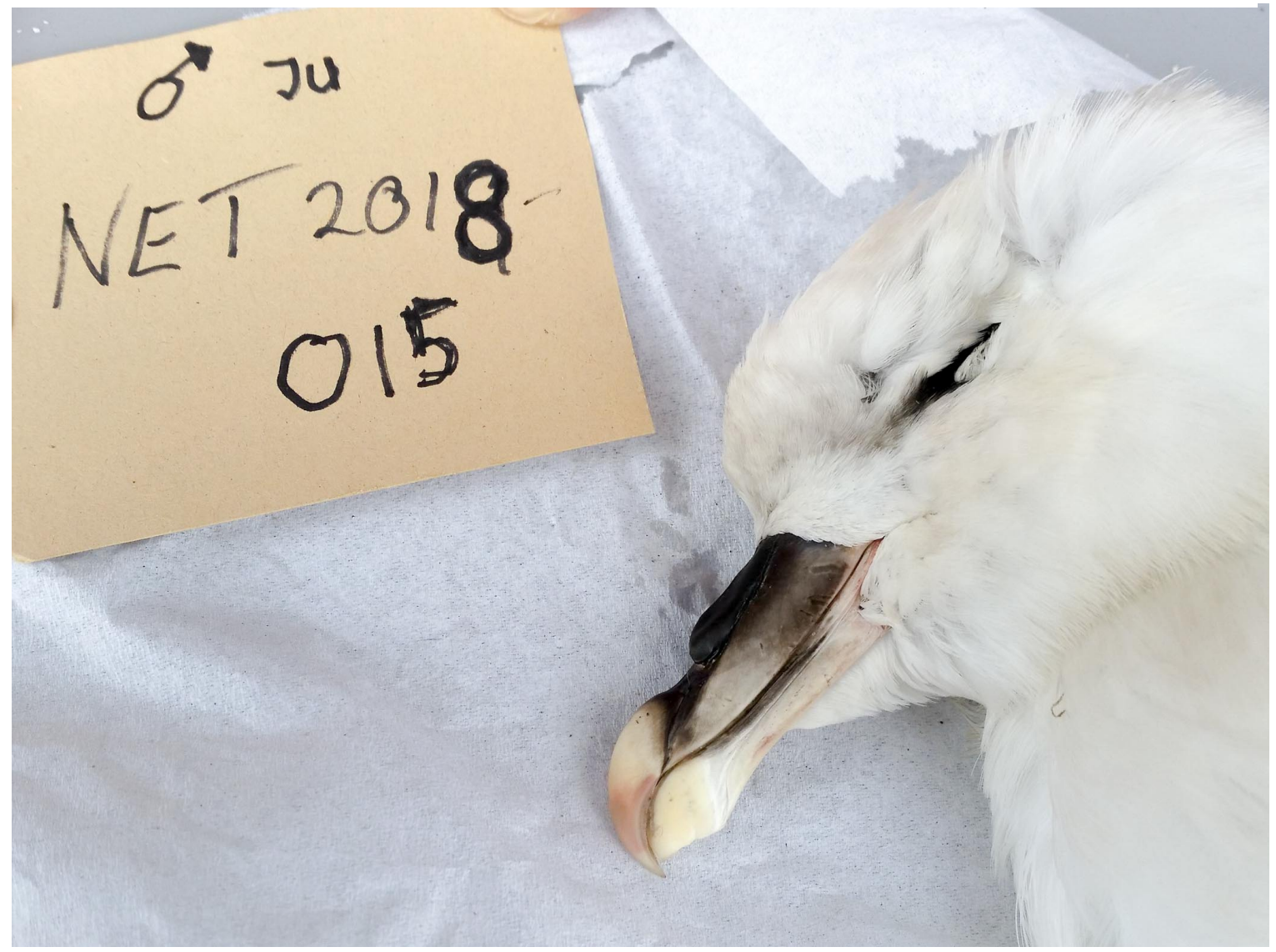

Photo 9 Age of fulmars. Various tables in this report provide the proportion of adult birds in the sample. In the background, age of birds in the samples is an important aspect of the fulmar monitoring program. Among our beached study birds, age is mostly assessed by condition of the sex organs during the autopsies, but other external characters may help. We have joined a project by our colleague Jens-Kjeld Jensen on the Faroe Islands, trying to look at bill and leg colouration as a potential indicator of age. The bird on the photo shows what appears to be a characteristic bill for a juvenile fulmar, very dark or blackish on tube and upper side plates of the bill. 
Table 1 Summary of sample characteristics and stomach contents of fulmars collected for Dutch marine litter monitoring in a) the year 2018 and b) the current 5-year period

2014-2018. The top line in each table shows the sample composition in terms of age, sex, origin (by colour-phase; darker phases are of distant Arctic origin), death cause oil, and the average conditionindex (which ranges from emaciated condition=0 to very good condition=9; Van Franeker 2004b). For each litter-(sub)category the table lists: Incidence, representing the proportion of birds with one or more items of the litter category present; average number of plastic items per bird stomach \pm standard error; average mass of plastic \pm standard error per bird stomach; and the maximum mass observed in a single stomach. The final column shows the geometric mean mass, which is calculated from In-transformed values as used in trend-analyses.

\section{a) Year 2018}

\begin{tabular}{|c|c|c|c|c|c|c|c|c|}
\hline & $\begin{array}{c}\text { The Netherlands } \\
2018 \\
\end{array}$ & $\begin{array}{c}\text { nr of birds } \\
12 \\
\end{array}$ & $\begin{array}{c}\% \text { adult } \\
\mathbf{5 0} \% \\
\end{array}$ & $\begin{array}{c}\% \text { male } \\
\mathbf{3 0 \%} \\
\end{array}$ & $\begin{array}{c}\text { \% LL colour } \\
92 \% \\
\end{array}$ & $\begin{array}{c}\text { death oil } \\
0 \% \\
\end{array}$ & $\begin{array}{c}\text { avg condition } \\
2.1 \\
\end{array}$ & \\
\hline & & incidence & $\begin{array}{r}\text { average nur } \\
\text { (n/bir }\end{array}$ & $\begin{array}{l}\text { mber of items } \\
\text { rd) } \pm \text { se }\end{array}$ & $\begin{array}{r}\text { average ma } \\
(\mathrm{g} / \mathrm{bir}\end{array}$ & $\begin{array}{l}\text { ass of litter } \\
\text { d) } \pm \text { se }\end{array}$ & $\begin{array}{c}\text { max. mass } \\
\text { recorded }\end{array}$ & $\begin{array}{c}\text { geometric mean } \\
\text { mass }(g / b i r d)\end{array}$ \\
\hline 1 & ALL PLAS TICS & $100 \%$ & 15.8 & \pm 7.762 & 0.117 & \pm 0.061 & 0.8 & 0.0518 \\
\hline 1.1 & INDUS TRIAL PLASTIC & $50 \%$ & 1.3 & \pm 0.538 & 0.024 & $\pm \mathbf{0 . 0 1 2}$ & 0.1 & 0.0045 \\
\hline 1.2 & USER PLASTIC & $100 \%$ & 14.5 & \pm 7.303 & 0.093 & $\pm \mathbf{0 . 0 5 0}$ & 0.6 & 0.0377 \\
\hline 1.2 .1 & sheets & $50 \%$ & 1.8 & \pm 0.672 & 0.005 & \pm 0.003 & 0.0 & 0.0016 \\
\hline 1.2 .2 & threads & $25 \%$ & 0.3 & \pm 0.188 & 0.001 & \pm 0.000 & 0.0 & 0.0003 \\
\hline 1.2 .3 & foamed & $33 \%$ & 4.8 & \pm 3.869 & 0.010 & \pm 0.008 & 0.1 & 0.0016 \\
\hline 1.2 .4 & fragments & $100 \%$ & 7.3 & \pm 3.158 & 0.061 & \pm 0.030 & 0.4 & 0.0236 \\
\hline 1.2 .5 & other plastic & $25 \%$ & 0.3 & \pm 0.131 & 0.015 & \pm 0.013 & 0.2 & 0.0013 \\
\hline 2 & OTHER RUBBISH & $25 \%$ & 0.4 & \pm 0.260 & 0.019 & \pm 0.017 & 0.2 & 0.0014 \\
\hline 2.1 & paper & $0 \%$ & 0.0 & \pm 0.000 & 0.000 & \pm 0.000 & 0.0 & 0.0000 \\
\hline 2.2 & kitchenwaste (food) & $25 \%$ & 0.4 & \pm 0.260 & 0.019 & \pm 0.017 & 0.2 & 0.0014 \\
\hline 2.3 & rubbish various & $0 \%$ & 0.0 & \pm 0.000 & 0.000 & \pm 0.000 & 0.0 & 0.0000 \\
\hline 2.4 & fishhook & $0 \%$ & 0.0 & \pm 0.000 & 0.000 & \pm 0.000 & 0.0 & 0.0000 \\
\hline
\end{tabular}

\section{b) 5-year period 2014-2018}

\begin{tabular}{|c|c|c|c|c|c|c|c|c|}
\hline & $\begin{array}{c}\text { The Netherlands } \\
\text { 2014-18 }\end{array}$ & $\begin{array}{c}\text { nr of birds } \\
115 \\
\end{array}$ & $\begin{array}{c}\% \text { adult } \\
33 \% \\
\end{array}$ & $\begin{array}{c}\% \text { male } \\
42 \% \\
\end{array}$ & $\begin{array}{c}\% \text { LL colour } \\
91 \% \\
\end{array}$ & $\begin{array}{c}\text { death oil } \\
2 \% \\
\end{array}$ & $\begin{array}{c}\text { avg condition } \\
1.8 \\
\end{array}$ & \\
\hline & & incidence & $\begin{array}{r}\text { average nur } \\
\text { (n/bir }\end{array}$ & $\begin{array}{l}\text { nber of items } \\
\text { d) } \pm \text { se }\end{array}$ & $\begin{array}{r}\text { average ma } \\
(\mathrm{g} / \mathrm{birc}\end{array}$ & $\begin{array}{l}\text { sss of litter } \\
\text { d) } \pm \text { se }\end{array}$ & $\begin{array}{c}\text { max. mass } \\
\text { recorded }\end{array}$ & $\begin{array}{c}\text { geometric mean } \\
\text { mass (g/bird) }\end{array}$ \\
\hline 1.0 & ALL PLASTICS & $93 \%$ & 23.6 & \pm 5.904 & 0.258 & \pm 0.049 & 3.5 & 0.0658 \\
\hline 1.1 & INDUS TRIAL PLASTIC & $45 \%$ & 1.6 & \pm 0.310 & 0.033 & \pm 0.006 & 0.4 & 0.0049 \\
\hline 1.2 & USER PLASTIC & $92 \%$ & 22.0 & \pm 5.701 & 0.226 & \pm 0.046 & 3.3 & 0.0503 \\
\hline 1.2 .1 & sheets & $48 \%$ & 3.5 & \pm 0.868 & 0.030 & \pm 0.023 & 2.6 & 0.0015 \\
\hline 1.2 .2 & threads & $32 \%$ & 1.1 & \pm 0.379 & 0.007 & \pm 0.004 & 0.4 & 0.0009 \\
\hline 1.2 .3 & foamed & $43 \%$ & 2.6 & \pm 0.606 & 0.019 & \pm 0.006 & 0.4 & 0.0017 \\
\hline 1.2 .4 & fragments & $86 \%$ & 14.5 & \pm 4.850 & 0.111 & \pm 0.019 & 1.2 & 0.0282 \\
\hline 1.2 .5 & other plastic & $11 \%$ & 0.3 & \pm 0.092 & 0.058 & \pm 0.032 & 3.1 & 0.0007 \\
\hline 2.0 & OTHER RUBBISH & $18 \%$ & 5.4 & \pm 4.395 & 0.142 & \pm 0.128 & 14.7 & 0.0008 \\
\hline 2.1 & paper & $1 \%$ & 0.0 & \pm 0.026 & 0.000 & \pm 0.000 & 0.0 & 0.0000 \\
\hline 2.2 & kitchenwaste (food) & $14 \%$ & 5.3 & \pm 4.395 & 0.141 & \pm 0.128 & 14.7 & 0.0007 \\
\hline 2.3 & rubbish various & $3 \%$ & 0.1 & \pm 0.081 & 0.000 & \pm 0.000 & 0.0 & 0.0001 \\
\hline 2.4 & fishhook & $0 \%$ & 0.0 & \pm 0.000 & 0.000 & \pm 0.000 & 0.0 & 0.0000 \\
\hline
\end{tabular}


Table 2 Annual details for plastic abundance in fulmars from the Netherlands. A. all plastic categories combined; B. separate data for industrial and user plastic categories.

Sample size is given with the proportion of adult birds in brackets; Incidence (\%FO) represents the proportion of birds with one or more items of that litter present; number ( $n$ ) abundance by average number of items, and mass $(g)$ abundance by average mass per bird in grams. Total plastics mass also shown in terms of medians and geometric mean mass (for comparative purposes reducing the influence of outliers) and as level of performance in relation to the OSPAR ECOQO, viz. the percentage of birds having more than the threshold of 0.1 gram of plastic in the stomach. Note sample sizes ( $n$ ) to be very low for particular years implying low reliability of the annual averages for such years, not to be used as separate figures (only years with sample size over 10 birds are printed in bold).

Table 2A.

\begin{tabular}{|c|c|c|c|c|c|c|c|c|}
\hline \multicolumn{3}{|c|}{ Netherlands } & \multicolumn{6}{|c|}{ Total plastics } \\
\hline YEAR & $\begin{array}{c}\text { sample } \\
n\end{array}$ & $(\% a d)$ & $\begin{array}{c}\text { Incidence } \\
\% \mathrm{FO}\end{array}$ & $\begin{array}{l}\text { average number } \\
n \mathrm{n} \pm \mathrm{se}\end{array}$ & $\begin{array}{c}\text { average mass } \\
\mathrm{g} \pm \mathrm{se}\end{array}$ & $\begin{array}{c}\text { median } \\
\text { mass }\end{array}$ & $\begin{array}{l}\text { geometric } \\
\text { mean mass }\end{array}$ & $\begin{array}{c}\text { EcoQO \% } \\
\text { (over } 0.1 \mathrm{~g} \text { ) }\end{array}$ \\
\hline 1979 & 1 & $(0 \%)$ & $100 \%$ & 5.0 & 0.24 & & & \\
\hline 1980 & 0 & & & & & & & \\
\hline 1981 & 0 & & & & & & & \\
\hline 1982 & 3 & $(0 \%)$ & $100 \%$ & $11.0 \pm 4.0$ & $0.61 \pm 0.34$ & & & \\
\hline 1983 & 19 & $(41 \%)$ & $100 \%$ & $16.0 \pm 2.5$ & $0.49 \pm 0.13$ & 0.302 & 0.284 & $89 \%$ \\
\hline 1984 & 20 & $(40 \%)$ & $90 \%$ & $17.9 \pm 5.5$ & $0.35 \pm 0.13$ & 0.160 & 0.073 & $55 \%$ \\
\hline 1985 & 3 & $(33 \%)$ & $100 \%$ & $10.3 \pm 1.5$ & $0.28 \pm 0.07$ & & & \\
\hline 1986 & 4 & $(25 \%)$ & $75 \%$ & $5.5 \pm 1.8$ & $0.08 \pm 0.05$ & & & \\
\hline 1987 & 17 & $(59 \%)$ & $82 \%$ & $13.6 \pm 4.0$ & $0.19 \pm 0.08$ & 0.112 & 0.056 & $59 \%$ \\
\hline 1988 & 1 & $(0 \%)$ & $100 \%$ & 2.0 & 0.04 & & & \\
\hline 1989 & 2 & $(100 \%)$ & $100 \%$ & $12.5 \pm 9.5$ & $0.43 \pm 0.40$ & & & \\
\hline 1990 & 0 & & & & & & & \\
\hline 1991 & 1 & $(0 \%)$ & $100 \%$ & 11.0 & 0.14 & & & \\
\hline 1992 & 0 & & & & & & & \\
\hline 1993 & 0 & & & & & & & \\
\hline 1994 & 0 & & & & & & & \\
\hline 1995 & 2 & $(50 \%)$ & $100 \%$ & $5.0 \pm 1.0$ & $0.06 \pm 0.02$ & & & \\
\hline 1996 & 8 & $(62 \%)$ & $100 \%$ & $27.4 \pm 13.7$ & $0.26 \pm 0.11$ & & & \\
\hline 1997 & 31 & $(16 \%)$ & $97 \%$ & $35.8 \pm 7.3$ & $0.73 \pm 0.17$ & 0.325 & 0.298 & $84 \%$ \\
\hline 1998 & 74 & $(45 \%)$ & $96 \%$ & $29.0 \pm 5.3$ & $0.95 \pm 0.36$ & 0.187 & 0.168 & $72 \%$ \\
\hline 1999 & 107 & $(70 \%)$ & $98 \%$ & $35.3 \pm 6.2$ & $0.44 \pm 0.11$ & 0.138 & 0.123 & $61 \%$ \\
\hline 2000 & 38 & $(58 \%)$ & $100 \%$ & $22.0 \pm 5.2$ & $0.35 \pm 0.13$ & 0.160 & 0.129 & $61 \%$ \\
\hline 2001 & 55 & $(37 \%)$ & $96 \%$ & $22.7 \pm 4.2$ & $0.24 \pm 0.05$ & 0.094 & 0.088 & $49 \%$ \\
\hline 2002 & 56 & $(54 \%)$ & $98 \%$ & $51.8 \pm 12.5$ & $0.50 \pm 0.20$ & 0.227 & 0.154 & $68 \%$ \\
\hline 2003 & 39 & $(56 \%)$ & $95 \%$ & $28.5 \pm 7.2$ & $0.17 \pm 0.03$ & 0.135 & 0.068 & $54 \%$ \\
\hline 2004 & 131 & $(80 \%)$ & $91 \%$ & $23.4 \pm 3.0$ & $0.27 \pm 0.04$ & 0.140 & 0.081 & $60 \%$ \\
\hline 2005 & 51 & $(68 \%)$ & $98 \%$ & $17.8 \pm 2.8$ & $0.27 \pm 0.06$ & 0.094 & 0.089 & $47 \%$ \\
\hline 2006 & 27 & $(62 \%)$ & $93 \%$ & $33.9 \pm 7.6$ & $0.30 \pm 0.08$ & 0.199 & 0.131 & $85 \%$ \\
\hline 2007 & 62 & $(43 \%)$ & $92 \%$ & $35.5 \pm 5.7$ & $0.37 \pm 0.05$ & 0.274 & 0.131 & $71 \%$ \\
\hline 2008 & 20 & $(58 \%)$ & $95 \%$ & $44.5 \pm 12.3$ & $0.31 \pm 0.10$ & 0.196 & 0.104 & $55 \%$ \\
\hline 2009 & 68 & $(40 \%)$ & $97 \%$ & $19.3 \pm 3.6$ & $0.22 \pm 0.04$ & 0.075 & 0.084 & $46 \%$ \\
\hline 2010 & 36 & $(46 \%)$ & $94 \%$ & $56.4 \pm 16.3$ & $0.46 \pm 0.20$ & 0.127 & 0.112 & $64 \%$ \\
\hline 2011 & 19 & $(37 \%)$ & $100 \%$ & $43.6 \pm 13.1$ & $0.43 \pm 0.19$ & 0.214 & 0.183 & $79 \%$ \\
\hline 2012 & 81 & $(46 \%)$ & $90 \%$ & $20.6 \pm 3.4$ & $0.30 \pm 0.09$ & 0.098 & 0.075 & $49 \%$ \\
\hline 2013 & 24 & $(42 \%)$ & $92 \%$ & $26.8 \pm 8.3$ & $0.18 \pm 0.04$ & 0.083 & 0.067 & $46 \%$ \\
\hline 2014 & 12 & $(64 \%)$ & $100 \%$ & $21.4 \pm 3.9$ & $0.36 \pm 0.14$ & 0.176 & 0.184 & $83 \%$ \\
\hline 2015 & 22 & $(32 \%)$ & $95 \%$ & $12.0 \pm 3.3$ & $0.26 \pm 0.16$ & 0.061 & 0.058 & $36 \%$ \\
\hline 2016 & 31 & $(18 \%)$ & $87 \%$ & $31.7 \pm 12.9$ & $0.29 \pm 0.10$ & 0.133 & 0.059 & $52 \%$ \\
\hline 2017 & 38 & $(31 \%)$ & $92 \%$ & $26.8 \pm 14.1$ & $0.24 \pm 0.07$ & 0.073 & 0.060 & $37 \%$ \\
\hline 2018 & 12 & $(50 \%)$ & $100 \%$ & $15.8 \pm 7.8$ & $0.12 \pm 0.06$ & 0.048 & 0.052 & $17 \%$ \\
\hline
\end{tabular}


Table 2B. (for caption see Table 2A)

\begin{tabular}{|c|c|c|c|c|c|c|c|}
\hline \multicolumn{2}{|c|}{ Netherlands } & \multicolumn{3}{|c|}{ Industrial granules } & \multicolumn{3}{|c|}{ User plastics } \\
\hline YEAR & $\begin{array}{c}\text { sample } \\
n\end{array}$ & $\begin{array}{c}\text { Incidenc } \\
\mathrm{e} \\
\% \mathrm{FO}\end{array}$ & $\begin{array}{l}\text { avg number } \\
\quad \mathrm{n} \pm \mathrm{se}\end{array}$ & $\begin{array}{l}\text { avg mass } \\
\mathrm{g} \pm \mathrm{se}\end{array}$ & $\begin{array}{c}\text { Inc. } \\
\%\end{array}$ & $\begin{array}{l}\text { avg number } \\
\mathrm{n} \pm \mathrm{se}\end{array}$ & $\begin{array}{c}\text { avg mass } \\
\mathrm{g} \pm \mathrm{se}\end{array}$ \\
\hline 1979 & 1 & $100 \%$ & 2.0 & 0.07 & $100 \%$ & 3.0 & 0.17 \\
\hline 1980 & 0 & & & & & & \\
\hline 1981 & 0 & & & & & & \\
\hline 1982 & 3 & $100 \%$ & $5.0 \pm 2.1$ & $0.11 \pm 0.04$ & $67 \%$ & $6.0 \pm 3.2$ & $0.50 \pm 0.33$ \\
\hline 1983 & 19 & $84 \%$ & $8.8 \pm 2.2$ & $0.19 \pm 0.04$ & $89 \%$ & $7.2 \pm 1.8$ & $0.31 \pm 0.12$ \\
\hline 1984 & 20 & $70 \%$ & $9.6 \pm 2.6$ & $0.19 \pm 0.05$ & $90 \%$ & $8.4 \pm 3.1$ & $0.17 \pm 0.09$ \\
\hline 1985 & 3 & $100 \%$ & $5.3 \pm 1.2$ & $0.14 \pm 0.05$ & $100 \%$ & $5.0 \pm 2.5$ & $0.14 \pm 0.08$ \\
\hline 1986 & 4 & $50 \%$ & $0.8 \pm 0.5$ & $0.02 \pm 0.01$ & $75 \%$ & $4.8 \pm 1.7$ & $0.06 \pm 0.04$ \\
\hline 1987 & 17 & $82 \%$ & $3.9 \pm 1.8$ & $0.11 \pm 0.05$ & $71 \%$ & $9.7 \pm 2.7$ & $0.09 \pm 0.04$ \\
\hline 1988 & 1 & $0 \%$ & 0.0 & 0.00 & $100 \%$ & 2.0 & 0.04 \\
\hline 1989 & 2 & $50 \%$ & $6.5 \pm 6.5$ & $0.17 \pm 0.17$ & $100 \%$ & $6.0 \pm 3.0$ & $0.25 \pm 0.23$ \\
\hline 1990 & 0 & & & & & & \\
\hline 1991 & 1 & $0 \%$ & 0.0 & 0.00 & $100 \%$ & 11.0 & 0.14 \\
\hline 1992 & 0 & & & & & & \\
\hline 1993 & 0 & & & & & & \\
\hline 1994 & 0 & & & & & & \\
\hline 1995 & 2 & $100 \%$ & $1.5 \pm 0.5$ & $0.02 \pm 0.01$ & $100 \%$ & $3.5 \pm 0.5$ & $0.03 \pm 0.01$ \\
\hline 1996 & 8 & $75 \%$ & $2.9 \pm 1.2$ & $0.07 \pm 0.03$ & $100 \%$ & $24.5 \pm 13.7$ & $0.19 \pm 0.10$ \\
\hline 1997 & 31 & $74 \%$ & $5.9 \pm 1.9$ & $0.13 \pm 0.04$ & $97 \%$ & $29.8 \pm 6.8$ & $0.60 \pm 0.17$ \\
\hline 1998 & 74 & $69 \%$ & $3.1 \pm 0.5$ & $0.07 \pm 0.01$ & $95 \%$ & $25.9 \pm 5.2$ & $0.88 \pm 0.35$ \\
\hline 1999 & 107 & $58 \%$ & $3.4 \pm 0.8$ & $0.06 \pm 0.01$ & $97 \%$ & $31.8 \pm 5.7$ & $0.38 \pm 0.11$ \\
\hline 2000 & 38 & $61 \%$ & $3.4 \pm 1.8$ & $0.08 \pm 0.05$ & $100 \%$ & $18.6 \pm 3.7$ & $0.27 \pm 0.09$ \\
\hline 2001 & 55 & $64 \%$ & $2.5 \pm 0.6$ & $0.06 \pm 0.01$ & $96 \%$ & $20.1 \pm 3.8$ & $0.18 \pm 0.05$ \\
\hline 2002 & 56 & $68 \%$ & $4.6 \pm 0.8$ & $0.09 \pm 0.01$ & $96 \%$ & $47.2 \pm 11.9$ & $0.41 \pm 0.19$ \\
\hline 2003 & 39 & $51 \%$ & $2.3 \pm 0.6$ & $0.05 \pm 0.01$ & $92 \%$ & $26.3 \pm 6.9$ & $0.12 \pm 0.03$ \\
\hline 2004 & 131 & $54 \%$ & $2.6 \pm 0.4$ & $0.06 \pm 0.01$ & $91 \%$ & $20.8 \pm 2.8$ & $0.22 \pm 0.04$ \\
\hline 2005 & 51 & $53 \%$ & $2.0 \pm 0.5$ & $0.05 \pm 0.01$ & $96 \%$ & $15.8 \pm 2.7$ & $0.22 \pm 0.06$ \\
\hline 2006 & 27 & $78 \%$ & $3.5 \pm 0.7$ & $0.08 \pm 0.01$ & $93 \%$ & $30.4 \pm 7.2$ & $0.23 \pm 0.07$ \\
\hline 2007 & 62 & $71 \%$ & $3.2 \pm 0.5$ & $\mathbf{0 . 0 7} \pm \mathbf{0 . 0 1}$ & $90 \%$ & $32.3 \pm 5.5$ & $0.30 \pm 0.04$ \\
\hline 2008 & 20 & $65 \%$ & $3.8 \pm 1.2$ & $\mathbf{0 . 0 8} \pm \mathbf{0 . 0 3}$ & $95 \%$ & $40.8 \pm 11.2$ & $0.23 \pm 0.08$ \\
\hline 2009 & 68 & $46 \%$ & $1.7 \pm 0.5$ & $0.04 \pm 0.01$ & $96 \%$ & $17.6 \pm 3.2$ & $0.18 \pm 0.03$ \\
\hline 2010 & 36 & $58 \%$ & $10.7 \pm 7.7$ & $0.23 \pm 0.17$ & $94 \%$ & $45.7 \pm 12.5$ & $0.23 \pm 0.06$ \\
\hline 2011 & 19 & $63 \%$ & $6.6 \pm 4.1$ & $0.15 \pm 0.10$ & $95 \%$ & $37.0 \pm 10.4$ & $0.27 \pm 0.09$ \\
\hline 2012 & 81 & $59 \%$ & $1.8 \pm 0.3$ & $0.04 \pm 0.01$ & $89 \%$ & $18.8 \pm 3.3$ & $0.26 \pm 0.08$ \\
\hline 2013 & 24 & $63 \%$ & $2.2 \pm 0.6$ & $0.04 \pm 0.01$ & $92 \%$ & $24.6 \pm 7.9$ & $0.14 \pm 0.03$ \\
\hline 2014 & 12 & $75 \%$ & $2.4 \pm 0.8$ & $0.05 \pm 0.01$ & $100 \%$ & $19.0 \pm 3.5$ & $0.31 \pm 0.13$ \\
\hline 2015 & 22 & $45 \%$ & $1.1 \pm 0.4$ & $0.02 \pm 0.01$ & $91 \%$ & $10.8 \pm 3.0$ & $0.24 \pm 0.15$ \\
\hline 2016 & 31 & $48 \%$ & $2.0 \pm 0.7$ & $0.04 \pm 0.01$ & $87 \%$ & $29.7 \pm 12.7$ & $0.25 \pm 0.10$ \\
\hline 2017 & 38 & $32 \%$ & $1.4 \pm 0.7$ & $0.03 \pm 0.01$ & $92 \%$ & $25.5 \pm 13.5$ & $0.21 \pm 0.07$ \\
\hline 2018 & 12 & $50 \%$ & $1.3 \pm 0.5$ & $0.02 \pm 0.01$ & $100 \%$ & $14.5 \pm 7.3$ & $0.09 \pm 0.05$ \\
\hline
\end{tabular}


Table 3 Running averages by 5-year period for plastic abundance in fulmars from the Netherlands. A. all plastic categories combined; B. separate data for industrial and user plastic categories. Sample size is given with the proportion of adult birds in brackets. Incidence (\%FO) represents the proportion of birds with one or more items of that litter present; number ( $n$ ) abundance by average number of items per bird; and mass $(g)$ abundance by average mass per bird in grams. For total plastics mass data are also shown in terms of medians and geometric mean mass (for comparative purposes reducing the influence of outliers) and as level of performance in relation to the OSPAR ECOQO, viz. the percentage of birds having more than the threshold of 0.1 gram of plastic in the stomach. Note sample sizes $(n)$ to be very low for particular years implying low reliability of the averages for such periods. Results are not shown where the 5-year sample size was 40 stomachs or less.

Table 3A.

\begin{tabular}{|c|c|c|c|c|c|c|c|c|}
\hline \multicolumn{3}{|c|}{ NETHERLANDS } & \multicolumn{6}{|c|}{ Total plastics } \\
\hline 5-year period & $\begin{array}{c}\text { sample } \\
n\end{array}$ & $(\% a d)$ & $\begin{array}{l}\text { Incidence } \\
\% \mathrm{FO}\end{array}$ & $\begin{array}{c}\text { average number } \\
\mathrm{n} \pm \mathrm{se}\end{array}$ & $\begin{array}{c}\text { average mass } \\
\mathrm{g} \pm \mathrm{se}\end{array}$ & $\begin{array}{l}\text { median } \\
\text { mass }\end{array}$ & $\begin{array}{l}\text { geometric } \\
\text { mean mass }\end{array}$ & $\begin{array}{l}\text { EcoQO \% } \\
\text { (over } 0.1 \mathrm{~g} \text { ) }\end{array}$ \\
\hline \multirow[t]{4}{*}{$1979-89$} & 70 & $(43 \%)$ & $91 \%$ & $14.4 \pm 2.0$ & $0.34 \pm 0.06$ & 0.162 & 0.109 & $67 \%$ \\
\hline & 1 & & & & & & & \\
\hline & 3 & & & & & & & \\
\hline & 10 & & & & & & & \\
\hline 1993-97 & 41 & $(27 \%)$ & $98 \%$ & $32.6 \pm 6.1$ & $0.61 \pm 0.13$ & 0.286 & 0.217 & $76 \%$ \\
\hline 1994-98 & 115 & $(38 \%)$ & $97 \%$ & $30.3 \pm 4.0$ & $0.83 \pm 0.23$ & 0.224 & 0.184 & $73 \%$ \\
\hline 1995-99 & 222 & $(53 \%)$ & $97 \%$ & $32.7 \pm 3.7$ & $0.64 \pm 0.13$ & 0.172 & 0.151 & $67 \%$ \\
\hline 1996-00 & 258 & $(54 \%)$ & $98 \%$ & $31.3 \pm 3.2$ & $0.60 \pm 0.12$ & 0.175 & 0.149 & $67 \%$ \\
\hline 1997-01 & 305 & $(51 \%)$ & $97 \%$ & $29.9 \pm 2.8$ & $0.55 \pm 0.10$ & 0.155 & 0.137 & $64 \%$ \\
\hline 1998-02 & 330 & $(55 \%)$ & $98 \%$ & $33.0 \pm 3.3$ & $0.52 \pm 0.10$ & 0.151 & 0.130 & $62 \%$ \\
\hline 1999-03 & 295 & $(57 \%)$ & $98 \%$ & $33.5 \pm 3.6$ & $0.37 \pm 0.06$ & 0.141 & 0.112 & $59 \%$ \\
\hline $2000-04$ & 319 & $(62 \%)$ & $95 \%$ & $28.7 \pm 2.9$ & $0.30 \pm 0.04$ & 0.141 & 0.095 & $59 \%$ \\
\hline 2001-05 & 332 & $(64 \%)$ & $95 \%$ & $27.8 \pm 2.7$ & $0.29 \pm 0.04$ & 0.134 & 0.091 & $57 \%$ \\
\hline 2002-06 & 304 & $(68 \%)$ & $94 \%$ & $29.3 \pm 3.0$ & $0.30 \pm 0.04$ & 0.142 & 0.094 & $61 \%$ \\
\hline 2003-07 & 310 & $(66 \%)$ & $93 \%$ & $26.5 \pm 2.1$ & $0.28 \pm 0.02$ & 0.150 & 0.092 & $62 \%$ \\
\hline 2004-08 & 291 & $(67 \%)$ & $93 \%$ & $27.4 \pm 2.2$ & $0.30 \pm 0.03$ & 0.164 & 0.097 & $62 \%$ \\
\hline 2005-09 & 228 & $(51 \%)$ & $95 \%$ & $27.3 \pm 2.5$ & $0.29 \pm 0.03$ & 0.139 & 0.103 & $58 \%$ \\
\hline 2006-10 & 213 & $(46 \%)$ & $94 \%$ & $34.5 \pm 3.8$ & $0.32 \pm 0.04$ & 0.150 & 0.108 & $62 \%$ \\
\hline 2007-11 & 205 & $(43 \%)$ & $95 \%$ & $35.4 \pm 4.0$ & $0.33 \pm 0.04$ & 0.149 & 0.111 & $60 \%$ \\
\hline 2008-12 & 224 & $(44 \%)$ & $94 \%$ & $30.0 \pm 3.6$ & $0.31 \pm 0.05$ & 0.116 & 0.092 & $54 \%$ \\
\hline 2009-13 & 228 & $(43 \%)$ & $94 \%$ & $28.4 \pm 3.4$ & $0.30 \pm 0.05$ & 0.109 & 0.088 & $53 \%$ \\
\hline 2010-14 & 172 & $(45 \%)$ & $93 \%$ & $31.5 \pm 4.3$ & $0.34 \pm 0.06$ & 0.129 & 0.094 & $58 \%$ \\
\hline 2011-15 & 158 & $(43 \%)$ & $93 \%$ & $23.1 \pm 2.8$ & $0.30 \pm 0.06$ & 0.118 & 0.085 & $53 \%$ \\
\hline 2012-16 & 170 & $(40 \%)$ & $91 \%$ & $22.4 \pm 3.1$ & $0.28 \pm 0.05$ & 0.104 & 0.073 & $50 \%$ \\
\hline 2013-17 & 127 & $(33 \%)$ & $92 \%$ & $24.9 \pm 5.5$ & $0.26 \pm 0.04$ & 0.094 & 0.067 & $46 \%$ \\
\hline 2014-18 & 115 & $(33 \%)$ & $93 \%$ & $23.6 \pm 5.9$ & $0.26 \pm 0.05$ & 0.077 & 0.066 & $43 \%$ \\
\hline
\end{tabular}


Table 3 B. (for caption see table 3A.)

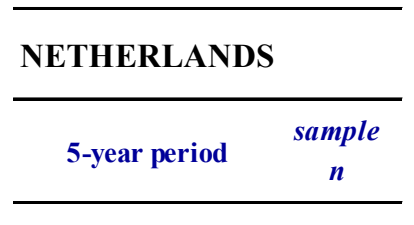

70

1

3

10

1993-97 41

1994-98 115

1995-99 222

1996-00 258

1997-01 305

1998-02 330

1999-03 295

2000-04 319

2001-05 332

2002-06 304

2003-07 310

2004-08 291

2005-09 228

2006-10 213

2007-11 205

2008-12 224

2009-13 228

2010-14 172

2011-15 158

2012-16 170

2013-17 127

2014-18 115
Industrial granules

\begin{tabular}{ccc}
\hline Incidenc & avg number & avg mass \\
$\mathrm{e}$ & $\mathrm{n} \pm \mathrm{se}$ & $\mathrm{g} \pm \mathrm{se}$ \\
$\% \mathrm{FO}$ & & \\
\hline
\end{tabular}

$77 \%$

$6.8 \pm 1.1$

$0.15 \pm 0.02$

$\begin{array}{lll}76 \% & 5.1 \pm 1.5 & 0.12 \pm 0.03 \\ 71 \% & 3.8 \pm 0.6 & 0.09 \pm 0.01 \\ 65 \% & 3.6 \pm 0.5 & 0.07 \pm 0.01 \\ 64 \% & 3.6 \pm 0.5 & 0.08 \pm 0.01 \\ 64 \% & 3.4 \pm 0.4 & 0.07 \pm 0.01 \\ 63 \% & 3.4 \pm 0.4 & 0.07 \pm 0.01 \\ 60 \% & 3.3 \pm 0.4 & 0.07 \pm 0.01 \\ 59 \% & 3.0 \pm 0.3 & 0.06 \pm 0.01 \\ 58 \% & 2.8 \pm 0.3 & 0.06 \pm 0.01 \\ 58 \% & 2.9 \pm 0.3 & 0.06 \pm 0.01 \\ 59 \% & 2.7 \pm 0.2 & 0.06 \pm 0.01 \\ 60 \% & 2.8 \pm 0.3 & 0.06 \pm 0.01 \\ 60 \% & 2.6 \pm 0.3 & 0.06 \pm 0.01 \\ 61 \% & 4.1 \pm 1.3 & 0.09 \pm 0.03 \\ 59 \% & 4.4 \pm 1.4 & 0.10 \pm 0.03 \\ 56 \% & 3.8 \pm 1.3 & 0.08 \pm 0.03 \\ 56 \% & 3.6 \pm 1.3 & 0.08 \pm 0.03 \\ 61 \% & 4.3 \pm 1.7 & 0.10 \pm 0.04 \\ 59 \% & 2.4 \pm 0.5 & 0.05 \pm 0.01 \\ 57 \% & 1.8 \pm 0.2 & 0.04 \pm 0.01 \\ 48 \% & 1.7 \pm 0.3 & 0.03 \pm 0.01 \\ 45 \% & 1.6 \pm 0.3 & 0.03 \pm 0.01 \\ & & \\ 58 & & \end{array}$

\section{User plastics}

\begin{tabular}{ccc}
\hline $\begin{array}{c}\text { Inc. } \\
\%\end{array}$ & $\begin{array}{c}\text { avg number } \\
\mathrm{n} \pm \mathrm{se}\end{array}$ & $\begin{array}{c}\text { avg mass } \\
\mathrm{g} \pm \mathrm{se}\end{array}$ \\
\hline & & \\
$84 \%$ & $7.7 \pm 1.2$ & $0.19 \pm 0.05$
\end{tabular}

$84 \%$

$\begin{array}{lll}98 \% & 27.5 \pm 5.8 & 0.49 \pm 0.13 \\ 96 \% & 26.5 \pm 3.9 & 0.74 \pm 0.23 \\ 96 \% & 29.1 \pm 3.4 & 0.57 \pm 0.13 \\ 97 \% & 27.7 \pm 3.0 & 0.53 \pm 0.11 \\ 97 \% & 26.4 \pm 2.6 & 0.47 \pm 0.10 \\ 97 \% & 29.6 \pm 3.1 & 0.45 \pm 0.09 \\ 97 \% & 30.1 \pm 3.3 & 0.30 \pm 0.06 \\ 94 \% & 25.7 \pm 2.7 & 0.24 \pm 0.04 \\ 94 \% & 25.0 \pm 2.6 & 0.23 \pm 0.04 \\ 93 \% & 26.4 \pm 2.8 & 0.24 \pm 0.04 \\ 92 \% & 23.8 \pm 2.0 & 0.22 \pm 0.02 \\ 92 \% & 24.7 \pm 2.1 & 0.24 \pm 0.02 \\ 94 \% & 24.7 \pm 2.3 & 0.23 \pm 0.02 \\ 93 \% & 30.4 \pm 3.2 & 0.23 \pm 0.02 \\ 94 \% & 31.0 \pm 3.3 & 0.24 \pm 0.02 \\ 93 \% & 26.2 \pm 2.9 & 0.23 \pm 0.04 \\ 93 \% & 24.8 \pm 2.8 & 0.22 \pm 0.03 \\ 92 \% & 27.3 \pm 3.5 & 0.24 \pm 0.04 \\ 91 \% & 20.8 \pm 2.5 & 0.24 \pm 0.05 \\ 90 \% & 20.6 \pm 3.1 & 0.24 \pm 0.05 \\ 91 \% & 23.2 \pm 5.3 & 0.22 \pm 0.04 \\ 92 \% & 22.0 \pm 5.7 & 0.23 \pm 0.05 \\ & & \end{array}$



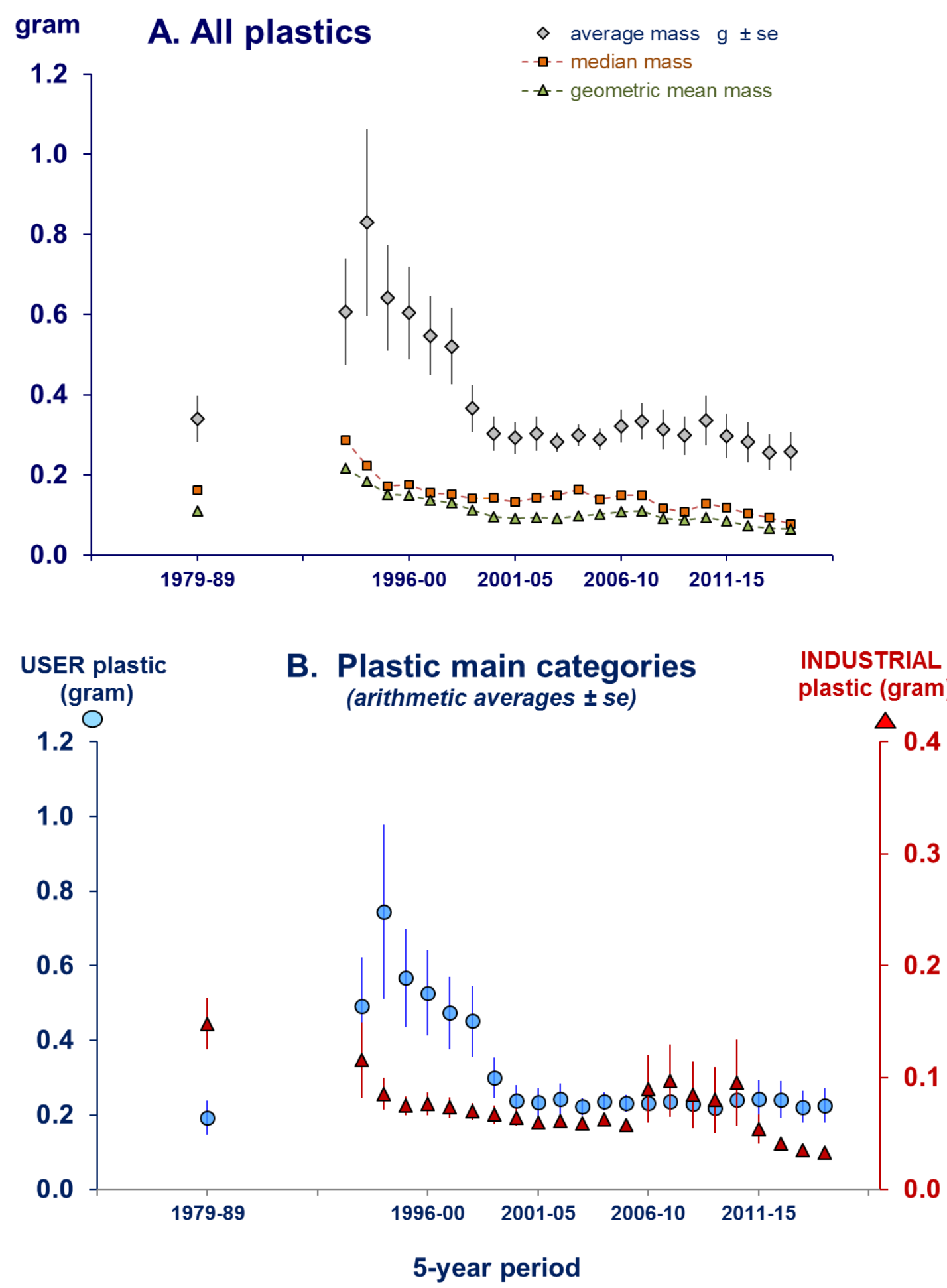

Figure 2 Plastic mass in stomachs of fulmars from the Netherlands 1979-2018. Shown by 5-year running averages, except all data combined for the early period 1979-1989. Data only shown where sample size over 40 stomachs. A: Data for all plastics combined visualising changes in arithmetic average mass \pm se (grey diamonds), median mass (oranges squares) and geometric mean mass (green triangles); B: arithmetic mass data, split into user plastic (blue circles, left $y$-axis) and industrial plastic (red triangles, right $y$-axis). Data are visualized as running 5 -year averages (i.e. data-points shift one year ahead at a time) and do not represent statistical trends. 


\subsection{Trends}

In the EcoQO approach, the emphasis in detailed trend analyses is on the mass of plastics in stomachs of beached fulmars rather than on incidence or number of plastic particles. In trend discussions, a distinction is made between:

\subsubsection{Long-term trends}

The 'long-term trend' is defined as the trend over all years in the dataset (now 1979-2018). The current dataset holds records for 1115 fulmars, with 559 adult birds and 527 non-adults, which are juveniles to immatures several years of age. In 29 birds insufficient information was available to assess the age-group.

Long-term trends are influenced by the fact that in initial years, trends for industrial and user plastics were opposite (Fig. 2B, Table 4A). The industrial plastics halved from early 1980s to mid-1990s while user plastics nearly tripled in mass. Measured over the full period of over 40 years of data for the Netherlands, the initial strong decrease of industrial plastics still contributes strongly to a long-term significant decline in industrial plastic $(p<0.001)$, in spite of the fact that since the early $2000 \mathrm{~s}$ changes have been much less evident (Table 2 ). The decrease in abundance of industrial plastics in the marine environment has been signalled in different oceanographic regions all over the globe (Van Franeker \& Meijboom 2002, Vlietstra \& Parga 2002, Ryan 2008, Van Franeker et al. 2011; Van Franeker \& Law 2015). For user plastics, the initial increase from the 1980s to mid-1990s was largely 'compensated' by a rapid decrease from late 1990s to around 2003, and relative small changes after that, resulting in absence of a significant overall long-term trend in mass of user plastics. However, due to the decrease in industrial plastic, the long-term trend for all plastics combined is a significant reduction $(p<0.001)$. Trends are similar in the different age groups, but due to smaller samples sizes do not always reach the same significance level (adults decrease at $p=0.052$, just not significant; the non-adult trend shows a significant reduction at $\mathrm{p}=0.002)$.

\subsubsection{Recent trends}

The 'recent trend' is defined as the trend in plastic mass in fulmar stomachs over the past 10 years, so in this report: 2009-2018. After the early 2000s, and up to 2014, recent trends were generally described as stable or as potential slow but non-significant decline. However, the analyses of the period 2006-2015 based on 372 birds for the first time showed significant declines in both industrial plastics $(0.015)$ and user plastics $(p=0.047)$ although their combined trend did not reach significance $(p=0.062)$. The next 10-year analysis over years 2007-2016 $(n=374)$ for the first time demonstrated an overall significant 10 year decline $(p=0.04)$ mainly based on a reduced mass of user plastic debris $(p=0.040)$ but less on industrial plastics $(p=0.054)$. Over the period 2008-2017 $(n=349)$, the direction of change was still the same, but did not reach significance: $p=0.096$ for all plastics combined; $p=0.057$ for industrial plastics and $p=0.151$ for user plastic waste (Van Franeker \& Kühn 2018). The loss of significance will in part be related to lower sample sizes in recent years. The current 10 -year analysis over the 2009-2018 period is based on 343 birds. The direction of change is consistently that of less plastics (negative value of $t$ in table $4 \mathrm{C}$ ), but the rate of change is too slow to reach the statistical level of significance within the limited time frame of 10 recent years and the sample size that can be obtained within such period.

The new policy relevant addition of EcoQO performance, has led to an added wider perspective of the time periods to be considered in analysing trends. This has led to evaluate trends since the start of the international fulmar monitoring in the North Sea triggered by funds from the European Interreg IIIB project Save the North Sea (SNS) in 2002. In addition to the test on annual EcoQ percentages, this means we have added also an analysis of the more detailed individual plastic mass data over the years since 2002. Trends over this 17-year period (Table 4B) are clearer than over the recent 10 years (Table 4C). Industrial plastics showed a significant decrease over the 2002-2018 period $(p=0.004)$ also for separate age groups. User plastics showed negative but non-significant slopes of the regression line. Combined for all plastics, the non-adult age group showed significant decline $(p=0.013)$ but not so among adults $(p=0.089)$. For both age groups combined the downward trend for all plastics is significant at $p=0.043$. 


\section{Table 4 Details of linear regression analyses for time related trends in plastic}

abundance by mass in stomachs of fulmars in the Netherlands. Analysis by linear regression, fitting In-transformed litter mass values for individual birds on the year of collection. Tests were conducted over A. full time period of data, B. the period since start of the Save the North Sea project in 2002, and C. the most recent 10 years of data, which is the recommended period in OSPAR guidelines for testing in the Fulmar EcoQO. The regression line ('trend') is described by $y=$ Constant + estimate $^{*} x$ in which $y$ is the calculated value of the regression-line for year $x$. When the $t$-value of a regression is negative, it indicates a decrease in the tested litter-category; a positive $t$-value indicates increase. A trend is considered significant when the probability $(p)$ of misjudgement of data is less than $5 \%(p<0.05)$. Significant trends in the table are labelled with positive signs in case of increase $(+)$ in plastic mass or negative signs in case of decrease $(-)$. Significance at the $5 \%$ level $(p<0.05)$ is labelled as - or + ; at the $1 \%$ level $(p<0.01)$ as -- or ++ ; and at the $0.1 \%$ level $(p<0.001)$ as --- or +++ . Where test results are not significant (n.s.) but close $(p<0.1)$, upward or downward arrow indicates the potential direction of change.

A.

LONG TERM TRENDS 1979-2018

for plastics in Fulmar stomachs, the Netherlands

\begin{tabular}{lcrrrrrr} 
& Industrial plastics (InGIND) & $\boldsymbol{n}$ & constant & slope & s.e. & $\mathbf{t}$ & $\mathbf{p}$ \\
\hline all ages & 1115 & 98.5 & -0.0513 & 0.0085 & -6.02 & $<.001$ & $--\downarrow$ \\
adults & 559 & 85.5 & -0.0450 & 0.0137 & -3.29 & 0.001 & $--\downarrow$ \\
non adults & 527 & 116.5 & -0.0602 & 0.0110 & -5.45 & $<.001$ & $--\downarrow$
\end{tabular}

\begin{tabular}{lcrrrrrr} 
User plastics (InGUSE) & $\boldsymbol{n}$ & constant & slope & s.e. & $\mathbf{t}$ & $\mathbf{p}$ & \\
\cline { 1 - 6 } all ages & 1115 & 7.2 & -0.0049 & 0.0074 & -0.66 & 0.509 & n.s. \\
adults & 559 & 23.4 & -0.0131 & 0.0124 & -1.06 & 0.289 & n.s. \\
non adults & 527 & -1.3 & -0.0005 & 0.0092 & -0.06 & 0.954 & n.s.
\end{tabular}

\begin{tabular}{lcrrrrrr} 
All plastics combined (InGPLA) & $\boldsymbol{n}$ & constant & slope & s.e. & $\mathbf{t}$ & $\mathbf{p}$ \\
\hline all ages & 1115 & 46.7 & -0.0245 & 0.0072 & -3.39 & $<.001$ & $--\downarrow$ \\
adults & 559 & 45.0 & -0.0237 & 0.0122 & -1.94 & 0.052 & n.s. $\downarrow$ \\
non adults & 527 & 51.7 & -0.0268 & 0.0087 & -3.08 & 0.002 & $--\downarrow$ \\
\hline
\end{tabular}

B.

TRENDS 2002-2018 since start SNS project for plastics in Fulmar stomachs, the Netherlands

\begin{tabular}{lcrrrrrr} 
& Industrial plastics (InGIND) & $\boldsymbol{n}$ & Constant & estimate & s.e. & $\mathbf{t}$ & $\mathbf{p}$ \\
\hline all ages & 729 & 95.9 & -0.0500 & 0.0173 & -2.89 & 0.004 & $--\downarrow$ \\
adults & 370 & 114.5 & -0.0594 & 0.0261 & -2.28 & 0.023 & $-\downarrow$ \\
non adults & 334 & 95.9 & -0.0500 & 0.0173 & -2.89 & 0.004 & $--\downarrow$
\end{tabular}

\begin{tabular}{lcrrrrrr} 
User plastics (InGUSE) & $\boldsymbol{n}$ & Constant & estimate & s.e. & $\mathbf{t}$ & $\mathbf{p}$ & \\
\cline { 1 - 7 } all ages & 729 & 39.4 & -0.0210 & 0.0150 & -1.40 & 0.163 & n.s. \\
adults & 370 & 64.3 & -0.0335 & 0.0242 & -1.38 & 0.168 & n.s. \\
non adults & 334 & 72.8 & -0.0375 & 0.0200 & -1.88 & 0.062 & ns $\downarrow$
\end{tabular}

\begin{tabular}{lcrrrrrr} 
All plastics com bined (InGPLA) & $\boldsymbol{n}$ & Constant & estimate & s.e. & t & p & \\
\hline all ages & 729 & 58.2 & -0.0302 & 0.0149 & -2.03 & 0.043 & $-\downarrow$ \\
adults & 370 & 79.4 & -0.0409 & 0.0240 & -1.70 & 0.089 & $n s \downarrow$ \\
non adults & 334 & 96.2 & -0.0489 & 0.0196 & -2.49 & 0.013 & $-\downarrow$ \\
\hline
\end{tabular}


C.

RECENT 10-YEAR TRENDS 2009-2018

for plastics in Fulmar stomachs, the Netherlands

\begin{tabular}{lcrrrrrr} 
Industrial plastics (InGIND) & $\boldsymbol{n}$ & constant & slope & s.e. & $\mathbf{t}$ & $\mathbf{p}$ & \\
\cline { 1 - 6 } all ages & 343 & 122.9 & -0.0635 & 0.0400 & -1.59 & 0.113 & n.s. \\
adults & 129 & 106.0 & -0.0550 & 0.0654 & -0.84 & 0.402 & n.s. \\
non adults & 198 & 192.0 & -0.0979 & 0.0520 & -1.88 & 0.061 & ns $\downarrow$
\end{tabular}

\begin{tabular}{lcrrrrrr} 
User plastics (InGUSE) & $\boldsymbol{n}$ & constant & slope & s.e. & $\mathbf{t}$ & $\mathbf{p}$ & \\
\cline { 1 - 6 } all ages & 343 & 107.3 & -0.0547 & 0.0349 & -1.57 & 0.118 & n.s. \\
adults & 129 & 160.0 & -0.0809 & 0.0618 & -1.31 & 0.193 & n.s. \\
non adults & 198 & 107.3 & -0.0546 & 0.0431 & -1.27 & 0.206 & n.s.
\end{tabular}

\begin{tabular}{lcrrrrrr} 
All plastics combined (InGPLA) & $\boldsymbol{n}$ & constant & slope & s.e. & $\mathbf{t}$ & $\mathbf{p}$ & \\
\cline { 1 - 7 } all ages & $\mathbf{3 4 3}$ & $\mathbf{1 2 2 . 9}$ & $\mathbf{- 0 . 0 6 2 3}$ & $\mathbf{0 . 0 3 4 5}$ & $-\mathbf{1 . 8 1}$ & $\mathbf{0 . 0 7 2}$ & n.s. $\downarrow$ \\
adults & 129 & 187.0 & -0.0942 & 0.0607 & -1.55 & 0.123 & n.s. \\
non adults & 198 & 122.1 & -0.0618 & 0.0424 & -1.46 & 0.147 & n.s. \\
\hline
\end{tabular}

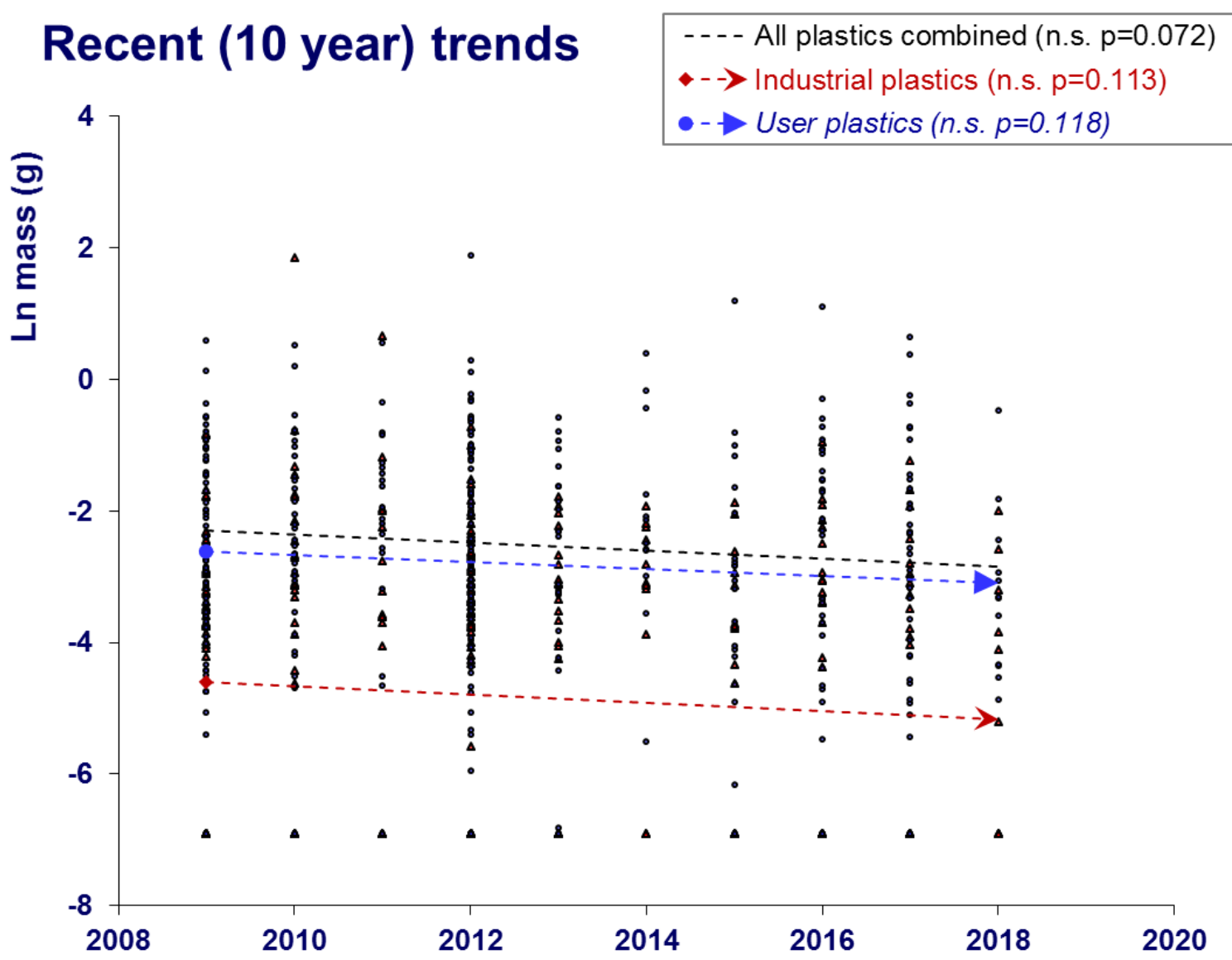

Figure 3 Statistical trend in plastic mass in stomachs of fulmars from the Netherlands 2009-2018. The graph, as an example of the statistical approach, shows plotted In-transformed mass data for industrial plastic and user plastic in stomachs of individual fulmars, plotted against year, and linear trendlines for industrial (lower, red line), user (middle blue line) and total plastics (top black line). Full details for results of statistical tests for trends are available in Table 4. n.s. means that the test result is not significant. Trendlines are shown as solid line when significant, dashed when nonsignificant. 
Younger fulmars (the 'non-adult' category which includes first year juveniles, second year birds and immatures up to several years of age), have consistently higher levels of ingested plastics than adult birds. Nevertheless, in EcoQO monitoring, all age groups are combined on the assumption that in the long-term, there will be no major directional change in the age-composition of beached birds. Fig. 4 illustrates age related variations in our monitoring data: in geometric means, the persistent difference in plastic loads between adults and non-adults is very clear. However, both age groups follow, at a different level, a very similar pattern, which strengthens the validity of the monitoring approach combining data for all birds. The graph shows similar drop for recent running 5-year averages in both age groups. These changes are not always evidenced in the statistical tests over recent periods, but do support the conclusion of a downward trend in the mass of plastics ingested by fulmars off the Dutch coast.

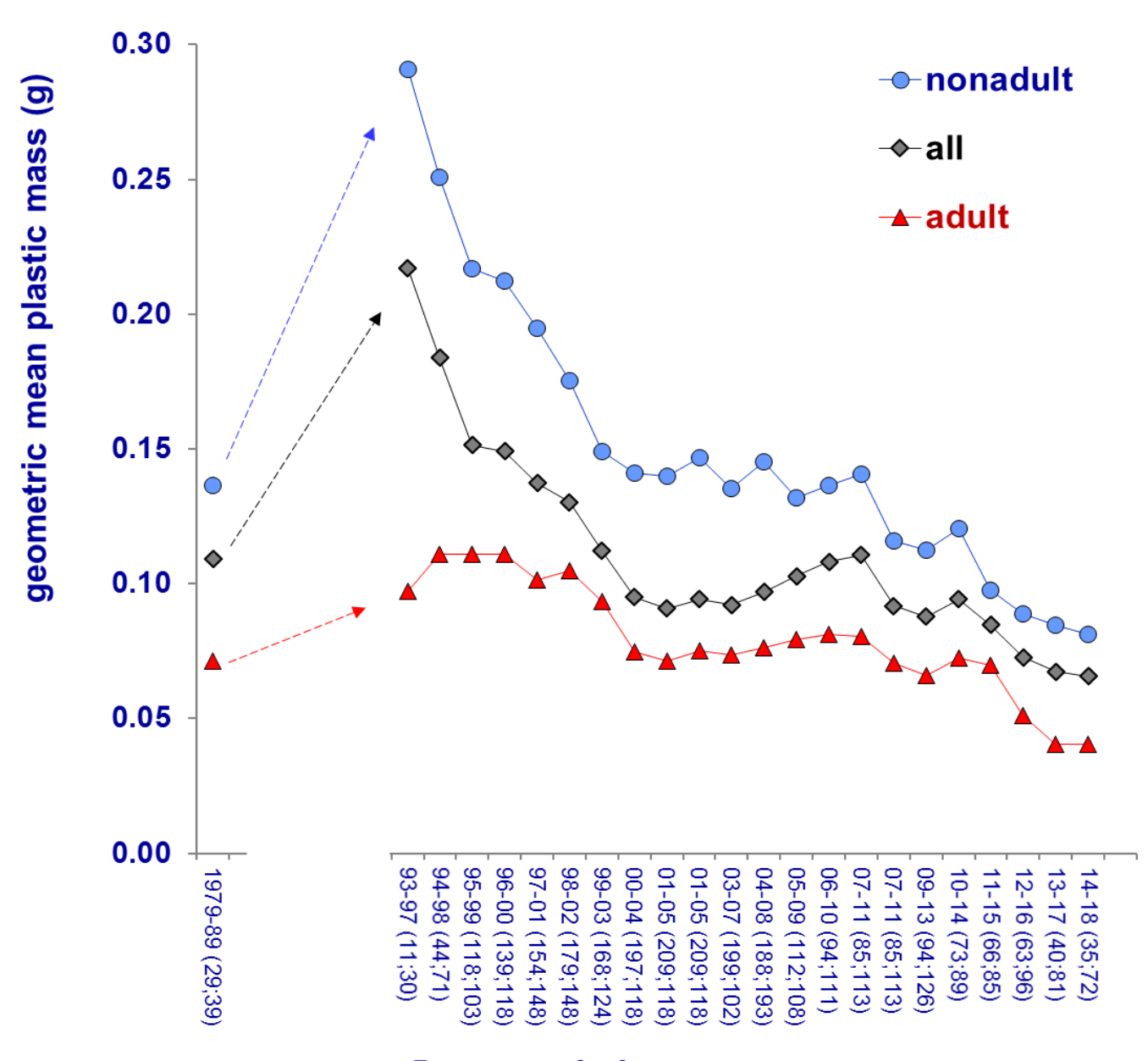

5-year period (sample size adult; non-adult)

\section{Figure 4 Geometric mean mass of plastics in stomachs of beached fulmars from the} Netherlands 1979-2018 for all age groups combined (grey diamonds; including birds of unknown age), adult birds (red triangles) and non-adults, with respective sample sizes in brackets in the $x$-axis labels. Full sample sizes available in e.g. Table 3A. Data illustrate the trends and consistency in agedifferences that allow usage of the all-age trendline in the summary. This graphic visualization does not represent a statistical trend analysis. 


\subsection{Dutch data in terms of the OSPAR EcoQO metric}

ICES working groups (e.g. ICES-WGSE 2001, 2003), followed by OSPAR (2008, 2009), have initiated the approach in which the EcoQO metric for marine litter is expressed in terms of a percentage of birds exceeding a threshold value of plastic in the stomach. At first sight, one might argue that it would be easier to use an EcoQO definition based on for example only the average mass of plastics. However, whether intentional or not, the 'percentage above threshold value' definition represents a simplified procedure to avoid the mathematical problems caused by a few excessive stomach contents that distort comparative analyses and averaged values. In our standard statistical testing procedures and calculations of geometric means, such problems are overcome by logarithmic transformation of data. This is a standard statistical procedure. However, it is not always easily conveyed to the general public, and differences between arithmetic averages versus geometric means can be confusing. The EcoQO metric avoids such problems by using a classification of birds in which the exceptional stomach contents lose their influence. Currently, the long-term target for ecological quality is defined by OSPAR as the situation in which

"less than $10 \%$ of Northern Fulmars (Fulmarus glacialis) have more than 0.1 gram plastic particles in the stomach in samples of 50 to 100 beach-washed fulmars from each of 4 to 5 different areas of the North Sea over a period of at least 5 years".

In such a definition, an excessive stomach content of e.g. 10 gram of plastic does not change the metric compared to the situation in which that bird would have had for example only $0.2 \mathrm{~g}$ in its stomach. Using the same data as in earlier sections of this report, Fig. 5 illustrates the time trends in the 5-year average EcoQO performance of fulmars found in the Netherlands. Although the graph does indicate improvement, it also emphasizes the distance from the 10\% EcoQO target set by OSPAR. Over the integrated recent 5-year period 2014-2018, 43\% of Dutch fulmars exceed the 0.1 gram critical EcoQO level of $0.1 \mathrm{~g}$ of plastic in the stomach.

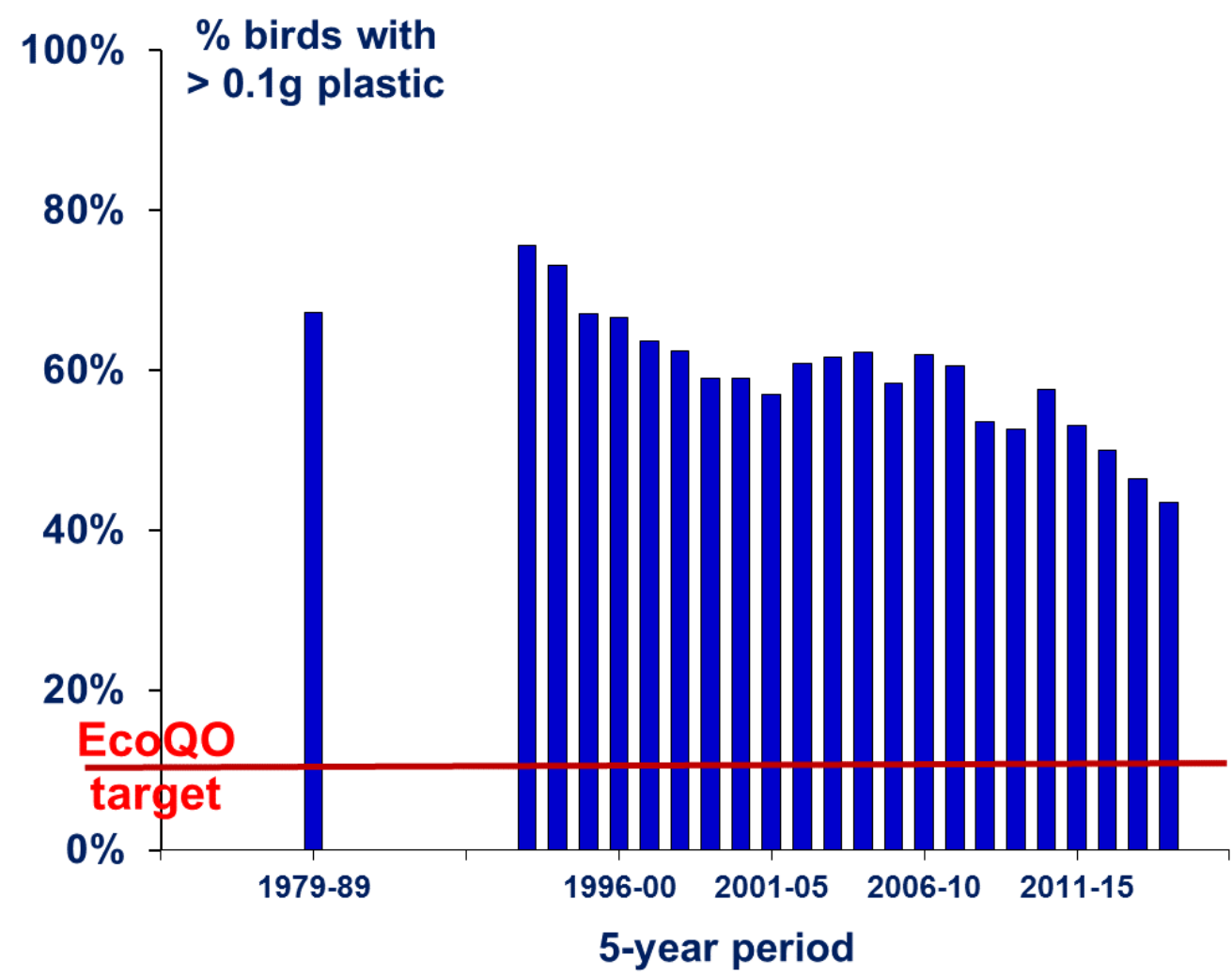

Figure 5 EcoQO performance of fulmars in the Netherlands over running 5-year periods up to 2018. Data for the 1980s were combined due to relatively small sample size. The red line illustrates the OSPAR ECOQO target to reduce the percentage of birds with more than 0.1 gram of plastic in the stomach to below $10 \%$. This graphic visualization does not represent a statistical trend analysis. 
As done in Fig. 4 for ingested mass, looking at the EcoQO performances for separate age groups may provide further confidence in findings. Adult birds and non-adults, in spite of their consistently different level of plastic ingestion, show strongly comparable trends over time and thus support reliability of the trend for all birds combined (Fig.6).

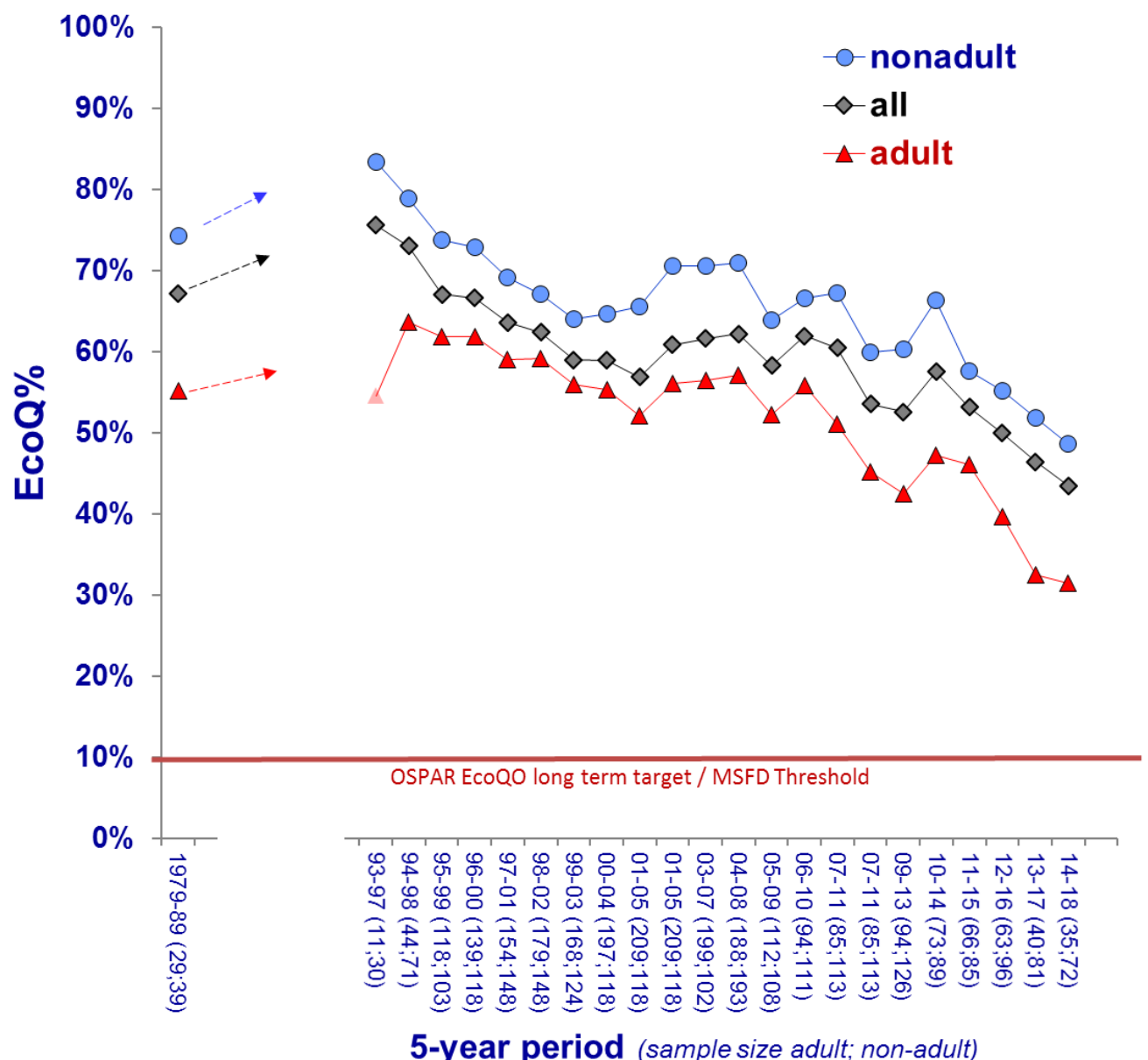

Figure 6 Trend in EcoQO performance of different age classes of beached fulmars from the Netherlands 1979-2018. Trend-lines for all birds combined (grey diamonds, including birds of unknown age), for adult birds (red triangles) and for non-adults (blue circles). This graphic visualization is based on overlapping running 5-year averages and does not represent a statistical trend analysis. 


\subsection{Modelling future EcoQO performance.}

Policy makers involved in the OSPAR and MSFD process have asked to provide models that might predict plastic ingestion rates by fulmars in future years. Such information could assist in focused planning of actions aiming at reaching policy targets by specific dates.

We first considered a model for predicting future developments based on the actual plastic mass ingested by individual fulmars as in our statistical trend analyses. However, data-transformation of an increasing component of birds with no plastics tended to create erratic results in such longer-term predictions. Therefore that approach was not continued. In addition, OSPAR has not defined its longterm target for North Sea Ecological Quality for plastic ingestion in terms of individually ingested plastic mass but as a percentage of birds exceeding the level of $0.1 \mathrm{~g}$ plastic in the stomach. Simplified data as percentages above or below a threshold do have another problem, which is that the dataset is reduced to periodic (annual) average performance. In our approach of evaluating trends over a period of the most recent ten years, the statistical procedure then has only ten data-points available for statistical tests and modelling. Simple linear regression cannot be applied to this type of data. The data need to be considered in a GLM approach (Generalized Linear Modelling), more specifically in a logistic analysis dedicated for binomial distributions (birds yes or no above threshold) and using logit transformed data. A similar type of analysis is used since long in the analyses of oiling rates among seabirds for OSPAR (cf. Camphuysen 2018 and earlier publications on that topic). In an initial trial over the earlier 2007-2016 period, the logistic trend tested as significant $(p=0.05)$ with the EcoQO target reached around year 2044, but with a considerable level of uncertainty shown in the standard errors of predicted annual averages. In principle, significance of the model should be the decision rule to whether or not use the trend for calculating future predicted values.

In our previous analysis of data up to 2017 (Van Franeker \& Kühn 2018), the ten-year binomial regression was not significant, but the same type of analysis over a longer period of data since the start of the Save the North Sea project in 2002 was significant $(p=0.003)$. That analysis predicted that the first year of the long-term EcoQO target could be reached between years 2055 to 2060.

In the current data analysis up to 2018, both the 10 year binomial trend (Fig.7a; Table 5A p=0.026) and the longer trend since 2002 (Fig 7B; Table 5B; $p<0.001$ ) were statistically significant. Note that the traditional linear regressions were just not significant for the 10 -year analysis $(p=0.072$; Table $4 C$ ), but only for the 2002-2018 period ( $p=0.043$; Table 4B). Apparently the logistic analysis of annual data is somewhat quicker in assigning statistical significance than the linear regression of individual data. In the 10-year binomial data, the exceptionally low values for 2018 will play a role. This shortterm analysis predicts that the OSPAR ECOQO target might be in reach by the year 2038. The longerterm analysis 2002-2018 calculates that such may be the case in 2049.

It has to be emphasized that a predicted trend does not imply that we can now relax and take no further action. The model prediction is not based on a status-quo, but on the current rate of change. We assume the observed change to be the result of increased policy measures and improved awareness and behaviour. This implies that the predicted future change will require further new policy measures and further changes in awareness and behaviour. Without extra effort, it is unlikely that the EcoQO target could be reached in the predicted time period. 
A. EcoQO Performance - Observed 2009-2018 and modelled 2009-2060

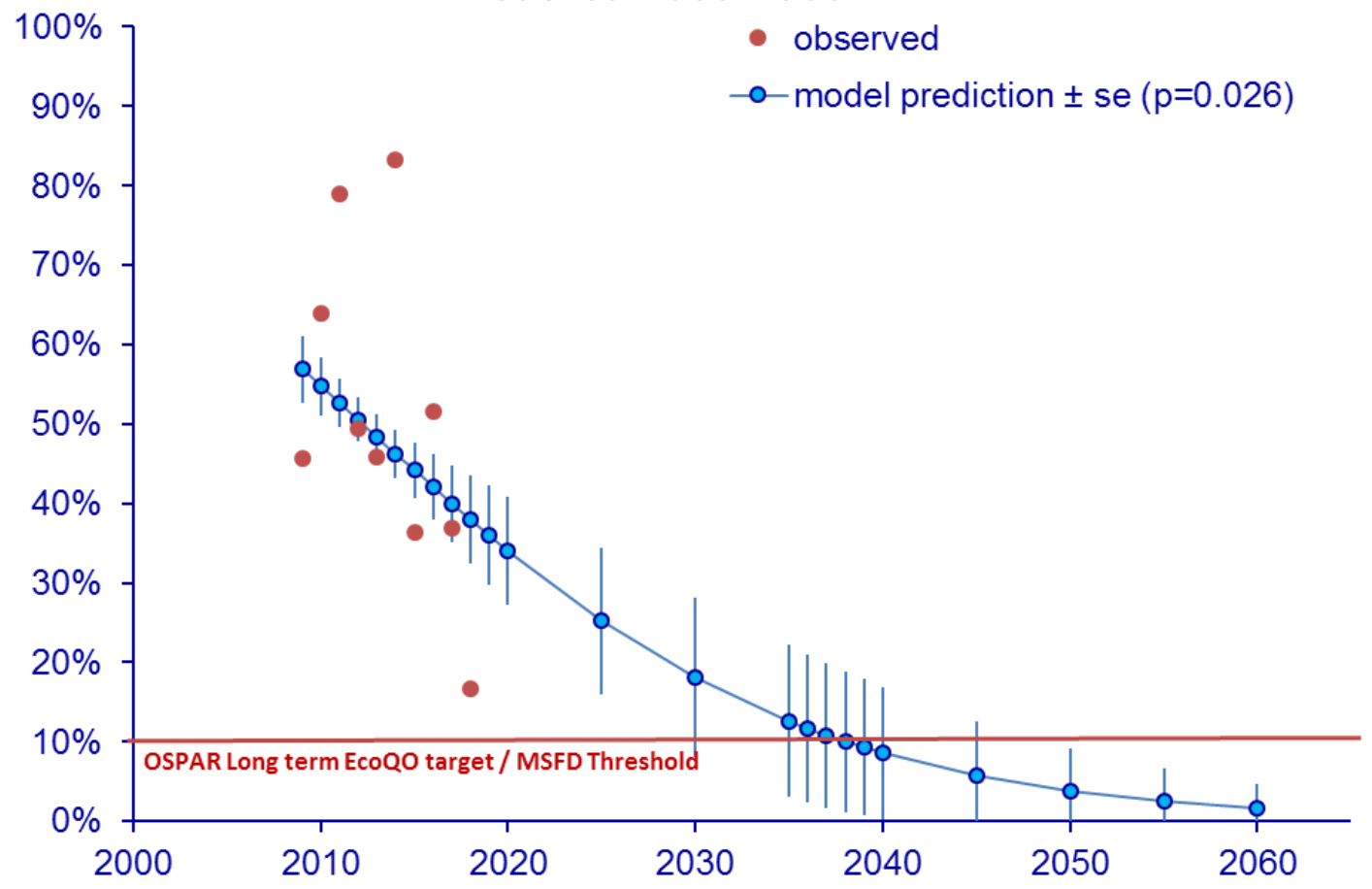

B. EcoQO Performance - Observed 2002-2018 and

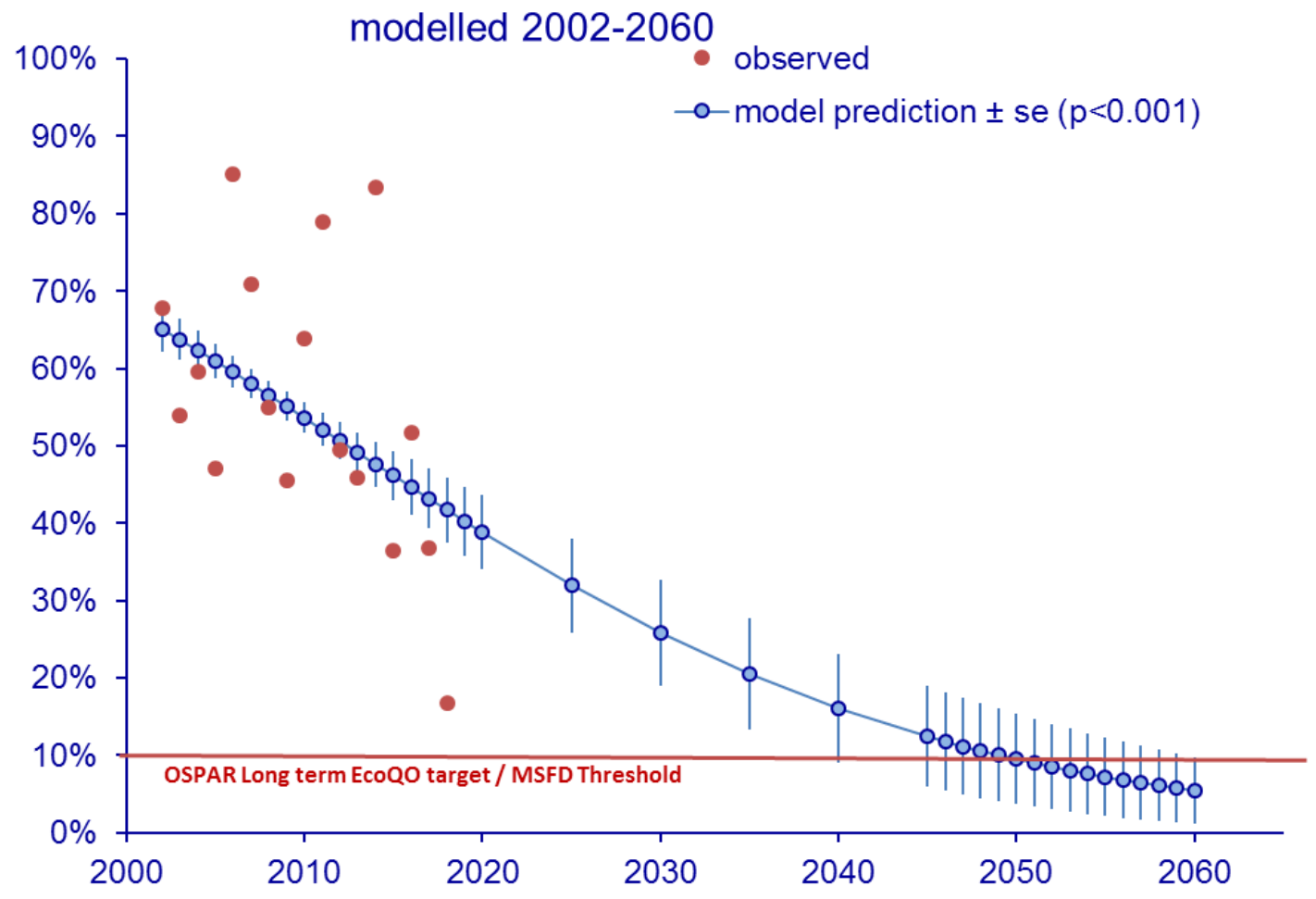

Figure 7 Predicted trajectory to the OSPAR long-term EcoQO target for plastics ingested by Fulmars in Dutch offshore waters, based on a logistic binomial model from annual EcoQO performances. A: model based on observed EcoQO performance over the 10-year period 2009-2018 $(p=0.0 .26)$. B: model based on observed EcoQO performance over the 17-year period 2002-2018 $(p<0.001)$. 
Table 5 Observed and modelled data in logistic binomial model from annual EcoQo

performances observed over A: the 10-year period 2009-2018 $(p=0.026)$ and B: the 17 year Save the North Sea period 2002-2018 $(p<0.001)$.

A.

\begin{tabular}{|c|c|c|c|c|}
\hline \multicolumn{5}{|c|}{ SOURCE DATA FOR LOGISTIC REGRESSION } \\
\hline Year & $\begin{array}{c}\text { sample } \\
\text { size }\end{array}$ & (\% adult) & $\begin{array}{c}\mathrm{nr} \text { of birds } \\
\text { with }>0.1 \mathrm{~g} \\
\text { plastic }\end{array}$ & $\begin{array}{c}\text { proportion } \\
\text { of birds } \\
\text { with }>0.1 \mathrm{~g} \\
\text { plastic }\end{array}$ \\
\hline 2009 & 68 & $(40 \%)$ & 31 & 0.46 \\
\hline 2010 & 36 & $(46 \%)$ & 23 & 0.64 \\
\hline 2011 & 19 & $(37 \%)$ & 15 & 0.79 \\
\hline 2012 & 81 & $(46 \%)$ & 40 & 0.49 \\
\hline 2013 & 24 & $(42 \%)$ & 11 & 0.46 \\
\hline 2014 & 12 & $(64 \%)$ & 10 & 0.83 \\
\hline 2015 & 22 & $(32 \%)$ & 8 & 0.36 \\
\hline 2016 & 31 & $(18 \%)$ & 16 & 0.52 \\
\hline 2017 & 38 & $(31 \%)$ & 13 & 0.37 \\
\hline 2018 & 12 & $(50 \%)$ & 2 & 0.17 \\
\hline
\end{tabular}

\begin{tabular}{|c|c|}
\hline \multicolumn{2}{|c|}{ Modelled EcoQO performance } \\
\hline Year & $\begin{array}{l}\text { model prediction } \pm \text { se } \\
\qquad(p=0.026)\end{array}$ \\
\hline 2009 & $0.57 \pm 0.04$ \\
\hline 2010 & $0.55 \pm 0.04$ \\
\hline 2011 & $0.53 \pm 0.03$ \\
\hline 2012 & $0.51 \pm 0.03$ \\
\hline 2013 & $0.48 \pm 0.03$ \\
\hline 2014 & $0.46 \pm 0.03$ \\
\hline 2015 & $0.44 \pm 0.04$ \\
\hline 2016 & $0.42 \pm 0.04$ \\
\hline 2017 & $0.40 \pm 0.05$ \\
\hline 2018 & $\mathbf{0 . 3 8} \pm 0.06$ \\
\hline 2019 & $0.36 \pm 0.06$ \\
\hline 2020 & $0.34 \pm 0.07$ \\
\hline 2025 & $0.25 \pm 0.09$ \\
\hline 2030 & $0.18 \pm 0.10$ \\
\hline 2035 & $0.13 \pm 0.10$ \\
\hline 2036 & $0.12 \pm 0.09$ \\
\hline 2037 & $0.108 \pm 0.09$ \\
\hline 2038 & $0.100 \pm 0.09$ \\
\hline 2039 & $0.093 \pm 0.09$ \\
\hline 2040 & $0.09 \pm 0.08$ \\
\hline 2045 & $0.06 \pm 0.07$ \\
\hline 2050 & $0.04 \pm 0.05$ \\
\hline 2055 & $0.03 \pm 0.04$ \\
\hline 2060 & $0.02 \pm 0.03$ \\
\hline
\end{tabular}


B.

\begin{tabular}{|c|c|c|c|c|}
\hline \multicolumn{5}{|c|}{ SOURCE DATA FOR LOGIS TIC REGRESSION } \\
\hline Year & $\begin{array}{c}\text { sample } \\
\text { size }\end{array}$ & (\% adult) & $\begin{array}{c}\text { nr of birds } \\
\text { with }>0.1 \mathrm{~g} \\
\text { plastic }\end{array}$ & $\begin{array}{c}\text { proportion } \\
\text { of birds } \\
\text { with }>0.1 \mathrm{~g} \\
\text { plastic }\end{array}$ \\
\hline 2002 & 56 & $(54 \%)$ & 38 & 0.68 \\
\hline 2003 & 39 & $(56 \%)$ & 21 & 0.54 \\
\hline 2004 & 131 & $(80 \%)$ & 78 & 0.60 \\
\hline 2005 & 51 & $(68 \%)$ & 24 & 0.47 \\
\hline 2006 & 27 & $(62 \%)$ & 23 & 0.85 \\
\hline 2007 & 62 & $(43 \%)$ & 44 & 0.71 \\
\hline 2008 & 20 & $(58 \%)$ & 11 & 0.55 \\
\hline 2009 & 68 & $(40 \%)$ & 31 & 0.46 \\
\hline 2010 & 36 & $(46 \%)$ & 23 & 0.64 \\
\hline 2011 & 19 & $(37 \%)$ & 15 & 0.79 \\
\hline 2012 & 81 & $(46 \%)$ & 40 & 0.49 \\
\hline 2013 & 24 & $(42 \%)$ & 11 & 0.46 \\
\hline 2014 & 12 & $(64 \%)$ & 10 & 0.83 \\
\hline 2015 & 22 & $(32 \%)$ & 8 & 0.36 \\
\hline 2016 & 31 & $(18 \%)$ & 16 & 0.52 \\
\hline 2017 & 38 & $(31 \%)$ & 13 & 0.37 \\
\hline 2018 & 12 & $(50 \%)$ & 2 & 0.17 \\
\hline
\end{tabular}

\begin{tabular}{|c|c|}
\hline \multicolumn{2}{|c|}{ Modelled EcoQO performance } \\
\hline Year & $\begin{array}{l}\text { model prediction } \pm \text { se } \\
\qquad(p<0.001)\end{array}$ \\
\hline 2002 & $0.651 \pm 0.03$ \\
\hline 2003 & $0.638 \pm 0.03$ \\
\hline 2004 & $\mathbf{0 . 6 2 4} \pm 0.02$ \\
\hline 2005 & $0.609 \pm 0.02$ \\
\hline 2006 & $0.595 \pm 0.02$ \\
\hline 2007 & $0.580 \pm 0.02$ \\
\hline 2008 & $\mathbf{0 . 5 6 6} \pm 0.02$ \\
\hline 2009 & $0.551 \pm 0.02$ \\
\hline 2010 & $\mathbf{0 . 5 3 6} \pm 0.02$ \\
\hline 2011 & $\mathbf{0 . 5 2 1} \pm 0.02$ \\
\hline 2012 & $0.506 \pm 0.02$ \\
\hline 2013 & $0.491 \pm 0.03$ \\
\hline 2014 & $\mathbf{0 . 4 7 6} \pm 0.03$ \\
\hline 2015 & $\mathbf{0 . 4 6 1} \pm 0.03$ \\
\hline 2016 & $\mathbf{0 . 4 4 6} \pm 0.04$ \\
\hline 2017 & $0.432 \pm 0.04$ \\
\hline 2018 & $\mathbf{0 . 4 1 7} \pm 0.04$ \\
\hline 2019 & $0.402 \pm 0.05$ \\
\hline 2020 & $0.388 \pm 0.05$ \\
\hline 2025 & $0.320 \pm 0.06$ \\
\hline 2030 & $0.258 \pm 0.07$ \\
\hline 2035 & $0.205 \pm 0.07$ \\
\hline 2040 & $0.160 \pm 0.07$ \\
\hline 2045 & $0.124 \pm 0.07$ \\
\hline 2048 & $0.106 \pm 0.06$ \\
\hline 2049 & $0.100 \pm 0.06$ \\
\hline 2050 & $0.095 \pm 0.06$ \\
\hline 2051 & $0.090 \pm 0.06$ \\
\hline 2052 & $0.085 \pm 0.06$ \\
\hline 2055 & $0.072 \pm 0.05$ \\
\hline 2060 & $0.054 \pm 0.04$ \\
\hline
\end{tabular}




\subsection{Data-based MSFD Threshold Definition}

Within the MSFD (EC 2017) it has been decided that all indicators included in the evaluation of 'Good Environmental Status' should develop a data-based 'Threshold' of 'no harm' to be used in future assessments.

In the fulmar and plastic particle indicator, OSPAR has a long established long-term target in which the proportion of birds with over $0.1 \mathrm{~g}$ plastic in the stomach should be reduced to under $10 \%$. Lacking the knowledge to develop a 'no harm' threshold, it has been agreed in the European Task Group for Marine Litter (TGML) expert group, that the threshold may use reference to the litter situation in an area considered to be the most pristine known. From a mix of literature data, it had been seen that fulmars from the 'pristine' high Canadian arctic showed stomach contents close to the OSPAR long-term target. Van Franeker \& Kühn (2019) submitted an advise for a future data-based MSFD Threshold definition in the Fulmar indicator to the 13th meeting of MSFD Technical Group on Marine Litter (MSFD-TGML). Using raw data from studies by Mallory et al. (2006), Mallory (2008), Provencher et al. (2009) and Poon et al. (2017), calculations showed that when data for all known fulmars from these studies were combined, that 18 out of the sample of 179 Canadian Arctic fulmars $(10.06 \%)$ exceeded the $0.1 \mathrm{~g}$ gram plastic separator value. So this value is virtually identical to the existing long-term EcoQO target. Therefore, this set of 179 fulmars from Canada is advised to be used as the data-derived pristine threshold value in fulmar monitoring. In order to indicate statistical reliability $95 \%$ confidence intervals for this figure can be calculated at $6.3 \%-15.1 \%$. These confidence limits were calculated as recommended by Provencher et al. (2017) that is using http://epitools.ausvet.com.au/content.php?page=CIProportion following Brown et al. (2001) and using the Jeffreys Interval.

Monitoring results from elsewhere can be compared to this threshold. Frequencies of birds exceeding the $0.1 \mathrm{~g}$ mass limit in future assessments may be tested for their statistical level of differences to the Canadian based threshold by a 2-sample z-test to compare sample proportions, http://epitools.ausvet.com.au/content.php?page=z-test-2 as provided by Sergeant (2019).

The current Dutch sample over the $2014-2018$ period showed that $50(43.48 \%)$ of 115 fulmars exceeded the limit of 0.1 gram plastic. The $95 \%$ confidence limits of this figure can be calculated at $34.7 \%-52.6 \%$. Comparing the recent Dutch data to the Canadian based threshold, in which 18 out of $179(10.06 \%)$ fulmars had over $0.1 \mathrm{~g}$ of plastic, gives a test result that the null hypothesis that these sample proportions are equal has to be rejected ( $z$-value $6.6 ; p<0.0001$ ). At current rates of plastic abundance, this test is not really required. However, when the required threshold level is approached, the test can indicate the statistical reliability of the difference. 


\section{Concluding remarks}

Following rapid changes in plastic ingestion by fulmars in the North Sea during the 1980s and 1990s, patterns from the early 2000s were not very clear. However, gradually it is becoming evident that plastic abundance in fulmar stomachs is decreasing slowly but at a statistically significant or near significant rate depending on the length of period evaluated and the specific statistics used.

It is difficult to pinpoint specific events that triggered the strong increase in consumer plastics and simultaneous decrease in industrial plastics from the 1980 s to the 1990 s, nor can we identify a clear background for the subsequent sharp decrease in user plastics during the late 1990 s.

The more gradual change since early 2000s likely reflects media attention and public awareness of the existence of oceanic 'garbage patches' and 'plastic soup' which started with the publication on the North Pacific gyre by Moore et al. (2001). The added element of micro- or nano-sized plastics ingested by marine organisms that could physically or chemically find their way into human food, has certainly led to increased concern and awareness, and has led to a range of dedicated policies and actions by authorities, industry and general public. These appear to gradually take effect.

If current rates of change persist, the first year of the long-term EcoQO target (in which the proportion of fulmars with more than $0.1 \mathrm{~g}$ of plastic in the stomach remains under $10 \%$ ) may be reached in the Netherlands between the late 2030s to late 2040s. The most recent changes have strengthened the conclusions in the previous report (Van Franeker and Kühn 2018). Currently $43 \%$ of beached fulmars in the Netherlands exceed the $0.1 \mathrm{~g}$ level. Plastics are present in $93 \%$ of fulmars and the average per individual is 23.6 particles with a combined mass of $0.26 \mathrm{~g}$.

For the shorter-term policy goals, tendency in international discussions is that intermediate assessments should provide evidence of 'significant improvement'. The year 2020 is of major relevance for the Good Environmental Status in the EU Marine Strategy Framework Directive. Our models indicate that continued significant improvement implies that EcoQO performance by the year 2020 should have decreased to about 34 to $38 \%$ of fulmars exceeding the $0.1 \mathrm{~g}$ threshold in the stomach (Fig. 7; Table 5).

It is important to remain aware that the predicted trend does not imply that we can now relax and take no further action. The model prediction is not based on a status-quo, but on the current rate of change. We assume that change to be the result of increased policy measures and improved awareness and behaviour. This implies that the predicted future change will require further new policy measures and further improvements in awareness and behaviour. Without extra effort, it is unlikely that the EcoQO target could be reached in the predicted time period.

\section{CONCLUSION}

Stomach contents of fulmars beached in the Netherlands indicate that the marine litter situation off the Dutch coast is slowly improving. Currently $93 \%$ of the birds has some plastic in the stomach. The average number of plastic particles is 24 per bird, weighing 0.26 gram. Among Dutch fulmars $43 \%$ exceeds the $0.1 \mathrm{~g}$ level of plastic whereas the long-term policy target is that this should be reduced to below $10 \%$. Trend modelling indicates that observed improvements are slow but statistically significant, and indicate that the target may be reached between years 2038 and 2049. 


\section{Acknowledgements}

Fulmar monitoring in the Netherlands is supported financially by the Netherlands Ministry of Infrastructure and Waterways (I\&W). The concept an EcoQO based on the abundance of plastics in seabird stomachs was initiated by the ICES Working Group on Seabird Ecology and guided in several workgroups within ICES and OSPAR. The EU Interreg IIIB North Sea program supported the work in the 2002-2004 Save the North Sea project. The work has also been funded by the NYK Group Europe Ltd and Chevron Upstream Europe.

Mrs. S. Kühn is currently participating in this marine litter research as PhD in the JPI Oceans PLASTOX project 'Direct and indirect ecotoxicological impacts of microplastics on marine organisms' under ALWNWO project number 856.15.001.

Beached fulmars are mainly collected by volunteers without whom a project such as this is impossible. Below is a list of beach surveyors that contributed to the collection of beached fulmars. If people find that their name or group is listed incorrectly, or worse, not at all, our sincere apologies and please take up contact.

A van der Spoel, A Varkevisser, Ad van den Berge, Albert van den Ende, Alma de Groot, André Meijboom, Annemarie Mewe, Annet de Willigen, Anthony James, Arnold Gronert, Arnoud Heikens, Arnout de Vries, Arthur Oosterbaan, Barend Kuiken, Bart Ebbinge, Ben Brugge, Bert Winters, Bezoekerscentrum Nat.Park Schiermonnikoog, BJ Bulsink, Bob Loos, Boogaart, Bram Fey, Buijtelaar, C Boele, Carl Zuhorn, CDI Lelystad, Cees Swennen, Cees van Hoven, Chris Braat, Chris Winter, CJ de Graaf, Coby Kuiken, De Windbreker Petten, Dick Schermer, Dick Veenendaal, Dierenambulances Den Haag, Velsen, Dirk Bruin, Dirk Kuikent, Dirk Moerbeek, ECOMARE, EConnection, Eddie Douwma, Edward Soldaat, Elisa Bravo Rebolledo, Ep van Hijum, Esther de Jong, Floor Arts DPM, Florian Müller, Folkert Janssens, Frank van den Ende, Frank Willems, Frits-Jan Maas, G Fuchs, GJ Bruin, Guido Keijl, Guus van Duin, H de Groot, H Horn, Hans Schekkerman, Hans Verdaat, Hauke Flores, Hein Verkade, Henk Brugge, Henk Mellema, Henk Sandee, Huib den Heijer, Ilse Kootkar, Ingrid Tulp, J Alewijn Dijkhuizen, J Appeloo, JT Kuiken, JW Vergeer, Jaap Boersma, Jaap Hiele, Jack van Velzen, Jacky Kuiper, Jacob de Vries, Jan den Ouden, Jan F de Jong, Jan Goedbloed, Janne Ouwehand, Jannes Heusinkveld, Jasmijn Hulleman, Jeffrey Huizenga, Jelle van Dijk, Jeroen Reneerkens, Job ten Horn, Johan Krol, Jurgen Rotteveel, K Boele, K Post, Kees Borrius, Kees Camphuysen, Kees de Graaf, Kees Kooiker, Kees Roselaar, Kees Woutersen, Klaas de Jong, Klaas van Dijk, Lars Gaedicke, Laurens Kikkert, Laurens van Kooten, Leon Kelder, LH Kuiken, M Janssen, Maarten Brugge, Maarten Platteeuw, Marc Kerkhove, Marc Plomp, Marco Bakker, Mardik Leopold, Maria Elisa Hobbelink, Mariëtte Smit, Marijke Barhorst, Marion Mensink, Marjolein Postma, Mark Fonds, Mark van Veen, Martin Baptist, Martin de Jong, Martin Poot, Meinte Engelmoer, Michael Hermse, Natuurmonumenten, Nicole Janinhoff, Nina Dieters, Noordwester Vlieland, $P$ Bison, Peter de Boer, Peter Meininger, Peter Quist, Peter Spannenburg, Peter van Horssen, Pierre Bonnet, Piet Zumkehr, Pieter Duin, Pieter van Klaveren, Pim Wolff, REP Maan, Rob Dekker, Rob Mantel, Rob Strietman, Rob van Bemmelen, Rob Vink, Roel Draijer, Roeland Bom, Romke Kats, Roy de Hey, Rutger Rotscheid, Ruud Costers. Ruud van Halewijn, S Smit, Salko de Wolf. Sander Lagerveld, Sanne van den Berg-Blok, Saskia Kipp. SBB Staatsbosbeheer, SC Kipp, Sharon Lexmond. Simon de Vries, Simon Hart, Sophie Brasseur. St Damland Bergen, Susanne Kühn, Sytske Dijksen. T Pieters, Theo Kiewiet, Theunis Piersma. Tim van Nus, Tom van Spanje, Tonny van Kooten. van Eck, Vogelasiel Bergen, Vogelasiel de Groot. Vogelasiel De Wulp, Vogelasiel Fugelpits, Vogelasiel Zandvoort. VogelRampenFonds Haarlem, VWG Steenloper, Wandelaar. Wiebe Boomsma, Willem Pompert, Wim de Winter. Wouter Vahl, Y de Jong, Yerko Hankmann. Yvonne Hermes 


\section{References}

Acampora, H., Lyashevska, O., Van Franeker, J.A. \& O'Connor, I. 2016. The use of beached bird surveys for marine plastic litter monitoring in Ireland. Marine Environmental Research 120: 122129. http://dx.doi.org/10.1016/j.marenvres.2016.08.002

Andrady, A.L. \& Neal, M.A. 2009. Applications and societal benefits of plastics. Philosophical Transactions of the Royal Society B 364: 1977-1984 (http://dx.doi.org/10.1098/rstb.2008.0304)

Arthur, C., Baker, J. \& Bamford, H. (Eds.) 2009. Proceedings of the International Research Workshop on the Occurrence, Effects and Fate of Microplastic Marine Debris. Sep 9-11, 2008. NOAA Technical Memorandum NOS-OR\&R-30. NOAA, Silver Spring 530pp. https://marinedebris.noaa.gov/file/2192/download?token=5dvab-YY

Avery-Gomm, S., O'Hara, P.D., Kleine, L., Bowes, V., Wilson, L.K. \& Barry, K.L. 2012. Northern fulmars as biological monitors of trends of plastic pollution in the eastern North Pacific. Marine Pollution Bulletin 64: 1776-1781. http://dx.doi.org/10.1016/j.marpolbul.2012.04.017

Avery-Gomm, S., Provencher, J.F., Liboiron, M., Poon, F.E. \& Smith, P.A. 2018. Plastic pollution in the Labrador Sea: An assessment using the seabird northern fulmar Fulmarus glacialis as a biological monitoring species. Marine Pollution Bulletin 127: 817-822. https://doi.org/10.1016/j.marpolbul.2017.10.001

Baltz, D.M. \& Morejohn, G.V. 1976. Evidence from seabirds of plastic pollution off central California. Western Birds 7: 111-112. https://www.westernfieldornithologists.org/archive/V07/7(3)\%20p0111p0112.pdf

Beaman, J., \& Bergeron, C. (Eds.) 2016. State of the Science White Paper - A Summary of Literature on the Chemical Toxicity of Plastics Pollution to Aquatic Life and Aquatic-Dependent Wildlife. EPA822-R-16-009, United States Environmental Protection Agency, Washington DC, 50pp. https://www.epa.gov/sites/production/files/2017-02/documents/tfw-trash free waters plasticsaquatic-life-report-2016-12.pdf

Bergmann, M., Gutow, L. \& Klages, M. (eds) 2015. Marine Anthropogenic Litter. Springer, Berlin, 447pp. http://link.springer.com/book/10.1007\%2F978-3-319-16510-3

Besseling, E., Foekema, E.M., Van den Heuvel-Greve, M.J., \& Koelmans, A.A. 2017. The effect of microplastic on the uptake of chemicals by the lugworm Arenicola marina (L.) under environmentally relevant exposure conditions. Environmental Science and Technology 51: 87958804 http://dx.doi.org/10.1021/acs.est.7b02286

Blight, L.K. \& Burger, A.E. 1997. Occurrence of plastic particles in seabirds from the eastern North Pacific. Marine Pollution Bulletin 34: 232-325. http://web.uvic.ca/ mamu/pdf/Blight\%20\&\%20Burger\%201997\%20plastic\%20MPB.pdf

Bond, A.L., Provencher, J.F., Daoust, P.-Y. \& Lucas, Z.N. 2014. Plastic ingestion by fulmars and shearwaters at Sable Island, Nova Scotia, Canada. Marine Pollution Bulletin 87: 68-75 http://dx.doi.org/10.1016/j.marpolbul.2014.08.010

Booth, A.M., Hansen, B.H., Frenzel, M., Johnsen, H. \& Altin, D. 2016. Uptake and toxicity of methylmethacrylate-based nanoplastic particles in aquatic organisms. Environmental Toxicology and Chemistry 35: 1641-1649. http://dx.doi.org/10.1002/etc.3076

Bourne, W.R.P. 1976. Seabirds and Pollution. in: R. Johnston, (Ed.), Marine Pollution. Academic Press, London. pp 403-502.

Bravo Rebolledo, E.L., Van Franeker, J.A., Jansen, O.E. \& Brasseur, M.J.M. 2013. Plastic ingestion by harbour seals (Phoca vitulina) in The Netherlands. Marine Pollution Bulletin 67: 200-202. http://dx.doi.org/10.1016/j.marpolbul.2012.11.035

Bray, L., Digka, N., Tsangaris, C., Camedda, A., Gambaiani, D., de Lucia, G.A., Matiddi, M., Miaud, C., Palazzo, L., Pérez-del-Olmo, A., Raga, J.A., Silvestri, C. \& Kaberi, H. 2019. Determining suitable fish to monitor plastic ingestion trends in the Mediterranean Sea.. Environmental pollution 247: 1071-1077 https://doi.org/10.1016/j.envpol.2019.01.100

Brown, L.D., Cat, T.T. \& DasGupta, A. 2001. Interval Estimation for a proportion. Statistical Science 16:101-133. http://dx.doi.org/10.1214/ss/1009213286

Browne, M.A., Sissanayake, A., Galloway, T.S., Lowe, D.M. \& Thompson, R.C. 2008. Ingested microscopic plastic translocates to the circulatory system of the Mussel, Mytilus edulis (L.). Environmental Science and Technology 42: 5026-5031 http://dx.doi.org/10.1021/es800249a

Browne, M.A., Niven, S.J., Galloway, T.S., Rowland, S.J. \& Thompson, R.C. 2013. Microplastic moves pollutants and additives to worms, reducing functions linked to health and biodiversity. Current Biology 23: 2388-2392 http://dx.doi.org/10.1016/j.cub.2013.10.012

Browne, M.A., Underwood, A.J., Chapman, M.G., Williams, R., Thompson, R.C. \& Van Franeker, J.A. 2015. Linking effects of anthropogenic debris to ecological impacts. Proceedings Royal Society B 282: 20142929 (11pp). http://dx.doi.org/10.1098/rspb.2014.2929

Camphuysen C.J. 2018. Monitoring and assessment of the proportion of oiled Common Guillemots in The Netherlands: annual update winter 2016/17, with a preview into 2017/18.. NIOZ Report 2018-04, RWS Centrale Informatievoorziening BM 18.06, May 2017. Royal Netherlands Institute for Sea Research, Texel. http://publicaties.minienm.nl/download-bijlage/90861/monitoring-and- 
assessment-of-the-proportion-of-oiled-common-quillemots-in-the-netherlands-annual-update-winter2016-17-with-a-preview-into-2017-18.pdf

CBD 2016. Marine debris: understanding, preventing and mitigating the significant adverse impacts on marine and coastal biodiversity. Technical Series No.83. Secretariat of the Convention on Biological Diversity, Montreal, 78 pages. https://www.cbd.int/doc/publications/cbd-ts-83-en.pdf

Chua, E.M., Shimeta, J., Nugegoda, D., Morrison, P.D. \& Clarke, O.B. 2014. Assimilation of Polybrominated Diphenyl Ethers from Microplastics by the Marine Amphipod, Allorchestes compressa. Environmental Science and Technology 48(14): 8127-8134 http://dx.doi.org/10.1021/es405717z.

Cole, M., Lindeque, P., Fileman, E., Halsband, C. \& Galloway, T.S. 2015. The impact of polystyrene microplastics on feeding, function and fecundity in the marine copepod Calanus helgolandicus. Environmental Science and Technology 49: 1130-1137 http://dx.doi.org/10.1021/es504525u.

Cózar, A., Martí, E., Duarte, C.M., García-de-Lomas, J., Van Sebille, E., Ballatore, T.J., Eguíluz, V.M., González-Gordillo, J.I., Pedrotti, M.L., Echevarría, F., Troublè, R. \& Irigoien, X. 2017. The Arctic Ocean as a dead end for floating plastics in the North Atlantic branch of the Thermohaline Circulation. Science Advances 3: e1600582 (8pp). http://dx.doi.org/10.1126/sciadv.1600582

Dagevos, J.J., Hougee, M., Van Franeker, J.A., Wenneker, B., Van Loon, W.M.G.M. \& Oosterbaan, L. 2013. OSPAR Beach Litter Monitoring in the Netherlands First annual report 2002-2012. Stichting de Noordzee Report BLM.afv-2310. Stichting de Noordzee, Utrecht, 36pp. https://www.noordzee.nl/project/userfiles/OSPAR Beach Litter Monitoring 2013.pdf

Danielsen, J., Van Franeker, J.A., Olsen, B. \& Bengtson, S.-A. 2010. Preponderance of mesopelagic fish in the diet of the Northern Fulmar (Fulmarus glacialis) around the Faroe Islands. Seabird 23: 66-75. http://www.seabirdgroup.org.uk/journals/seabird-23/seabird-23-66.pdf

Day, R.H., Wehle, D.H.S. \& Coleman, F.C. 1985. Ingestion of plastic pollutants by marine birds. pp 344-386 in: R.S. Shomura and H.O. Yoshida (Eds.), Proceedings of the workshop on the fate and impact of Marine debris, 26-29 November 1984, Honolulu, Hawaii. U.S. Dep. Commerce, NOAA Tech. Memo. NMFS, NOAA-TM-NMFS-SWFC-54. http://www.st.nmfs.noaa.gov/tm/swfc/swfc054.pdf

Derraik, J.G.B 2002. The pollution of the marine environment by plastic debris: a review. Marine Pollution Bulletin 44: 842-852. https://doi.org/10.1016/S0025-326X(02)00220-5

Donnelly-Greenan, E.L., Harvey, J.T., Nevins, H.M., Hester, M.M. \& Walker, W.A. 2014. Prey and plastic ingestion of Pacific Northern Fulmars (Fulmarus glacialis rodgersii) from Monterey Bay, California. Marine Pollution Bulletin 85: 214-224. http://dx.doi.org/10.1016/j.marpolbul.2014.05.046.

EC 2000. Directive 2000/59/EC of the European Parliament and of the Council of 27 November 2000 on port reception facilities for ship-generated waste and cargo residues. Official Journal of the European Communities L 332: 81-90 (28 Dec 2000). http://eurlex.europa.eu/resource.html?uri=cellar:15945efb-a7e8-4840-ab4d0535f12692a8.0004.02/DOC 1\&format=PDF

EC 2008. Directive 2008/56/EC of the European Parliament and of the Council of 17 June 2008 establishing a framework for community action in the field of marine environmental policy (Marine Strategy Framework Directive). Official Journal of the European Union L 164: 19-40 (25 Jun 2008). http://eur-lex.europa.eu/legal-content/EN/TXT/PDF/?uri=CELEX:32008L0056\&from=EN

EC 2010. Commission Decision of 1 September 2010 on criteria and methodological standards on good environmental status of marine waters (notified under document C(2010) 5956) (Text with EEA Relevance) (2010/477/EU). Official Journal of the European Union L232:14-24. http://eurlex.europa.eu/legal-content/EN/TXT/PDF/?uri=CELEX:32010D0477(01)\&from =EN

EC, 2017. Commission Decision (EU) 2017/848 of 17 May 2017 laying down criteria and methodological standards on good environmental status of marine waters and specifications and standardised methods for monitoring and assessment, and repealing Decision 2010/477/EU. Official Journal of the European Union L125: 43-74 (18 May 2017) https://publications.europa.eu/en/publication-detail/-/publication/a7523a58-3b91-11e7-a08e01aa75ed71a1/language-en

Edwards, R. 2005. Litter at sea means a bellyful of plastic. New Scientist 185(2481): 11. http://www.lexisnexis.com.ezproxy.library.wur.nl/hottopics/Inacademic/?verb $=s r \& c s i=158275 \& s r=B Y L I$ NE(edwards)+AND+HLEAD(Litter+at+sea+means+a+bellyful+of+plastic) +AND+DATE+IS+2005

Endo, S., Takizawa, R., Okuda, K., Takada, H., Chiba, K., Kanehiro, H., Ogi, H., Yamashita, R. \& Date, T. 2005. Concentration of polychlorinated biphenyls (PCBs) in beached resin pellets: Variability among individual particles and regional differences. Marine Pollution Bulletin 50: 1103-1114. http://dx.doi.org/10.1016/j.marpolbul.2005.04.030

Endo, D., Yuyama, M. \& Takada, H. 2013. Desorption kinetics of hydrophobic organic contaminants from marine plastic pellets. Marine Pollution Bulletin 74: 125-131 http://dx.doi.org/10.1016/j.marpolbul.2013.07.018

EU 2019. Directive (EU) 2019/883 of the European Parliament and of the Council of 17 April 2019 on port reception facilities for the delivery of waste from ships, amending Directive 2010/65/EU and repealing Directive 2000/59/EC. Official Journal of the European Union L 151: 116-142 (7.6.2019). https://eur-lex.europa.eu/legal-content/EN/TXT/PDF/? Uri=CELEX:32019L0883\&from=EN.

Fischer, V., Elsner, N.O. Brenke, N., Schwabe, E. \& Brandt, A. 2015. Plastic pollution of the KurilKamchatka-trench area (NW Pacific). Deep-Sea Research II 111: 399-405. http://dx.doi.org/10.1016/j.dsr2.2014.08.012 
Fleet, D.M 2003. Untersuchung der Verschmutzung der Spülsäume durch Schiffsmüll and der deutschen Nordseeküste. (UFOPLAN) FAZ 20296 183, im Auftrag des Umweltbundesamtes, Hochschule Bremen. 194pp.

Foekema, E.M., De Gruijter, C., Mergia, M.T., Van Franeker, J.A., Murk, T.J. \& Koelmans, A.A. 2013. Plastic in North Sea fish. Environmental Science \& Technology 47: 8818-8824. http://dx.doi.org/10.1021/es400931b

Furness, R.W. 1985. Plastic particle pollution: accumulation by Procellariiform seabirds at Scottish colonies. Marine Pollution Bulletin 16: 103-106. https://doi.org/10.1016/0025-326X(85)90531-4

Galgani, F., Fleet, D., Van Franeker, J., Katsanevakis, S., Maes, T., Mouat, J., Oosterbaan, L., Poitou, I., Hanke, G., Thompson, R., Amato, E., Birkun, A. \& Janssen, C. 2010. Marine Strategy Framework Directive - Task Group 10 Report Marine litter. JRC Scientific and Technical Reports (EUR collection), Publications Office of the European Union - EUR 24340 EN OPOCE LB-NA-24340EN-N, 57pp. http://dx.doi.org/10.2788/86941

GESAMP 2019. Guidelines for the monitoring and assessment of plastic litter and microplastics in the ocean (Kershaw P.J., Turra A. and Galgani F. editors). IMO/FAO/UNESCOIOC/UNIDO/WMO/IAEA/UN/UNEP/UNDP/ISA Joint Group of Experts on the Scientific Aspects of Marine Environmental Protection). Reports and Studies GESAMP No. 99, 130p. http://www.gesamp.org/publications/quidelines-for-the-monitoring-and-assessment-of-plastic-litter-inthe-ocean.

Geyer, R., Jambeck, J.R. \& Law, K.L. 2017. Production, use, and fate of all plastics ever made. Science Advances 3: e1700782 (5pp + suppl). https://doi.org/10.1126/sciadv.1700782

Gigault, J., Pedrono, B., Maxit, B. \& Ter Halle, A. 2016. Marine plastic litters: the unanalyzed nanofraction. Environmental Science: Nano 3: 346-350 http://dx.doi.org/10.1039/C6ENO0008H .

Gouin, T., Roche, N., Lohmann, R. \& Hodges, G. 2011. A thermodynamic approach for assessing the environmental exposure of chemicals absorbed to microplastic. Environmental Science \& Technology 45: 1466-1472. http://dx.doi.org/10.1021/es1032025

Guse, N., Fleet, D., van Franeker, J. \& Garthe, S. 2005. Der Eissturmvogel (Fulmarus glacialis)Mülleimer der Nordsee? Seevögel 26(2): 3-12.

Hall, K. 2000. Impacts of marine debris and oil: economic and social costs to coastal communities. KIMO, c/o Shetland Islands Council, Lerwick. 104pp.

Hatch, S.A. \& Nettleship, D.N. 1998. Northern Fulmar (Fulmarus glacialis). No. 361 (31 pp) in: A. Poole and F. Gill, (Eds.), The Birds of North America, Inc. Philadelphia, P.A.

Hauser, R., Skakkebaek, N.E., Hass, U., Toppari, J., Juul, A., Andersson, A.M., Kortenkamp, A., Heindel, J.J. \& Trasande, L. 2015. Male Reproductive Disorders, Diseases, and Costs of Exposure to Endocrine-Disrupting Chemicals in the European Union. Journal of Clinical Endocrinology \& Metabolism 100: 1267-1277. http://dx.doi.org/10.1210/jc.2014-4325

Heindler, F.M., Alajmi, F., Huerlimann, R., Zeng, C., Newman, S.J., Vamvounis, G. \& Van Herwerden, L. 2017. Toxic effects of polyethylene terephthalate microparticles and Di(2-ethylhexyl)phthalate on the calanoid copepod, Parvocalanus crassirostris. Ecotoxicology and Environmental Safety 141: 298-305. http://doi.org/10.1016/j.ecoenv.2017.03.029

Hermabessiere, L., Dehaut, A., Paul-Pont, I., Lacroix, C., Jezequel, R., Soudant, P. \& Duflos, G. 2017. Occurrence and effects of plastic additives on marine environments and organisms: A review. Chemosphere 182: 781-793. http://dx.doi.org/10.1016/j.chemosphere.2017.05.096

Huerta Lwanga, E., Gertsen, H., Gooren, H., Peters, P., Salánki, T., Van der Ploeg, M., Besseling, E., Koelmans, A.A. \& Geissen, V. 2016. Microplastics in the terrestrial ecosystem: Implications for Lumbricus terrestris (Oligochaeta, Lumbricidae). Environmental Science and Technology 50: 2685-91. http://pubs.acs.org/doi/abs/10.1021/acs.est.5b05478

Hunt, P., Sathyanarayana, S., Fowler, P.A. \& Trasande, L. 2016. Female Reproductive Disorders, Diseases, and Costs of Exposure to Endocrine Disrupting Chemicals in the European Union. The Journal of Clinical Endocrinology \& Metabolism 101:1562-1570. http://dx.doi.org/10.1210/jc.2015$\underline{2873}$

ICES-WGSE 2001. Report of the Working Group on Seabird Ecology. Ices Headquarters, 16-19 March 2001. ICES CM 2001/C:05. Copenhagen. 68pp http://www.ices.dk/sites/pub/CM\%20Doccuments/2001/C/C0501.pdf

ICES-WGSE 2003. Report of the Working Group on Seabird Ecology. Ices Headquarters, 7-10 March 2003. ICES CM 2003/C:03. Copenhagen. 89pp http://www.ices.dk/sites/pub/CM\%20Doccuments/2003/C/C0303.PDF

Jambeck, J.R., Geyer, R., Wilcox, C., Siegler, T.R., Perryman, M., Andrady, A., Narayan, R. \& Law, K.L. 2015. Plastic waste inputs from land into the ocean. Science 347(6223): 768-771. http://dx.doi.org/10.1126/science.1260352

Jahnke, A., Arp, H.P.H., Escher, B.I., Gewert, B., Gorokhova, E., Kühnel, D., Ogonowski, M., Potthoff, A., Rummel, C., Schmitt-Jansen, M., Toorman, E. \& MacLeod, M. 2017. Reducing Uncertainty and Confronting Ignorance about the Possible Impacts of Weathering Plastic in the Marine Environment. Environmental Science and Technology Letters 4: 85-90. http://dx.doi.org/10.1021/acs. estlett.7b00008

Kershaw, P., Katsuhiko, S., Lee, S., Samseth, J. \& Woodring, D. 2011. Plastic Debris in the Ocean. pp 20-33 in: UNEP Year Book 2011: Emerging issues in our global environment, United Nations Environment Programme, Nairobi. Published February 2011. http://www.unep.org/yearbook/2011 
Koelmans, A.A., Besseling, E., Wegner, A. \& Foekema, E.M. 2013a. Plastic as a carrier of POPs to aquatic organisms: A model analysis. Environmental Science \& Technology 47: 7812-7820 http://dx.doi.org/10.1021/es401169n

Koelmans, A.A., Besseling, E., Wegner, A. \& Foekema, E.M. 2013b. Correction to Plastic As a Carrier of POPs to Aquatic Organisms: A Model Analysis. Environmental Science \& Technology 47: 89928993 http://pubs.acs.org/doi/pdf/10.1021/es403018h

Koelmans, A.A., Besseling, E. \& Foekema, E.M. 2014. Leaching of plastic additives to marine organisms. Environmental Pollution 187: 49-54 http://dx.doi.org/10.1016/j.envpol.2013.12.013

Koelmans, A.A., Besseling, E. \& Shim, W.J. 2015. Nanoplastics in the aquatic environment. Critical review. pp 325-340 Chpt.12 In: Bergmann, M., Gutow, L., and Klages, M. (eds). Marine Anthropogenic Litter. Springer, Berlin. http://link.springer.com/book/10.1007\%2F978-3-319-16510$\underline{3}$

Koelmans, A.A., Bakir, A., Burton, G.A. \& Janssen, C.R. 2016. Microplastic as a vector for chemicals in the aquatic environment: critical review and model-supported reinterpretation of empirical studies. Environmental Science \& Technology 50: 3315-3326. http://dx.doi.org/10.1021/acs.est.5b06069

Kühn, S. \& Van Franeker, J.A. 2012. Plastic ingestion by the Northern Fulmar (Fulmarus glacialis) in Iceland. Marine Pollution Bulletin 64: 1252-1254 http://dx.doi.org/10.1016/j.marpolbul.2012.02.027

Kühn, S., Bravo Rebolledo E.L. \& Van Franeker, J.A. 2015. Deleterious effects of litter on marine life. Pp 75-116 in: Bergmann, M., Gutow, L., and Klages, M. (Eds). Marine Anthropogenic Litter. Springer, Berlin (open access). http://dx.doi.org/10.1007/978-3-319-16510-3 4

Laist, D.W. 1987. Overview of the biological effects of lost and discarded plastic debris in the marine environment. Marine Pollution Bulletin 18(6B): 319-326. https://doi.org/10.1016/S0025326X(87)80019-X

Laist, D.W. 1997. Impacts of marine debris: entanglement of marine life in marine debris including a comprehensive list of species with entanglement and ingestion records. pp 99-140 in: Coe, J.M. and Rogers, D.B. (Eds.). Marine debris sources, impacts and solutions. Springer Series on Environmental Management. Springer Verlag, New York. 432pp. http://plastics.earthmind.net/files/ART Laist 1997.pdf

Law, K.L., Moret-Ferguson, S., Maximenko, N.A., Proskurowski, G., Peacock, E., Hafner, J. \& Reddy, C.M. 2010. Plastic Accumulation in the North Atlantic Subtropical Gyre. Science 329: 1185-1188. http://dx.doi.org/10.1126/science.1192321

Liu, L., Fokkink, R. \& Koelmans, A.A. 2016. Sorption of polycyclic aromatic hydrocarbons to polystyrene nanoplastic. Environmental Toxicology and Chemistry 35: 1650-1655. DOI: http://dx.doi.org/10.1002/etc.3311

Lozano, R.L. \& Mouat, J. 2009. Marine litter in the North-East Atlantic Region, Assessment and priorities for response. OSPAR/KIMO/UNEP. Biological Diversity and Ecosystems Nr 386. OSPAR, London, 127 pp. https://qsr2010.ospar.org/media/assessments/p00386 Marine Litter in the NorthEast Atlantic with addendum.pdf

Mallory, M.L., Roberston, G.J. \& Moenting, A. 2006. Marine plastic debris in northern fulmars from Davis Strait, Nunavut, Canada. Marine Pollution Bulletin 52: 813-815. https://doi.org/10.1016/j.marpolbul.2006.04.005

Mallory, M.L. 2008. Marine plastic debris in northern fulmars from the Canadian High Arctic. Marine Pollution Bulletin 56: 1486-1512. https://doi.org/10.1016/j.marpolbul.2008.04.017

Matiddi, M., Hochsheid, S., Camedda, A., Baini, M., Cocumelli, C., Serena, F., Tomassetti, P., Travaglini, A., Marra, S., Campani, T., Scholl, F., Mancusi, M,, Amato, E., Briguglio, P., Maffucci, F., Fossi, M.C., Bentivegna, F. \& Andrea de Lucia, G. 2017. Loggerhead sea turtles (Caretta caretta): A target species for monitoring litter ingested by marine organisms in the Mediterranean Sea. Environmental Pollution 230: 199-209. http://dx.doi.org/10.1016/j.envpol.2017.06.054

Maximenko, N., Hafner, J. \& Niiler, P. 2012. Pathways of marine debris derived from trajectories of Lagrangian drifters. Marine Pollution Bulletin 65: 51-62 http://dx.doi.org/10.1016/j.marpolbul.2011.04.016

MEPC 2011. Amendments to the Annex of the Protocol of 1978 relating to the International Convention for the Prevention of Pollution from Ships, 1973 (Revised MARPOL Annex V). RESOLUTION MEPC.201(62) IMO, London 12pp. http://www.imo.org/en/OurWork/Environment/PollutionPrevention/Garbage/Documents/2014\%20revisi on/RESOLUTION\%20MEPC.201(62)\%20Revised\%20MARPOL\%20Annex\%20V.pdf

Mintenig, S.M., Bauerlein, P., Koelmans, A.A., Dekker, S.C. \& Van Wezel, A. 2018. Closing the gap between small and smaller: towards a framework to analyse nano-and microplastics in aqueous environmental samples. Environmental Science: Nano 5 1640-1649. http://dx.doi.org/10.1039/C8EN00186C

Moore, C.J., Moore, S.L., Leecaster, M.K. \& Weisberg, S.B. 2001. A comparison of plastic and plankton in the North Pacific Central Gyre.. Marine Pollution Bulletin 42: 1297-1300. https://doi.org/10.1016/S0025-326X(01)00114-X

Moore, C.J. 2008. Synthetic polymers in the marine environment: a rapidly increasing, long-term threat. Environmental Research 108: 131-139. https://doi.org/10.1016/j.envres.2008.07.025

Moser, M.L. \& Lee, D.S. 1992. A fourteen-year survey of plastic ingestion by western North Atlantic seabirds. Colonial Waterbirds 15: 83-94. http://dx.doi.org/10.2307/1521357 
Mouat, J., Lozano, R.L. \& Bateson, H. 2010. Economic impacts of marine litter. KIMO Report September 2010. KIMO, Shetland 105pp.

https://www.noordzeeloket.nl/images/Economic\%20impacts\%20of\%20marine\%20litter 1290.pdf

MSFD-TSGML 2011. Marine Litter - Technical recommendations for the implementation of MSFD requirements. Joint Research Centre - Institute for Environment and Sustainability Report EU 25009 EN. Publications Office of the EU, Luxembourg, 91pp http://dx.doi.org/10.2788/91406

MSFD-TSGML 2013. Guidance on monitoring of marine litter in European Seas - a guidance document within the Common Implementation Strategy for the Marine Strategy Framework Directive. EUR26113 EN. JRC Scientific and Policy Reports JRC83985. 128pp http://dx.doi.org/10.2788/99475

Munari, C., Infantini, V., Scoponi, M., Rastelli, E., Corinaldesi, C. \& Mistri, M. 2017. Microplastics in the sediments of Terra Nova Bay (Ross Sea, Antarctica). Marine Pollution Bulletin 122: 161-165. http://dx.doi.org/10.1016/i.marpolbul.2017.06.039

Nevins, H., Donnelly, E., Hester, M. \& Hyrenbach, D. 2011. Evidence for Increasing Plastic Ingestion in Northern Fulmars (Fulmarus glacialis rodgersii) in the Pacific. Fifth International Marine Debris Conference, Honolulu Hawaii 20-25 Mar 2011. Oral Presentation Extended Abstracts 4.b.3. 140144.

Ng, E.-L., Huerta Lwanga, E., Eldridge, S.M., Johnston, P., Hu, H.-W., Geissen, W. \& Chen, D. 2018. An overview of microplastic and nanoplastic pollution in agroecosystems. Science of The Total Environment 627: 1377-1388 https://doi.org/10.1016/j.scitotenv.2018.01.341

Newman, S., Watkins, E., Farmer, A., Ten Brink, P. \& Schweitzer, J.-P. 2015. The economics of marine litter. pp 367-394 Chpt.14 In: Bergmann, M., Gutow, L., and Klages, M. (Eds). Marine Anthropogenic Litter. Springer, Berlin. http://link.springer.com/book/10.1007\%2F978-3-319-16510$\underline{3}$

North Sea Ministerial Conference 2002. Bergen Declaration. Ministerial declaration of the Fifth International Conference on the Protection of the North Sea. Bergen, Norway, 20-21 March 2002. NSMC Secretariat, Bergen. 50pp. http://www.regjeringen.no/upload/kilde/md/rap/2002/0002/ddd/pdfv/156076-engelsk.pdf

Obbard, R.W., Sadri, S., Wong, Y.Q., Khitun, A.A., Baker, I. \& Thompson, R.C. 2014. Global warming releases microplastic legacy frozen in Arctic Sea ice. Earth's Future 2:315-320. http://dx.doi.org/10.1002/2014EF000240

OECD-MTC (Organisation for Economic Co-operation and Development - Maritime Transport Committee) 2003. Cost savings stemming from non-compliance with international environmental regulations in the maritime sector. MEPC 49/INF.7. 14 March 2003. 53pp.

Olsen, K. 2005. Havhesten - en flygende söppelbötte. Var Fuglefauna 28: 28-32.

OSPAR 2005. North Sea Pilot Project on Ecological Quality Objectives: Background Document on the Ecological Quality Objective on Oiled Guillemots. OSPAR Commission Biodiversity Series Publication Number: 2005/252, OSPAR, London 33pp. https://www.ospar.org/documents?d=7011

OSPAR 2008. Background Document for the EcoQO on plastic particles in stomachs of seabirds. OSPAR Commission, Biodiversity Series. ISBN 978-1-905859-94-8 Publication Number: 355/2008. https://www.ospar.org/documents?v=7109

OSPAR 2009. EcoQO Handbook - Handbook for the application of Ecological Quality Objectives in the North Sea. Second Edition - 2009. OSPAR Biodiversity Series Publication 307/2009. OSPAR Commission London, 65pp. https://www.ospar.org/documents? $v=7127$

OSPAR 2010a. Quality Status Report 2010. OSPAR Commission, London. 175pp. http://qsr2010.ospar.org/en/

OSPAR 2010b. The OSPAR system of Ecological Quality Objectives for the North Sea: a contribution to OSPAR's Quality Status Report 2010. OSPAR Publication 404/2009. OSPAR Commission London, en Rijkswaterstaat VenW, Rijswijk. 16pp. (Update 2010). https://qsr2010.ospar.org/media/assessments/EcoQO/EcoQO P01-16 complete.pdf

OSPAR 2014. Marine Litter Regional Action Plan. London, 18p http://www.ospar.org/documents?v=34422

OSPAR 2015a. Guidelines for Monitoring of plastic particles in stomachs of fulmars in the North Sea area. OSPAR Commission Agreement 2015-03e (Source: EIHA 15/5/12 Add.1). 26pp. http://www.ospar.org/convention/agreements?q=fulmar.

OSPAR 2015b. Explanatory note for the data reporting format for the OSPAR common indicator on plastic particles in fulmars' stomachs. OSPAR Commission Agreement 2015-09ef 2pp. http://www.ospar.org/convention/agreements?q=fulmar.

OSPAR (2017) OSPAR Intermediate Assessment 2017. Plastic Particles in Fulmar Stomachs in the North Sea. OSPAR Assessment Portal OAP online document: https://oap.ospar.org/en/osparassessments/intermediate-assessment-2017/pressures-human-activities-v2/marine-litter/plasticparticles-fulmar-stomachs-north-sea/ Printable Abstract: https://oapcloudfront.ospar.org/media/filer public/f4/34/f434a292-3fad-466c-9e89-c2ffo9dc9e9d/fulmar.pdf

Peda, C., Caccamo, L., Fossi, M.C., Cai, F., Andaloro, F., Genovese, L., Perdichizzi, A., Romeo, T. \& Maricchiolo, G. 2016. Intestinal alterations in European sea bass Dicentrarchus labrax (Linnaeus, 1758) exposed to microplastics: Preliminary results. Environmental pollution 212: 251-256. http://dx.doi.org/10.1016/j.envpol.2016.01.083.

Pham, C.K., Rodríguez, Y., Dauphin, A., Carriço, R., Frias, J.P.G.L., Vandeperre, F., Otero, V., Santos, M.R., Martins, H.R., Bolten, A.B. \& Bjorndal, A. 2017. Plastic ingestion in oceanic-stage 
loggerhead sea turtles (Caretta caretta) off the North Atlantic subtropical gyre. Marine Pollution Bulletin 121: 222-229. http://dx.doi.org/10.1016/j.marpolbul.2017.06.008

PlasticsEurope 2018. Plastics - the Facts 2018. An analysis of European plastics production, demand and waste data. PlasticsEurope Association of Plastics Manufacturers. Report. Brussels, 41pp. https://www.plasticseurope.org/application/files/6315/4510/9658/Plastics the facts 2018 AF web.pdf

Poon, F.E., Provencher, J.F., Mallory, M.L., Braune, B.M. \& Smith, P.A. 2017. Levels of ingested debris vary across species in Canadian Arctic seabirds. Marine Pollution Bulletin 116: 517-520. http://dx.doi.org/10.1016/i.marpolbul.2016.11.051

Provencher, J.F., Gaston, A.J. \& Mallory, M.L. 2009. Evidence for increased ingestion of plastics by northern fulmars (Fulmarus glacialis) in the Canadian Arctic. Marine Pollution Bulletin 58: 10921095. https://doi.org/10.1016/j.marpolbul.2009.04.002

Provencher, J.F., Bond, A.L., Avery-Gomm, S., Borrelle, S.B., Bravo Rebolledo, E.L., Hammer, S., Kühn, S., Lavers, J.L., Mallory, M.L., Trevail, A. \& Van Franeker, J.A. 2017. Quantifying ingested debris in marine megafauna: a review and recommendations for standardization. Analytical Methods 9: 1454-1469. http://dx.doi.org/10.1039/C6AY02419J

Rakestraw, A. 2012. Open oceans and marine debris: solutions for the ineffective enforcement of MARPOL Annex V. Hastings International and Comparative Law Review 35:383-409. http://heinonline.org/HOL/LandingPage?handle=hein.journals/hasint35\&div=17\&id=\&page=

Ribeiro, F., Garcia, A.R., Pereira, B.P., Fonseca, M., Mestre, M.C., Fonseca, T.G., Ilharco, L.M. \& João Bebianno, M.J. 2017. Microplastics effects in Scrobicularia plana. Marine Pollution Bulletin 122: 379-391. https://doi.org/10.1016/j.marpolbul.2017.06.078

Robards, M.D., Piatt, J.F. \& Wohl, K.D. 1995. Increasing frequency of plastic particles ingested by seabirds in the subarctic North Pacific. Marine Pollution Bulletin 30: 151-157.

Rochman, C.M., Hoh, E., Kurobe, T. \& Teh, S.J. 2013. Ingested plastic transfers hazardous chemicals to fish and induces hepatic stress. Scientific Reports 3, 3263. 7pp http://dx.doi.org/10.1038/srep03263

Rochman, C.M., Kurobe, T., Flores, I. \& Teh, S.J. 2014a. Early warning signs of endocrine disruption in adult fish from the ingestion of polyethylene with and without sorbed chemical pollutants from the marine environment. Science of the Total Environment 493: 656-661 http://dx.doi.org/10.1016/j.scitotenv.2014.06.051.

Rochman, C.M., Lewison, R.L., Eriksen, M., Allen. H., Cook, A.-M. \& Teh, S.J. 2014b. Polybrominated diphenyl ethers (PBDEs) in fish tissue may be an indicator of plastic contamination in marine habitats. Science of The Total Environment, Volumes 476-477: 622-633 http://dx.doi.org/10.1016/j.scitotenv.2014.01.058

Rochman, C.M., Browne, M.A., Underwood, A.J., Van Franeker, J.A., Thompson, R.C. Amaral-Zettler, L. 2016. The ecological impacts of marine debris: unraveling the demonstrated evidence from what is perceived. Ecology 97: 302-312. http://www.esajournals.org/doi/pdf/10.1890/14-2070.1.

Ryan, P.G. 2008. Seabirds indicate changes in the composition of plastic litter in the Atlantic and south-western Indian Oceans. Marine Pollution Bulletin 56: 1406-1409. https://doi.org/10.1016/j.marpolbul.2008.05.004

Ryan, P.G., Moore, C.J., Van Franeker, J.A. \& Moloney, C.L. 2009. Monitoring the abundance of plastic debris in the marine environment. Philosophical Transactions of the Royal Society B 364: 19992012. http://dx.doi.org/10.1098/rstb.2008.0207.

Save the North Sea 2004. Reduce marine litter: 'Save the North Sea' project results. Keep Sweden Tidy Foundation, Stockholm, 17pp. http://www.hsr.se/sites/default/files/content media/save the north sea low.pdf

Schulz, M., Neumann, D., Fleet, D. \& Matthies, M. 2013. A multi-criteria evaluation system for marine litter pollution based on statistical analyses of OSPAR beach litter monitoring time series. Marine Environmental Research 92: 61-70 http://dx.doi.org/10.1016/j.marenvres.2013.08.013

Schulz, M. Van Loon, W, Fleet, D.M., Baggelaar, P. \& Van der Meulen, E. 2017. OSPAR standard method and software for statistical analysis of beach litter data. Marine Pollution Bulletin 122: 166-175. http://dx.doi.org/10.1016/j.marpolbul.2017.06.045

Sergeant, E.S.G., 2019. Epitools epidemiological calculators. Ausvet Pty Ltd. http://epitools.ausvet.com.au

Stichting De Noordzee 2003. Coastwatch Onderzoek 2002. Stichting de Noordzee, Utrecht. 17pp + addenda. (http://www. coastwatch.nl//)

Tanaka, K., Takada, H., Yamashita, R., Mizukawa, K., Fukuwaka, M. \& Watanuki, Y. 2013. Accumulation of plastic-derived chemicals in tissues of seabirds ingesting marine plastics. Marine Pollution Bulletin 69: 219-222. http://dx.doi.org/10.1016/j.marpolbul.2012.12.010

Tekman, M.B., Krumpen, T. \& Bergmann, M 2017. Marine litter on deep Arctic seafloor continues to increase and spreads to the north at the HAUSGARTEN observatory. Deep Sea Research Part I: 120: 88-99. http://doi.org/10.1016/j.dsr.2016.12.011

Terepocki, A.K., Brush, A.T., Kleine, L.U., Shugart, G.W. \& Hodum, P. 2017. Size and dynamics of microplastic in gastrointestinal tracts of Northern Fulmars (Fulmarus glacialis) and Sooty Shearwaters (Ardenna grisea). Marine Pollution Bulletin 116: 143-150. https://doi.org/10.1016/j.marpolbul.2016.12.064

Teuten, E.L., Rowland, S.J., Galloway, T.S. \& Thompson, R.C. 2007. Potential for Plastics to Transport Hydrophobic Contaminants. Environmental Science and Technology 41: 7759-7764 http://dx.doi.org/10.1021/es071737s 
Teuten, E. L., Saquing, J.M., Knappe, D.R.U., Barlaz, M.A., Jonsson, S., Björn, A., Rowland, S.J., Thompson, R.C., Galloway, T.S., Yamashita, R., Ochi, D., Watanuki, Y., Moore, C., Viet, P.H., Tana, T.S., Prudente, M., Boonyatumanond, R., Zakaria, M.P., Akkhavong, K., Ogata, Y., Hirai, H., Iwasa, S., Mizukawa, K., Hagino, U., Imamura, A., Saha, M. \& Takada, H. 2009. Transport and release of chemicals from plastics to the environment and to wildlife. Philosophical Transactions of the Royal Society B 364: 2027-2045 http://dx.doi.org/10.1098/rstb.2008.0284

Thompson, R.C., Moore, C.J., vom Saal, F.S. \& Swan, S.H. (Eds.) 2009. Plastics, the environment and human health. Philosophical Transactions of the Royal Society B 364 ( $\mathrm{nr} 1526$ Theme Issue) pages 1969-2166. http://rstb.royalsocietypublishing.org/content/364/1526

Thompson, R.C., Olsen, Y., Mitchell, R.P., Davis, A., Rowland, S.J., John, A.W.G., McGonigle. D. \& Russell, A.E. 2004. Lost at sea: Where is all the plastic?. Science 304 (5672): 838-838. http://dx.doi.org/10.1126/science.1094559

Trevail, A.M., Gabrielsen, G.W., Kühn, S. \& Van Franeker, J.A. 2015. Elevated levels of ingested plastic in a high Arctic seabird, the northern fulmar (Fulmarus glacialis). Polar Biology 38: 975-981. (open access) http://dx.doi.org/10.1007/s00300-015-1657-4

Trouwborst, A. 2011. Managing marine litter: exploring the evolving role of international and European law in confronting a persistent environmental problem. Merkourios 27-73: 4-18. https://utrechtjournal.org/articles/abstract/10.5334/ujiel.an/

UNEP 2011. UNEP Year Book 2011: Emerging issues in our global environment. United Nations Environment Programme, Nairobi, 79pp. http://www.unep.org/yearbook/2011

UNEP 2016. Marine plastic debris and microplastics - Global lessons and research to inspire action and guide policy change. United Nations Environment Programme, Nairobi. 252pp. https://wedocs.unep.org/rest/bitstreams/11700/retrieve

Van Cauwenberghe, L. \& Janssen, C.R. 2014. Microplastics in bivalves cultured for human consumption. Environmental Pollution 193: 65-70 http://dx.doi.org/10.1016/j.envpol.2014.06.010

Van Franeker, J.A. 1985. Plastic ingestion in the North Atlantic Fulmar. Marine Pollution Bulletin 16: 367-369. https://doi.org/10.1016/0025-326X(85)90090-6

Van Franeker, J.A. \& Bell, P.J. 1988. Plastic ingestion by petrels breeding in Antarctica. Marine Pollution Bulletin 19: 672-674. https://doi.org/10.1016/0025-326X(88)90388-8

Van Franeker, J.A. \& Meijboom, A. 2002. Litter NSV - Marine litter monitoring by Northern Fulmars: a pilot study. ALTERRA-Rapport 401. Alterra, Wageningen, 72pp. http://edepot.wur.nl/45695

Van Franeker, J.A. \& Meijboom, A. 2003. Marine Litter Monitoring by Northern Fulmars: progress report 2002. ALTERRA-rapport 622. Alterra, Wageningen, $49 \mathrm{pp}$. http://library.wur.nl/WebQuery/wurpubs/fulltext/43713

Van Franeker, J.A. 2004a. The Fulmar-Litter-EcoQO in relation to EU Directive 2000/59/EC on Port Reception Facilities. Rapportage in opdracht van Directoraat Generaal Goederenvervoer, Ministerie van Verkeer en Waterstaat. Contract DGG-27020138. DGG-VenW, Den Haag. 47pp.

Van Franeker, J.A. 2004b. Save the North Sea - Fulmar Study Manual 1: Collection and dissection procedures. Alterra Rapport 672. Alterra, Wageningen. 38pp. http://edepot.wur.nl/40451

Van Franeker, J.A. 2004c. Fulmar wreck in the southern North Sea: preliminary findings. British Birds 97: 247-250.

Van Franeker, J.A., Meijboom, A. \& De Jong, M.L. 2004. Marine litter monitoring by Northern Fulmars in the Netherlands 1982-2003. Alterra Rapport 1093. Alterra, Wageningen. 48pp. http://library.wur.nl/WebQuery/wurpubs/fulltext/39233

Van Franeker, J.A. 2005. Schoon strand Texel 2005: onderzoeksresultaten van de schoonmaakactie van het Texelse strand op 20 april 2005. Alterra speciale uitgave 2005/09. Alterra, Texel. 23pp. http://edepot.wur.nl/19515

Van Franeker, J.A., Heubeck, M., Fairclough, K., Turner, D.M., Grantham, M., Stienen, E.W.M., Guse, N., Pedersen, J., Olsen, K.O., Andersson, P.J. \& Olsen, B. 2005. 'Save the North Sea' Fulmar Study 2002-2004: a regional pilot project for the Fulmar-Litter-EcoQO in the OSPAR area. Alterra-rapport 1162. Alterra, Wageningen, 70pp. http://edepot.wur.nl/35175

Van Franeker, J.A. \& Meijboom, A. 2006. Fulmar Litter EcoQO Monitoring in the Netherlands 19822004 in relation to EU Directive 2000/59/EC on Port Reception Facilities. Report for the Ministry of Transport, Public Works and Water Management (VenW), contract nr DGTL/ZH/2.53.2.5012. Alterra, Texel. 41pp.

Van Franeker, J.A. \& Meijboom, A. 2007. Fulmar Litter EcoQO Monitoring in the Netherlands 19822005 in relation to EU Directive 2000/59/EC on Port Reception Facilities. Wageningen IMARES Report Nr C019-07. IMARES Texel, 40pp

Van Franeker, J.A. \& the SNS Fulmar Study Group 2008. Fulmar Litter EcoQO monitoring in the North Sea - results to 2006. IMARES Report nr C033/08. Wageningen IMARES, Texel. 53pp.

Van Franeker, J.A., Meijboom, A., De Jong, M. \& Verdaat, H. 2009. Fulmar Litter EcoQO Monitoring in the Netherlands 1979-2007 in relation to EU Directive 2000/59/EC on Port Reception Facilities. Wageningen IMARES Report nr C032/09. Wageningen IMARES, Texel. 39pp.

Van Franeker, J.A. 2009. Fulmar Litter EcoQO Monitoring in the Netherlands 1979-2008 in relation to EU Directive 2000/59/EC on Port Reception Facilities. Interim Report dd 15 Dec 2009, IMARES Wageningen UR, Texel. 
Van Franeker, J.A. 2010. Fulmar Litter EcoQO Monitoring in the Netherlands 1979-2008 in relation to EU Directive 2000/59/EC on Port Reception Facilities. Wageningen IMARES Report nr C027/10. Wageningen IMARES, Texel. 40pp.

Van Franeker, J.A. \& the SNS Fulmar Study Group 2011. Fulmar Litter EcoQO monitoring along Dutch and North Sea coasts in relation to EU Directive 2000/59/EC on Port Reception Facilities: results to 2009. IMARES Report Nr C037/11. IMARES, Texel, 52pp +2app.

Van Franeker, J.A., Blaize, C., Danielsen, J., Fairclough, K., Gollan, J., Guse, N., Hansen, P.L., Heubeck, M., Jensen, J.-K., Le Guillou, G., Olsen, B., Olsen, K.O., Pedersen, J., Stienen, E.W.M. \& Turner, D.M. 2011. Monitoring plastic ingestion by the northern fulmar Fulmarus glacialis in the North Sea. Environmental Pollution 159: 2609-2615. http://dx.doi.org/10.1016/j.envpol.2011.06.008

Van Franeker, J.A. 2012. Plastic ingestion by fulmars at the Faroe Islands (Plastic i færoske mallemukkers fodeindtagelse). pp 82-85 in: Jensen, J.-K., Mallemukken på Færoerne / The Fulmar on the Faroe Islands. Prenta, Torshavn. http://www.wur.nl/upload mm/e/9/f/c7466bbdd617-4a01-943f-f6e7dfa3c7ba 2012 Faroe.pdf

Van Franeker, J.A. \& the SNS Fulmar Study Group 2013. Fulmar Litter EcoQO monitoring along Dutch and North Sea coasts - Update 2010 and 2011. IMARES Report C076/13. IMARES, Texel. 61pp. http://edepot.wur.nl/258764

Van Franeker, J.A., Kühn, S., Bravo Rebolledo, E.L. \& Meijboom, A. 2014. Fulmar Litter EcoQO monitoring in the Netherlands - Update 2012 and 2013. IMARES Report C122/14. IMARES, Texel, 56pp. http://edepot.wur.nl/315514

Van Franeker, J.A. \& Law, K.L. 2015. Seabirds, gyres and global trends in plastic pollution. Environmental Pollution 203: 89-96. http://dx.doi.org/10.1016/j.envpol.2015.02.034

Van Franeker, J.A. 2015. Fulmar Litter EcoQO monitoring in the Netherlands - Update 2014. IMARES Report C123/15. IMARES, Texel. 55 pp. http://edepot.wur.nl/365964

Van Franeker, J.A., Kühn, S. \& Bravo Rebolledo, E.L. 2016. Fulmar Litter EcoQO monitoring in the Netherlands - Update 2015. Wageningen Marine Research Report C091/16, RWS Centrale Informatievoorziening BM 16.12. Den Helder, 50pp. http://edepot.wur.nl/393794

Van Franeker, J.A., Kühn, S. \& Meijboom, A. 2017. Fulmar Litter EcoQO monitoring in the Netherlands - Update 2016. Wageningen Marine Research report C053/17 \& RWS Centrale Informatievoorziening BM 17.23 (WMR, Den Helder, 52pp). https://doi.org/10.18174/423968

Van Franeker, J.A. \& Kühn, S. 2018. Fulmar Litter EcoQO monitoring in the Netherlands - Update 2017. Wageningen Marine Research Report C060/18 \& RWS Centrale Informatievoorziening BM 18.20. Den Helder, 60pp. https://doi.org/10.18174/458857

Van Franeker, J.A., Bravo Rebolledo, E.L., Hesse, E., IJsseldijk, L.L., Kühn, S., Leopold, M. \& Mielke, L. 2018. Plastic ingestion by harbour porpoises Phocoena phocoena in the Netherlands: establishing a standardized method. Ambio 47: 387-397. https://doi.org/10.1007/s13280-017-1002-y

Van Franeker, J.A., Kühn, S., Kotterman, M. Kwadijk, C. 2019. Monitoring van paraffine-achtige stoffen op Nederlandse stranden en in magen van Noordse Stormvogels.. Wageningen University and Research Report C001/19. Wageningen Marine Research, Den Helder, 33pp. https://doi.org/10.18174/467759.

Van Franeker, J.A. \& Kühn, S. 2019. Advice for the definition of a MSFD Threshold for the Fulmar Plastic Particle indicator. Advise to 13th meeting of the MSFD Technical Group Marine Litter, 2628 June 2019 Gothenburg, Sweden. Unnumbered meeting document 15pp.

Van Sebille, E., England, M.H. \& Froyland, G. 2012. Origin, dynamics and evolution of ocean garbage patches from observed surface drifters. Environmental Research Letters 7: 044040 (6pp) http://dx.doi.org/10.1088/1748-9326/7/4/044040.

Van Sebille, E., Wilcox, C., Lebreton, L., Maximenko, N., Hardesty, B.D., Van Franeker, J.A., Eriksen, M., Siegel, D., Galgani, F. \& Law, K.L. (2015). A global inventory of small floating plastic debris. Environmental Research Letters 10: 124006 (11pp). http://dx.doi.org/10.1088/17489326/10/12/124006

Veiga, J.M., Fleet, D., Kinsey, S., Nilsson, P., Vlachogianni, T., Werner, S., Galgani, F., Thompson, R.C., Dagevos, J., Gago, J., Sobral, P. \& Cronin, R. 2016. Identifying Sources of Marine Litter. MSFD GES TG Marine Litter Thematic Report. JRC Technical Report, EUR 28309. http://publications.jrc.ec.europa.eu/repository/bitstream/JRC104038/lb-na-28309-en-n.pdf

Venables, V.N. \& Ripley, B.D. 2002. Modern applied statistics with S, fourth ed. Springer, New York, 503pp. http://www. bagualu.net/wordpress/wpcontent/uploads/2015/10/Modern Applied Statistics With S.pdf

Vlietstra, L.S. \& Parga, J.A. 2002. Long-term changes in the type, but not the amount, of ingested plastic particles in Shor1t-tailed Shearwaters in the southeastern Bering Sea. Marine Pollution Bulletin 44: 945-955. https://doi.org/10.1016/S0025-326X(02)00130-3

Watts, A.J.R., Urbina, M.A., Corr, S., Lewis, C. \& Galloway, T.S. 2015. Ingestion of plastic microfibers by the crab Carcinus maenas and its effect on food consumption and energy balance. Environmental Science and Technology 49: 14597-14604. http://dx.doi.org/10.1021/acs.est.5b04026

Werner, S., Budziak, A., Van Franeker, J., Galgani, F., Maes, T., Matiddi, M., Nilsson, P., Oosterbaan, L., Priestland, E., Thompson, R., Veiga, J. \& Vlachogianni, T. 2016. Harm caused by marine litter. 
MSFD GES TG Marine Litter - Thematic Report. JRC Technical Report EUR 28317, Publications Office of the European Union, Luxembourg, 89pp. http://dx.doi.org/10.2788/19937

\section{Relevant website}

www.wur.eu/plastics-fulmars

(in Dutch: www.wur.nl/plastics-stormvogels)

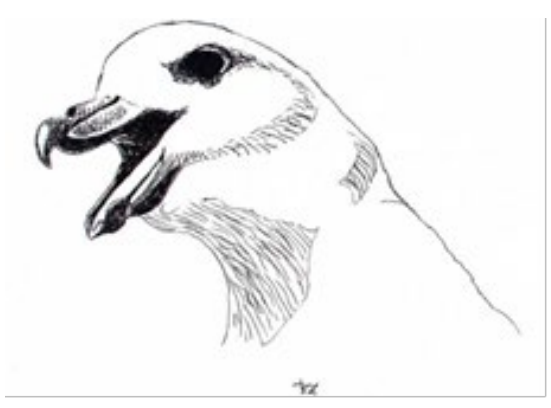

56 of 60 | Wageningen Marine Research report C077/19 \& RWS Centrale InformatieVoorziening BM 19.16 


\section{Quality Assurance}

Wageningen Marine Research utilises an ISO 9001:2015 certified quality management system. This certificate is valid until 15 December 2021. The organisation has been certified since 27 February 2001. The certification was issued by DNV GL. 


\section{Justification}

\section{Report}

Wageningen Marine Research C077/19 RWS Centrale Informatievoorziening BM 19.16

Project Number:

WMR project $4312100031 \quad$ Fulmar-EcoQO-NL2015-19

The scientific quality of this report has been peer reviewed by a colleague scientist and a member of the Management Team of Wageningen Marine Research

Approved: $\quad$ Dr. R.H. Jongbloed

Senior scientist Wageningen Marine Research

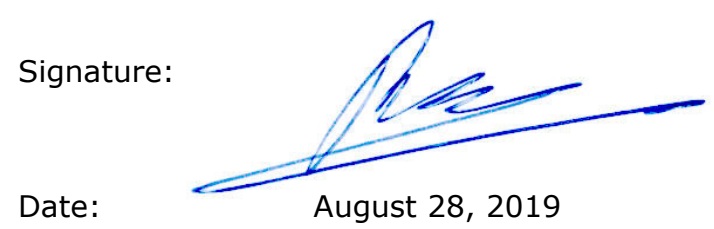

Approved: Dr. J. Asjes

Manager Integration

Signature:

Date:

August 28, 2019 
Wageningen Marine Research

T +31(0)317480900

E: marine-research@wur.nl

www.wur.eu/marine-research

Visitors' address

- Ankerpark 271781 AG Den Helder

- Korringaweg 7, 4401 NT Yerseke

- Haringkade 1, 1976 CP IJmuiden
With knowledge, independent scientific research and advice, Wageningen Marine Research substantially contributes to more sustainable and more careful management, use and protection of natural riches in marine, coastal and freshwater areas.

Wageningen Marine Research is part of Wageningen University \& Research. Wageningen University \& Research is the collaboration between Wageningen University and the Wageningen Research Foundation and its mission is: 'To explore the potential for improving the quality of life' 